\title{
SUPERFÍCIES DE RESPOSTA EM EXPERIMENTOS DE ADUBAÇÃO: O PROBLEMA DOS PONTOS DE SELA
}

\author{
ADHEMAR SANCHES
}

Orlentador: Prof. Dr. IZAIAS RANGEL NOGUEIRA

\begin{abstract}
Tese apresentada à Escola Superior de Agricultura "Luiz de Queiroz" da Universidade de São Paulo, para obtenção do título de Doutor em Agronomia. Área de Concentração: Estatística e Experimentação Agronômica.
\end{abstract}

P I R A C I C A B A

Estado de São Paulo - Brasil

Outubro, 1986 
Aos meus pais

FRANCISCO AMBROSIO SANCHES $\mathrm{E}$

MARIA JOSE DE JESUS SANCHES

\section{DEDICO}

$\bar{\Lambda}$ minha esposa bliktiter

aos meus fithos ESTEVAOO E LETICIA 


\section{AGRADECIMENTOS}

Ao Professor Dr. Izaias Rangel Nogueira, pela orientação, incentivo e amizade.

Aos professores e funcionários do Departamento de Matemáti ca e Estatística da ESALQ-USP, pelos ensinamentos, amizade e aporo.

Ao Professor Dr. Dilermando Perecin, pela sugestao do assun to da pesquisa e pelas valiosas sugestões apresentadas durante o desenvol vimento deste trabalho.

Ao Professor Dr. Euclides Braga Matheiros, pela elaboração do programa para o computador.

Ao Professor Dr. Josë Carlos Barbosa, pela disponibilidade na troca de idéias sobre a parte de computação.

Aos professores e funcionários do Departamento de Ciências Exatas da Faculdade de Ciências Agrárias e Veterinárias - UNFSP, Campus de Jaboticabal, pela colaboração e pelo ótimo ambiente de trabatho.

Aos funcionários da Unidade de processamento de Dados da Fa culdade de Ciências Agrārias e Veterinárias - UNESP, Campus de Jaboticabal, pela colaboração.

A Maria de Lourdes Moretto, pelo esmero e dedicaça nos tra balhos de datilografia.

Ao CNPq, à CAPES e à Fundação "Judith A. Buzaid", pelo apoío financeiro.

A todos que, de uma forma ou de outra, contribuíram para a realização deste trabalho. 


\section{INDICE}

página

RESUMO $\ldots \ldots \ldots \ldots \ldots \ldots \ldots \ldots \ldots \ldots \ldots \ldots \ldots \ldots \ldots \ldots \ldots \ldots$

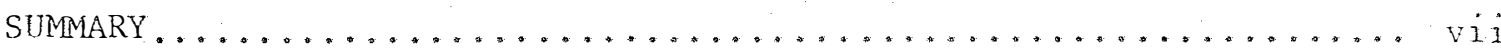

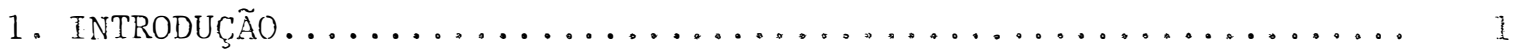

1.1. Considerações gerais.......................... 1

1.2. O problema dos pontos de sela.................. 3

1.3. Objetivos do trabalho....................... 4

2. REVISÃO DE LITERATURA............................ 7

2.1. A metodologia de superfície de resposta em ensaios de adu bаção................................. 7

2.2. A ocorrência de pontos de sela.................. 8

2.3. Formas de se aumentar a eficiência na obtenção de pontos

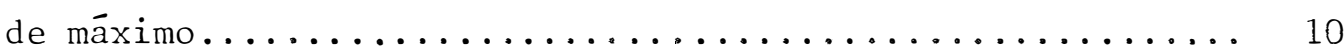

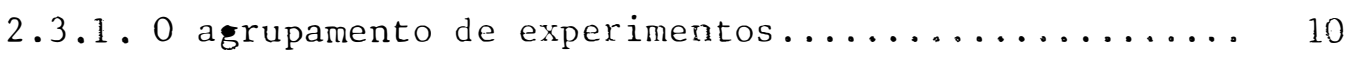

2.3.2. o posicionamento adequado de doses............. 11

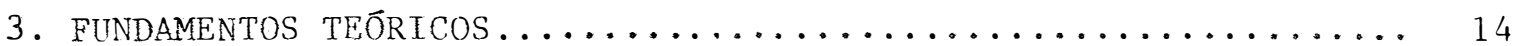

3.1. Modelo linear e estimação de parâmetros................ 14

3.2. O modelo de regressão polinomial quadrātico em três variá

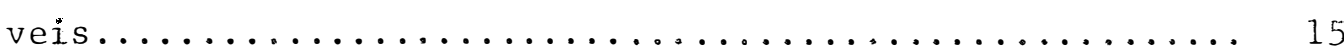

3.3. A determinação e a anālise do ponto crítico............ 16

3.4. A forma canônica da superfície de resposta............ 17

3.5. Construção de um modelo de superfície polinomial quadráti ca em $x_{1}, x_{2}$ e $x_{3}$, a partir de uma forma canônica dada... 19

3.6. o ponto de máximo fronteira.................... 23

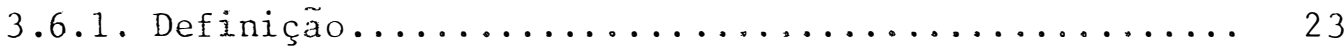

3.6.2. Considerações importantes na determinação do ponto de mäximo fronteira....................... 24

3.7. Comparação de delineamentos................... 38

3.8. Delineamentos de tratamentos com três fatores........... 41 3.8.1. Delineamento fatorial $3^{3} \ldots \ldots \ldots \ldots \ldots \ldots \ldots \ldots \ldots$

3.8.1.1. Delineamento fatorial $3^{3}$ com niveis igual mente espaçados................. 42

3.8.1.2. Delineamento fatorial com niveis do tipo 0 , $q$ e $3 q, q>0 \ldots \ldots \ldots \ldots \ldots \ldots \ldots \ldots$ 
Página

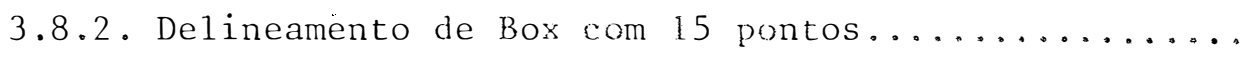

3.8.2.1. Delineamento de Box com 15 pontos com

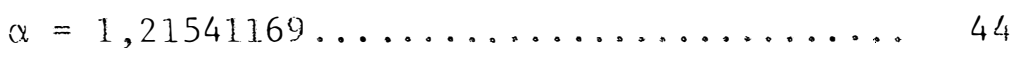

3.8.2.2. Delineamento de Box com 15 pontos com $\alpha=2 \quad 44$

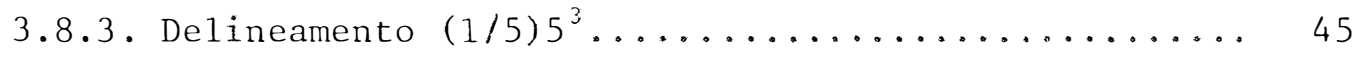

3.8.3.1. Delineamento $(1 / 5) 5^{3}$ tipo I, III, IV ou ti

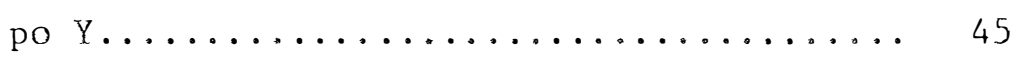

3.8.3.2. Delineamento $(1 / 5) 5^{3}$ tipo $w \ldots \ldots \ldots \ldots \ldots$

3.8.4. Delineamento composto central com duas estrelas... 47

3.8.5. Delineamento duplo central composto com 29 pontos.. 49

3.8.5.1. Delineamento duplo central composto com

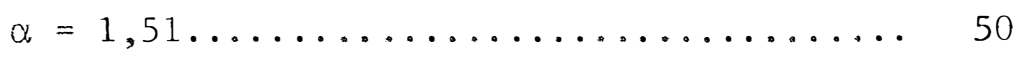

3.8.5.2. Delineamento duplo central composto com

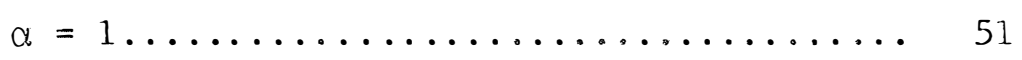

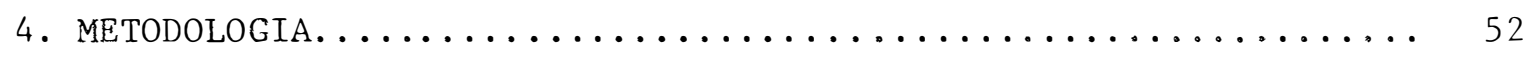

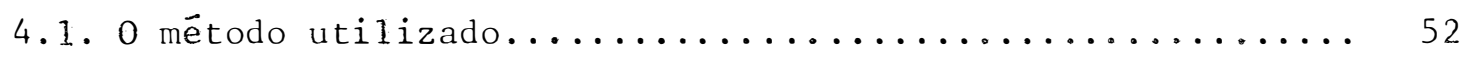

4.2. Os modelos de resposta para simulação.............. 53

4.3. Critério para a escolha de um $\lambda_{i}$ pequeno............ 61

4.4. O material utilizado e a obtenção dos resultados........ 63

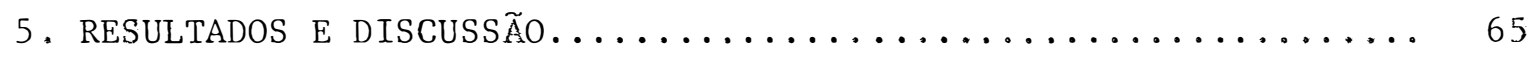

5.1 . Porcentagens de pontos de mäximo................ 6.5

5.2 . Porcentagens de pontos de sela.................. 68

5.3. o ponto de mäximo estimado.................. 70

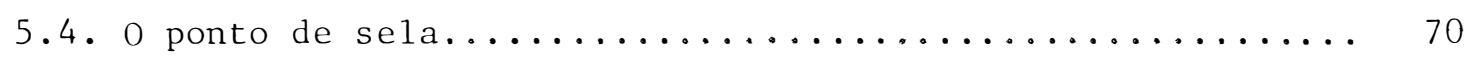

5.5. o ponto de mäximo fronteira.................. 73

5.6. o ponto de mäimo experimental................ 75

5.7 . Discussöes finais...................... 75

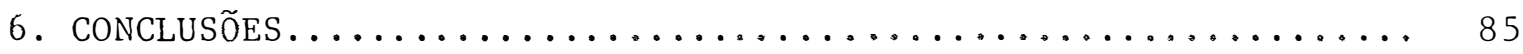

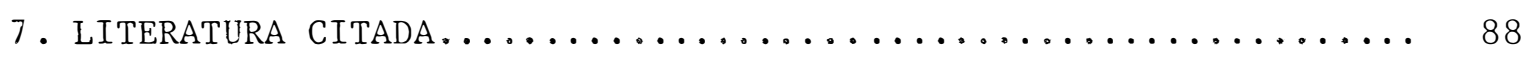

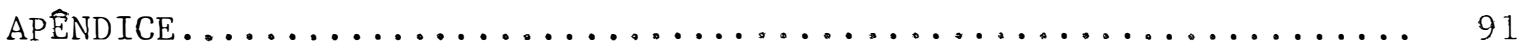




\section{SUPERFICIES DE RESPOSTA EM EXPERIMENTOS DE ADUBAÇÃO: \\ O PROBLEMA DOS PONTOS DE SELA}

Autor: ADHEMAR SANCHES

Orientador: IZAIAS RANGEL NOGUEIRA

\section{RESUMO}

A determinação da combinação de doses de nutrientes que dä a produção máxima, é um problema de interesse em ensaios de adubação. As sim, quando a superfície de resposta tem um ponto de sela ao învés de um ponto de máximo esperado, é de grande importância a obtenção de soluções alternativas para esse problema.

Neste trabalho, estudou-se a possibilidade de se substituir o ponto de máximo não encontrado pelo próprio ponto de sela ou pelo ponto de mäximo fronteira ou pelo ponto de máximo experimental. Foi feita tam bém uma comparação entre alguns delineamentos de tratamentos.

No estudo, foram utilizados nove delineamentos com três fa tores que são: fatorial $3^{3}$ com níveis igualmente espaçados e tipo 0 , q e $3 \mathrm{q}, \mathrm{q}>0$; Box $\operatorname{com} \alpha=1,215$ e $\alpha=2 ;(1 / 5) 5^{3}$ tipo $Y$ e tipo w; compos to central com duas estrelas; duplo central composto com 29 pontos com $\alpha=1,51$ e $\alpha=1$. Em todos os delineamentos, os níveis de cada fator fo ram tomados num mesmo intervalo com o extremo inferior igual ao nível mais baixo e o extremo superior igual ao nível mais alto.

Os dados experimentais foram obtidos por simulação em diver sas situações teóricas, segundo modelos de resposta do tipo polinomial qua drātico e com máximo. A posição de cada coordenada do ponto de máximo real foi colocada a $80 \%$ à direita do extremo inferior do intervalo dos níveis.

Foram obtidas as seguintes conclusöes:

a) o ponto de máximo fronteira e o ponto de máximo experí mental podem ser utilizados como bons substitutos do ponto de máximo não encontrado. O primeiro é indicado para os seguintes delineamentos: fato rial $3^{3}$ com níveis igualmente espaçados, $(1 / 5) 5^{3}$ tipo $Y$ ou tipo $W$ e duplo 
vií

central composto com 29 pontos e $\alpha=1$; o segundo $\vec{e}$ indicado para os se guintes delineamentos: fatorial $3^{3}$ com nîveis igualmente espaçados, Box com 15 pontos e $\alpha=2$, (1./5) $5^{3}$ tipo $Y$ ou tipo $W$ e composto central com duas estrelas;

b) O ponto de sela não e um bom substituto para o ponto de máximo não encontraio;

c) O delineamento fatorial $3^{3}$ com níveis igualmente espaça dos foi o que apresentou maior eficiência na obtenção de pontos de mäximo. 


\section{RESPONSE SUREACES IN FERTILIZER EXPERIMENTS: \\ THE PROBLEM OF SADDLE POINT}

Author: ADHEMAR SANCHES

Adviser: IZAIAS RANGEL NOGUEIRA

\section{SUMMARY}

The determination of nutrients combination dosis that gives maximum yield is an interesting problem in fertilizer trials. When the response surface has a saddle point instead of an expected point of maxi mum, it is of great importance to obtain alternative solutions for this problem.

In this work it was studied the possibility to substitute the unfounded point of maximum by the saddle point or by the frontier point of maximum or by the experimental point of maximum. It was also made a comparison among some treatments designs.

The following nine designs with three factors were studied: the $3^{3}$ factorial with equally spaced levels and type $0, q$, and $3 q, q>0$; Box with $\alpha=1.215$ and $\alpha=2 ;(1 / 5) 5^{3}$ type $Y$ and type $W$; central composite with two stars; double central composite with 29 points with $\alpha=1.51$ and $\alpha=1$. In all designs the levels of each factor were considered in a same interval with the lower extreme equal to the lowest level and the upper extreme equal to the highest.

The experimental data were obtained by simulation in many theoretical situations according to response models of the polynomial qua dratic type with a maximum. The position of each coordinate of a true point of maximum was situated $80 \%$ to the right of the lower extreme of the interval of levels.

The following conclusions were obtained:

a) The frontier point of maximum and the experimental point of maximum may be used as good substitutes of the unfounded point of maxi mum. The first is suitable to the following designs: the $3^{3}$ factorial 
with equally spaced levels, (1/5) $5^{3}$ type $Y$ ou type $W$ and the double cen tral composite with 29 points and $\alpha=1$; the latter is suitable to the following designs: the $3^{3}$ factorial with equally spaced levels, Box with 15 points and $\alpha=1,215$ ou $\alpha=2,(1 / 5) 5^{3}$ type $Y$ or type $W$ and the central composite with two stars;

b) The saddle point is not a good substitute to the unfounded point of maximum;

c) The $3^{3}$ factorial design with equally spaced levels was the one that presented more efficiency in obtaining points of maximum. 


\section{INTRODUÇÃO}

\subsection{Considerações gerais}

Dados de produção, obtidos em experimentos de adubação, são freqüentemente analisados através de superfícies de resposta, principal mente após o trabalho de BOX e WILSON (1951). Para isso, admite-se a exis tência de uma relação funcional entre a produção $\eta \mathrm{e} k$ fatores, $\mathrm{k} \geq 1$ e inteiro, os quais se supõe que exerçam influência sobre essa produção.

A produção $n$ é a resposta e os $k$ fatores são representados

por variäveis reais, quantitativas e contínuas $x_{1}, x_{2}, \ldots, x_{k}$, onde $x_{i}$ re presenta o nível considerado do fator $i, i=1,2, \ldots, k$. Uma suposição que é feita sobre essas variáveis é que as mesmas possam ser controladas pelo experimentador, com um erro desprezível. No campo agronômico e em um ensaio de adubação onde se tem $k=3$ fatores, por exemplo, as variāveis $\mathrm{x}_{1}, \mathrm{x}_{2}$ e $\mathrm{x}_{3}$ podem ser as doses de três diferentes fertilizantes aplicados numa cultura de milho e a resposta $n$ pode ser a produção de grãos em quí logramas por hectare.

Em alguns estudos dentro da literatura de superfícies de res posta, são utilizadas variáveis padronizadas (ou codificadas) $x_{1}, x_{2}, \ldots$, $x_{k}$ em lugar das variáveis $x_{1}, x_{2}, \ldots, x_{k}$, onde $x_{i} \bar{e}$ uma função linear de $x_{i}, i=1,2, \ldots, k$. De qualquer modo, porém, o que é mais comum na prä tica é o desconhecimento da relação funcional entre a resposta $\eta$ e as va riāveis. Nesse caso, o que usualmente se faz é considerar, de modo apro ximado, que

$$
\eta=h(\underset{\sim}{X} ; \underset{\sim}{B})
$$


onde $x=\left(x_{1}, x_{2}, \ldots, X_{k}\right)^{\prime}, \underset{\sim}{\beta}=\left(\beta_{1}, \beta_{2}, \ldots, \beta_{\ell}\right)^{\prime}$ é um vetor de $\ell$ para metros a serem estimados e h $\tilde{e}$ uma funçã̃o real de uma forma matemática es pecificada.

Do ponto de vista prätico, o que se espera é que $h\left(X ; X_{\sim}\right)$ se ja uma boa representação de $\eta$ dentro de uma região $A$ de interesse, conti da no espaço euclideano $k$-dimensional $R^{k}$. A região A de interesse é deno minada a região experimental e é a região onde são tomados os valores das variäveis $x_{1}, x_{2}, \ldots, x_{k}$. Após o trabalho de Box ewlLson (1951), tem sido muito utilizada em diversas aplicações a função polinomial quadráti ca, que em três variäveis $x_{1}, x_{2}$ e $x_{3} \vec{e}$ dada por

$$
\begin{aligned}
h\left(X_{\sim}^{X} ; \underset{\sim}{\beta}\right)= & \beta_{0}+\beta_{1} X_{1}+\beta_{2} X_{2}+\beta_{3} X_{3}+\beta_{11} X_{1}^{2}+\beta_{22} X_{2}^{2}+\beta_{33} X_{3}^{2}+ \\
& +\beta_{12} X_{1} X_{2}+\beta_{13} X_{1} X_{3}+\beta_{23} X_{2} X_{3}
\end{aligned}
$$

onde $\underset{\sim}{\beta}=\left(\beta_{0}, \beta_{1}, \beta_{2}, \beta_{3}, \beta_{11}, \beta_{22}, \beta_{33}, \beta_{12}, \beta_{13}, \beta_{23}\right)^{\prime} \vec{e}$ o vetor dos $\ell=10$ parâmetros reais.

Num experimento de adubação, a produção Y observada para um vetor particular $\underset{\sim}{X}$ na região experimental A não coincide necessariamente com o valor da verdadeira resposta $n$ neste vetor. o que se pode escrever è que

$$
Y=n+e
$$

onde e é o erro aleatório que representa a diferença entre o valor da pro dução observada e o valor da produção verdadeira.

Considerando-se, então, $N$ combinações de níveis

$$
\underset{\sim u}{X}=\left(x_{1 u}, x_{2 u}, \ldots, x_{k u}\right)^{\prime}, u=1,2, \ldots, N
$$

na região experimental A, pode-se obter um conjunto de observações $\mathrm{Y}_{1}$, $\mathrm{Y}_{2}, \ldots, \mathrm{Y}_{\mathrm{N}}$, onde

$$
\mathrm{Y}_{\mathrm{u}}=\eta_{\mathrm{u}}+\mathrm{e}_{\mathrm{u}}
$$

ouseja,

$$
\mathrm{Y}_{\mathrm{u}}=\mathrm{h}(\underset{\sim \mathrm{u}}{\mathrm{X}} ; \underset{\sim}{\beta})+\mathrm{e}_{\mathrm{u}}, \mathrm{u} \quad 1,2, \ldots, \mathrm{N}
$$

utilizando-se a relaçăo (1.1). A partir daí, considerando-se que os erros $\mathrm{e}_{1}, \mathrm{e}_{2}, \ldots, \mathrm{e}_{\mathrm{N}}$ tenham média zero, sejam nao correlacionados, de mesma va 
riância $\sigma^{2}$ e distribuição normal, pode-se obter, pelo método dos mínimos quadrados, as estimativas $\hat{\beta}_{1}, \hat{\beta}_{2}, \ldots, \widehat{B}_{\ell}$ dos parâmetros $\beta_{1}, \beta_{2}, \ldots, \beta_{\ell}$, respectivamente, com qualidades "ótimas". Com isso, obtēm-se a função de produção estimada

$\widehat{E(Y)}$ ou $\hat{n}$ ou $\hat{n}\left(X_{\sim}\right)=h(\underset{\sim}{X} ; \underset{\sim}{\widehat{\beta}})=h\left(X_{1}, X_{2}, \ldots, X_{k} ; \widehat{\beta}_{1}, \hat{\beta}_{2}, \ldots, \hat{\beta}_{l}\right)$

A equação (1.2) define a superfície de resposta que serä utilizada na anālise e uma de suas aplicações está na determinação dos ní veis ötimos, isto é, aquela combinação particular de valores das variáveis $x_{1}, x_{2}, \ldots, x_{k}$ para os quais se obtēm a produção máxima ou então, a mä xima renda líquida. Um problema que tem trazido preocupações na prática $\vec{e}$ que, com bastante freqüência, tem-se encontrado um ponto de sela em $1 \underline{u}$ gar de um ponto de máximo que era esperado devido a natureza do problema.

\subsection{O problema dos pontos de sela}

Se numa análise estatística de um ensaio de adubação, atra vês de superfície de resposta, não for encontrado o ponto de máximo espe rado, então não serão determinados os níveis ôtimos dos nutrientes. Assim sendo, o pesquisador poderá deixar de utilizar alguns resultados de inte resse.

A ocorrência de pontos de sela è um fato bastante comum em problemas práticos e muitas podem ser as causas, segundo os pesquisadores. Analisando a questão sob o ponto de vista geométrico, uma possível expli c ação para a ocorrência de falsos pontos de sela pode estar na inversãoda concavidade da função de resposta com um ou dois fatores (nutrientes) em algum subconjunto $S$ da região experimental.

No caso de três fatores, a inversão de concavidade para um fator, por exemplo na variável $x_{1}$, pode ser conseqüência de uma situação teórica, onde a resposta $n$ é de pouca sensibilidade na região experimen tal, na direção do eixo $x_{1}$. Isto é, mantidos valores fixos de $x_{2}$ e $x_{3}$ e variando-se $x_{1}$, a diferença entre as respostas é relativamente pequena mesmo para dois valores de $x_{1}$ bem afastados um do outro. Chamando de $\eta_{23}$ a função de resposta teórica para valores fixos de $\mathrm{X}_{2}$ e $\mathrm{X}_{3}$, a si.tuação teórica descrita corresponde a dizer que essa função, somente de $x_{1}$, é aproximadamente constante. 
Considere-se, então, a situação real, onde o problema è de máximo, isto é, a função de resposta verdadeira e desconhecida tem máximo. A concavidade de $\eta_{23}$ tem, entäo, um sentido determinado, indicando que $\eta_{23}$ tem máximo. Seja, agora, a função estimada $\hat{\eta}_{23}$, obtida de $\hat{n}=h(\underset{\sim}{x} ; \underset{\sim}{\widehat{B}})$ colocando-se $x_{2}$ e $x_{3}$ iguais aos valores anteriormente fixados.

A funçăo $\hat{\eta}_{23}$, por ter sido determinada a partir de observa ções experimentais e, portanto, sujeita à flutuações casuais, pode perfei tamente ter uma concavidade de sentido inverso da função térica $\eta_{23}$. na região experimental. Se isso ocorre, diz-se então que ocorre uma inver são de concavidade com um fator.

Uma inversão de concavidade com dois fatores ē uma generali zação do caso de inversão de concavidade com um fator. Se a situação teó rica é de máximo, a inversão de concavidade com um ou dois fatores leva o pesquisador a obter ponto de sela em lugar do ponto de máximo esperado. Se ocorrer uma inversão com os três fatores, isso levaráa à obtenção de um ponto de minimo.

\subsection{Objetivos do trabalho}

A partir de dados experimentais obtidos por simulação, são estudadas algumas questões relativas à superfícies de resposta em ensaios de adubação com três fatores, quando se estả interessado na determinação do ponto de máximo. Os objetivos do presente trabalho são os seguintes:

19) analisar formas alternativas de interpretação dos resul tados quando se encontra um ponto de sela em lugar do ponto de máximo es perado;

29) investigar formas de se aumentar a eficiencia na obten ção de pontos de máximo;

39) indicar delineamentos mas apropriados para se obter maior eficiência na obtençăo de pontos de máximo.

Quanto as formas alternativas de interpretação dos resulta dos quando se encontra um ponto de sela em lugar do ponto de mäximo espe rado, serão analisadas as possibilidades de se utilizar como substitutos do ponto de máximo não encontrado, os seguintes pontos: a) o ponto de se la; b) o ponto de maior valor de $\hat{n}$ na região experimental A que serä cha mado o ponto de máximo fronteira, pelo fato de estar situado na fronteira 
de A e c) o ponto experimental de maior resposta observada que será chama do o ponto de máximo experimental.

No que se refere às formas de se aumentar a eficiência na obtenção de pontos de máximo, podem ser sugeridas: a) a redução da variân cia residual através do aumento do número de repetições ou de análise de grupos de experimentos; b) o posicionamento mais adequado das doses e c) o aumento do número de níveis dos fatores. Com relação aos itens (a) e (b) existem conclusões jä estabelecidas, por exemp1o, nos trabalhos de MALHEIROS e PERECIN (1983) e DEPIZZOLATTI (1983). No presente trabalho será investigado o aumento do número de níveis como uma possível forma de se aumentar a eficiência na obtenção de pontos de máximo e isso será fei to pela consideração de alguns delineamentos com 3, 5, 7 e 9 níveis mais comumente empregados em estudos de ensaios de adubação.

Para se indicar delineamentos de modo a atender ao 39 obje tivo proposto, será utilizada uma medida de eficiência na obtenção de pon tos de máximo que é igual a porcentagem obtida de ocorrência de um evento de interesse. Com essa medida, um delineamento ou mesmo um método de aná lise será mais eficiente ou melhor que outro, se exibir uma porcentagem maior de ocorrência do evento de interesse. No caso específico da compa ração de dois delineamentos quanto a eficiência na obtenção de pontos de máximo, a ocorrência de um evento de interesse será a ocorrência de um ponto de máximo.

As hipóteses básicas sob as quais o presente trabalho serä desenvolvido são as seguintes:

i) é conhecida a região experimental A a ser pesquisada. Assim, para cada fator, é conhecido o intervalo de variação das doses;

ii) as coordenadas do ponto de máximo real estão situadas numa posição a $80 \%$ à direita do extremo inferior do intervalo de variação das doses;

iii) a função polinomial quadrātica em três variāveis $x_{1}$, $x_{2}$ e $x_{3}$ é uma representação adequada da função de produção $n$ na região ex perimental. Isto é, a função polinomial quadrática em $x_{1}, x_{2}$ e $x_{3}$ é utili zada como o modelo matemático para a estimação da função de resposta ver dadeira que, por sua vez, é também polinomial quadrática em $x_{1}, x_{2}$ e $x_{3}$.

Do ponto de vista das aplicações, as hipóteses (i) e (ii) definem situações que podem ser perfeitamente encontradas em ensaíos de 
adubação. De fato, a experiência passada e o conhecimento de ensaios de adubação, pode perfeitamente fazer com que o pesquisador delimite o inter valo de doses a ser pesquisado. Além disso, pode-se ter também uma idéia ao menos aproximada da posição mais provāvel da dose ótima.

A hipótese (iii), contudo, não é de fảcil verificação num problema prático, pois a forma matemática da função de resposta verdadei ra, se existe, è no geral desconhecida. No entanto, essa hipótese é uti lizada como uma hipótese de trabalho, para poder caracterizar uma situa ção onde não hã discrepância, quanto ao tipo, entre o modelo matemático da função de resposta verdadeira e o modelo matemático utilizado para a es timação.

A interação entre todos os três fatores ou entre dois quais quer deles, pode estar presente ou não num problema prätico. Por isso, são estudadas situações onde tais interações aparecem ou não, com o obje tivo de se verificar se têm ou não influência nas comparações de delinea mentos, dentro das hipóteses de trabalho estabelecidas. 


\section{REVISÃO DE LITERATURA}

\subsection{A metodologia de superficie de resposta em ensaios de adubação}

A literatura existente sobre a metodologia de superfícies de resposta é vasta, mostrando as aplicações à diferentes campos de pes quisa, bem como o desenvolvimento na área de construção de delineamentos ótimos na análise estatística de superfície. Até o ano de 1975, duas revi sões de literatura interessantes são apresentadas, uma por HILL e HUNTER (1966) e outra por MEAD e PIKE (1975).

O grande impulso dado na análise de dados experimentais atra vës de superfícies de resposta, foi dado pelo trabalho de pesquisa de Box e WILSON (1951), onde os autores desenvolveram métodos de determinação de condições ótimas em pesquisas industriais. Nesse trabalho, os autores in troduziram a função polinomial com duas ou mais variáveis independentes como uma boa aproximação da função de resposta e apresentaram delineamen tos de tratamentos com o objetivo de se encontrar um ponto na região expe rimental de interesse onde a resposta é máxima, utilizando para isso o me nor nümero possível de pontos.

No campo agronômico, a função polinomial de resposta tem si do largamente empregada em ensaios de adubação. Alëm da função polino mial, há ainda outros modelos matemáticos de curvas e superfícies de res posta que podem ser empregados como, por exemplo, a função polinomial da raiz quadrada, a polinomial inversa, curvas com "platô" e curvas exponen ciais, como pode se ver nos trabalhos de VIEIRA (1970), CONAGIN e JORGE (1977), NELDER (1966), ANDERSON e NELSON (1975) e outros. 
Quanto aos delineamentos de tratamentos, utilizados no estu do de superfícies de resposta em ensaios de adubação, muitos desses têm suas raízes nos delineamentos compostos introduzidos no trabalho de BOX e WILSON (1951). O próprio delineamento de Box com 15 pontos e outros ti pos que são pequenas variações dos delineamentos compostos, propostos por Box e Wilson, têm sido utilizados neste estudo, como pode-se ver, por exem plo, nos trabalhos de TRAMEL (1957), MIRANDA (1966), VOSS e PESEK (1967), CONAGIN et alii (1969), PAEZ e SILVA (1975), CONAGIN e JORGE (1979) e CO NAGIN (1982). Outros delineamentos não pertencentes a classe dos delinea mentos compostos tambëm têm sido sugeridos e utilizados, como pode-se ver nos trabalhos de CONAGIN e JORGE (1977), DAVILA (1979), PERECIN et alii (1982) e ROJAS (1982).

\subsection{A ocorrência de pontos de sela}

A ocorrência de pontos de sela, que é a motivação do presen te trabalho, tem sido referida em värios trabalhos de pesquisa e por di versos pesquisadores.

CAMPOS (1967) utilizou em seus estudos o modelo de regres são polinomial quadratica para a produção Y como

$$
\begin{aligned}
Y= & a_{0}+a_{11} x_{1}^{2}+a_{22} x_{2}^{2}+a_{33} x_{3}^{2}+a_{12} x_{1} x_{2}+a_{13} x_{1} x_{3}+ \\
& +a_{23} x_{2} x_{3}+a_{14} x_{1}+a_{24} x_{2}+a_{34} x_{3}+e
\end{aligned}
$$

aplicado a ensaios fatoriais $3^{3}$ de adubação, com o objetivo de apresentar uma discussão sobre a determinação das doses econônicas da equação da re ceita líquida. O autor utilizou dados experimentais de produção de milho de ARRUDA (1959) e, entre as conclusões de interesse na pesquisa, obser vou a ocorrência de pontos de sela da função receita líquida na maỉoria dos 50 ensaios individuais estudados. Em 42 desses ensaios ocorreram pon tos de sela, havendo apenas 7 pontos de márimo e até mesmo 1 ponto de mí nimo.

Em vista disso, o autor fez uma distribuição dos 50 ensaios em grupos. Na discussão da máxima receita líquida, o autor observou uma tendência de aparecimento de maior nümero de pontos de máximo quando se faz o agrupamento de ensaios. 
VIELRA (1970) estendeu o trabalho de CAMPOS (1967), utilizan do o modelo polinomial de segundo grau $\mathrm{em} \sqrt{x}$ (polinomial da raiz quadra da) dado por

$$
\begin{aligned}
Y= & a_{0}+a_{11} \sqrt{x_{1}}+a_{22} \sqrt{x_{2}}+a_{33} \sqrt{x_{3}}+a_{12} \sqrt{x_{1} x_{2}}+a_{13} \sqrt{x_{1} x_{2}}+ \\
& +a_{23} \sqrt{x_{2} x_{3}}+a_{12} x_{1}+a_{24} x_{2}+a_{34} x_{3}+e
\end{aligned}
$$

e o modelo $\operatorname{com} x^{3 / 2}$ dado por

$$
\begin{aligned}
Y= & a_{0}+a_{11} x_{1}^{3 / 2}+a_{22} x_{2}^{3 / 2}+a_{33} x_{3}^{3 / 2}+a_{12} x_{1} x_{2}+a_{13} x_{1} x_{3}+ \\
& +a_{23} x_{2} x_{3}+a_{14} x_{1}+a_{24} x_{2}+a_{34} x_{3}+e
\end{aligned}
$$

Com relação aos 50 ensaios individuais estudados por CAMPOS (1967), obser va-se a ocorrência de 40 pontos de sela para o modelo em $\sqrt{x}$ e 39 pontos de sela para o modelo com $x^{3 / 2}$. Entre os resultados e a discussão a respe to da máxima renda líquida, a autora também observou o aparecimento de maior nümero de pontos de mäximo quando se considera o agrupamento de en saios, para ambos os modelos.

Ainda, neste trabalho, a autora observou que cada um dos 4 grupos de ensaios anuais (com 13, 14, 11 e 12 ensaios individuais), cons tituídos por CAMPOS (1967), apresenta maior número de pontos de máximo do que cada um dos 5 grupos compostos de 10 ensaios sorteados ao acaso, com os três modelos em $x, \sqrt{x}$ e $x^{3 / 2}$. A explicação da autora é que nos en saios anuais os fatores climáticos são controlados, enquanto que nos gru pos de 10 ensaios sorteados ao acaso, a clima aparece como um erro siste mático não controlado.

CONAGIN (1978) cita outros trabathos onde foram realizados estudos em experimentos fatoriais $3^{3}$ de adubação em milho, por MIRANDA (1971), em algodão, por FUZATTo et ali (1970) e em feijão, por IGUE et. alii (1971). Esses estudos revelaram um nümero variável de pontos de se 1a. Segundo Conagin, alguns especialistas acreditam que esses fatos se jam normais, isto é, devam acontecer com certa freqüência na natureza.

Na opinião de Conagin, a ocorrência de pontos de sela pode ser conseqüência de causas diversas, duas das quais são apontadas a se guir, quais sejam:

a) A anālise conjunta de äreas ecológicas não homogêneas pode levar a reunir em um mesmo grupo, resultados que deveriam ser agrupa 
dos em duas ou três āreas mais homogêneas, confundindo em uma mesma super fície, duas ou três superfícies de resposta distintas;

b) A reunião de resultados experimentais de dois ou três anos de pesquisa (grupos de experimentos) provenientes da mesma ou de vá rias áreas ecológicas, pode levar à determinaçáo de um resultado médio me nos satisfatório quando, na realidade, o comportamento nos vários anos se ria diferente.

\subsection{Formas de se aumentar a eficiência na obtenção de pontos de máximo}

Um dos objetivos do presente trabalho é investigar formas de se aumentar a eficiência na obtenção de pontos de máximo em problemas onde realmente se espera um máximo. Sobre isso, existem alguns trabalhos de pesquisa que fazem referência a agrupamentos de experimentos e posicio namento adequado de doses.

\subsubsection{O agrupamento de experimentos}

CAMPOS (1967) e VIEIRA (1970) destacam que o agrupamento de experimentos aumenta a tendência de aparecimento de pontos de máximo. Ao falar sobre agrupamento de experimentos, CONAGIN (1978) observa que, quan do se tem uma rede de experimentos representando värias āreas ecológicas e conduzidos por dois ou três anos, deve-se efetuar a análise dos experi mentos reunindo em um grupo aqueles resultados que efetivamente podem ca racterizar determinada ärea ecológica (de fertilidade equivalente). Alẻm disso, esse agrupamento deve ser feito ano por ano.

JORGE e CONAGIN (1977) analisaram as propriedades de um gru po especial de delineamentos $(1 / 5) 5^{3}$ por meio de simulação de experimen tos individuais. Para gerar os dados, os autores utilizaram duas equa ções fundamentais particulares de produção de milho em quilogramas por hectare, sendo uma delas a função polinomial quadrática e a outra a fun ção polinomial da raiz quadrada, ambas com três variáveis independentes.

Entre as conclusões estão as seguintes:

a) Independentemente do modelo linear utilizado para gerar os dados, o agrupamento de 10 ensaios é suficiente para se obter $100 \%$ de 
pontos de mäximo quando a superfície adaptada aos clados é o modelo polino mial quadratico. Quando a superfície adaptada é o modelo polinomial da raiz quadrada, são suficientes 20 ensaios para se obter $100 \%$ de pontos de māximo;

b) Aumentando o tamanho do agrupamento, tende a aumentar a frequêencia dos resultados de lucro máximo, cujas coordenadas caem dentro do intervalo de níveis dos fatores, utilizados no experimento.

\subsection{2. o posicionamento adequado de doses}

o posicionamento adequado de doses é uma forma de escolha de um delineamento dentro de um conjunto de delineamentos de um mesmo ti po, segundo algum critério estabelecido. Por exemplo, no caso de três va riäveis $x_{1}, x_{2}$ e $x_{3}$, pode-se estar interessado em escolher um delineamento dentro do tipo fatorial $3^{3}$, pelo posicionamento de doses que dá a naior porcentagem de pontos de máximo da função receita líquida.

NOGUEIRA (1960) considerou a lei de Mitscherlich aplicada a ensaios de adubação com três níveis de um fertilizante, onde o primeiro níve1 é a testemunha (sem fertilizante) e o terceiro é uma dose fixa igual ao triplo de uma dose padrão q, previamente estabelecida. O nível interme diārio é igual a xq, onde $0<x<3$.

Utilizando a melhor precisão das estimativas obtidas como um critério para a escolha das doses, o autor concluiu que:

a) Sendo $r=10^{-c q}$, são ótimos os delineamentos do tipo $0,0,5$ e 3 para $0,2<r<0,4 ; 0,1$ e 3 para $0,5<r<0,7$ e $0,1,5$ e 3 para $0,8<r<0,9$;

b) Considerando as doses padrões à base de $\mathrm{P}_{2} \mathrm{O}_{5}, \mathrm{~K}_{2} \mathrm{O}$ e $\mathrm{N}$, o delineamento do tipo 0,1 e 3 é melhor que qualquer outro, sendo que para $\mathrm{N}$, o delineamento usual do tipo 0, 1,5 e 3 não é muito menos eficiente do que 0,1 e 3 ;

c) Os parâmetros da equação de Mitscherlich ficarão melhor estimados se forem adotados os esquemas do tipo 0,1 e 3 .

Mais recentemente, MALHEIROS e PERECIN (1983) simularam 5000 ensaios em um computador e estudaram os efeitos da posição das doses em relação às coordenadas do ponto de máximo de uma superfície de resposta, no sentido de se conseguir uma maior eficiência (maior porcentagem) na ob 
tenção de pontos de máximo. O modelo utilizado foi o polinomial quadráti co de superfície de resposta com três vaxiáveis e as combinações de ni veis foram escolhidas num delineamento fatorial fracionado (1/5) $5^{3}$ do ti po I, III, IV, segundo a classificação de CONAGIN e JoRGE (1977).

Para gerar os dados, os autores tomaram como base a equação de produção particular estabelecida por JORGE e CONAGIN (1977), como fun ção de resposta à adubação NPK (nitrogênio, fósforo e potássio) em milho (em $\mathrm{kg} / \mathrm{ha})$. Em termos das doses reais $\mathrm{x}_{1}, \mathrm{x}_{2}$ e $\mathrm{x}_{3}$, a equação considerada foi

$$
\begin{aligned}
Y_{u}= & 480,0000+22,4400 x_{1 u}+27,6400 x_{2 u}+25,2000 x_{3 u}- \\
& -0,0671 x_{1 u}^{2}-0,0879 x_{2 u}^{2}-0,1244 x_{3 u}^{2}-0,0400 x_{1 u} x_{2 u}- \\
& -0,0480 x_{1 u} x_{3 u}-0,0319 x_{2 u} x_{3 u}+e_{u}
\end{aligned}
$$

e foram analisados os seguintes casos:

a) Coordenadas do ponto de máximo entre as quartas e quin tas doses, nas mesmas condições do estudo de JORGE e CONAGIN (1977);

b) Coordenadas do ponto de máximo pouco maiores que as quin tas doses;

c) Coordenadas de pontos de máximo aproximadamente no ponto médio das doses e com amplitude entre as doses consideravelmente grande;

d) Coordenadas do ponto de máximo aproximadamente no ponto médio das doses e com amplitude entre as doses consideravelmente pequena;

e) Coordenadas do ponto de máximo entre as segundas e ter ceiras doses.

Nos 5000 ensaios individuais, houve reprodução de pontos de mäximo em 64, 44, 83, 14 e 64 por cento dos ensaios para os casos (a), (b), (c), (d) e (e), respectivamente. Descartados os casos (c) e (e), pois en tre outros inconvenientes apontados esses podem não ser de interesse eco nômico em ensaios de adubação, os autores concluíram que o caso (a) é me 1hor. Considerando grupos de $k=1,2, \ldots, 1000$ ensaios e verificando a convergência das estimativas para os verdadeiros valores dos parâmetros, eles concluíram que o caso (b) tem comportamento bem pröximo ao do caso (a), sugerindo que certas restrições (menor número de pontos de máximo e diferenças grandes entre as estimativas e os verdadeiros valores dos coe ficientes) que se têm na anālise de ensaios individuais, tendem a desapa recer quando se agrupam ensaios. 
DEPIZZOLATTI (1983) considerou o modelo polinomial da raiz quadrada como função de produção e por simulação de dados experimentais a partir da equação particular

$$
\begin{aligned}
& Y=2000+32 \sqrt{X_{1}}+32 \sqrt{X_{2}}+32{\sqrt{X_{3}}}_{3}-20 x_{1}-20 x_{2}-20 x_{3}+
\end{aligned}
$$

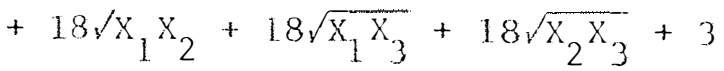

pesquisou o melhor posicionamento das doses $x_{1}, x_{2}$ e $x_{3}$ num ensaio fato rial $3^{3}$. O objetivo foi o de investigar o tipo e o comportamento dos pon tos criticos das superfïcies ajustadas para as diferentes combinações de valores (doses) das variāveis $x_{1}, x_{2}$ e $x_{3}$.

As doses utilizadas foram do tipo $0, \mathrm{q}_{i 1}, \mathrm{q}_{\mathrm{i} 2}(\mathrm{i}=1,2,3)$ e entre suas conclusões podem ser destacadas as seguintes:

a) as doses onde os valores de $\mathrm{q}_{i 2}(\mathrm{i}=1,2,3)$ eram a 1 tos e $\mathrm{q}_{\mathrm{i} 2}=3 \mathrm{q}_{\mathrm{i} 1}$, apresentaram os melhores resultados. Nesses casos obte ve-se um menor número de pontos de sela e as coordenadas do ponto de máxi mo foram mais concentradas em torno de seu valor real;

b) As doses onde $\mathrm{q}_{i 2}(i=1,2,3)$ eram baixos, ou então a diferença entre $q_{i 1}$ e $q_{i 2}$ era pequena, forneceram maior número de pontos de sela e grande dispersão das coordenadas do ponto de máximo obtidas, mes mo para pequenos valores tomados para o coeficiente de variação.

Diante das conclusões obtidas, o autor sugere os seguintes procedimentos:

i) Se ao ser planejado um experimento, possuir-se um conhe cimento prévio de valores aproximados das coordenadas do ponto de máximo, a sugestão seria colocar os níveis intermediärios $q_{i 1}, i=1,2,3$, nas proximidades do valor conhecido e o nível $q_{i 2}$ como sendo $2 q_{i 1}$ ou, de pre ferência, $3 \mathrm{q}_{\mathrm{il}}$;

ii) Quando não se tem nenhuma informação, o maìs aconselhá vel seria definir o nível máximo $2 q_{i 1}$ ou $3 q_{i 1}$, $i=1,2,3$, como sendo o máximo que as condições reais permitirem. 


\section{FUNDAMENTOS TEORICOS}

\subsection{Modelo linear e estimação de parâmetros}

$$
\begin{aligned}
& \text { Seja o modelo linear de regressão dado por } \\
& \underset{\sim}{Y}=\underset{\sim}{\mathrm{X}}+\underset{\sim}{\mathrm{e}}
\end{aligned}
$$

onde $\underset{\sim}{\mathrm{Y}}=\left(\mathrm{Y}_{1}, \mathrm{Y}_{2}, \ldots, \mathrm{Y}_{\mathrm{N}}\right)^{\prime}$ é o vetor coluna de $\mathrm{N}$ observações, $\mathrm{X}$ é uma ma triz de ordem $\mathrm{N} \times \ell$ de números reais dados, $\underset{\sim}{\beta} \overline{\mathrm{e}}$ o vetor coluna de $\ell$ parâme tros reais e $\underset{\sim}{e}=\left(e_{1}, e_{2}, \ldots, e_{N}\right)^{\prime} \bar{e}$ o vetor coluna dos $N$ erros aleatórios correspondentes às $N$ observações. Sejam ainda o vetor de médias e a ma

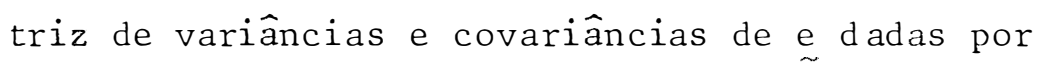

$$
E(\underset{\sim}{e})=\underset{\sim}{0} \text { e } \operatorname{Var} \underset{\sim}{(e)}=I_{N} \sigma^{2}
$$

respectivamente, onde $\underset{\sim}{0} \vec{e}$ o vetor nulo de ordem $N \times 1, I_{N}$ é a matriz identi dade de ordem $\mathrm{N}$ e $\sigma^{2}$ é um número real positivo.

Nestas condições, utilizando-se o mëtodo dos mínimos quadra dos, obtém-se o estimador $\underset{\sim}{\widehat{B}}$, do vetor $\underset{\sim}{R}$, dado por

$$
\underline{\beta}=\left(X^{\prime} X\right)^{-1} X^{\prime} \underline{\sim}
$$

onde $\left(X^{\prime} X\right)^{-1}$ é a matriz inversa de $X^{\prime} X$. Têm-se que

$$
\begin{aligned}
& E_{(}(\underset{\sim}{\hat{\beta}})=\underset{\sim}{B} \text { e } \operatorname{Var}(\underset{\sim}{\hat{B}})=(X \cdot X)^{-1} \sigma^{2} \\
& \text { Agora, se o vetor e tem distribuição multinormal, então. Y }
\end{aligned}
$$
tem distribuição multinormal com vetor mëdia $X \underset{\sim}{\beta}$ e matriz de variâncias e 
covariâncias $I_{N} \sigma^{2}$ e $\widehat{\beta}=\left(X^{\prime} X\right)^{-1} X^{\prime} Y$ tem distribuição multinornal com vetor média $\beta$ e matriz de variâncias e covariancias (ou matriz de dispersão) $\operatorname{Var}(\hat{\beta})^{\sim}=\left(X^{\prime} X\right)^{-1} \sigma^{2}$.

\subsection{O modelo de regressão polinomial quadrático em três variáveis}

Como já foi dito, a função polinomial quadrätica em três va riāveis $x_{1}, x_{2}$ e $x_{3}$ será considerada como uma representação da função de produção verdadeira $n$, dentro da região experimental de interesse. Consi derando-se então as produções observadas $Y_{1}, Y_{2}, \ldots, Y_{N}$ nos $N$ tratamen tos (combinações de níveis)

$$
\underset{\sim u}{x_{u}}=\left(X_{1 u}, x_{2 u}, X_{3 u}\right)^{i}, \quad u=1,2, \ldots, N
$$

escolhidos pelo experimentador, o modelo matemätico de regressão para $\mathrm{Y}_{\mathrm{u}}$ será dado por

$$
\begin{aligned}
Y_{u}= & \beta_{0}+\beta_{1} X_{1 u}+\beta_{2} X_{2 u}+\beta_{3} X_{3 u}+\beta_{11} X_{1 u}^{2}+\beta_{22} X_{2 u}^{2}+\beta_{33} X_{3 u}^{2}+ \\
& +\beta_{12} X_{1 u} X_{2 u}+\beta_{13} X_{1 u} X_{3 u}+\beta_{23} X_{2 u} X_{3 u}+e_{u}
\end{aligned}
$$

onde $e_{u}$ é o erro aleatörio correspondente à observação $Y_{u}$, com as suposí ções habituais que $e_{u}, u=1,2, \ldots, N$, são não correlacionados e de mes ma variância $\sigma^{2}$. Assim sendo, no modelo

$$
\underset{\sim}{Y}=\underset{\sim}{X}+\underset{\sim}{e}
$$

os vetores $\underset{\sim}{Y}, \underset{\sim}{\beta}, \underset{\sim}{e}$ e a matriz X são dados por

$$
\begin{aligned}
& \underset{\sim}{Y}=\left(Y_{1}, Y_{2}, \ldots, Y_{N}\right)^{\prime} \\
& \underset{\sim}{\beta}=\left(\beta_{0}, \beta_{1}, \beta_{2}, \beta_{3}, \beta_{11}, \beta_{22}, \beta_{33}, \beta_{12}, \beta_{13}, \beta_{23}\right)^{\prime} \\
& \underset{\sim}{e}=\left(e_{1}, e_{2}, \ldots, e_{N}\right)^{\prime}
\end{aligned}
$$

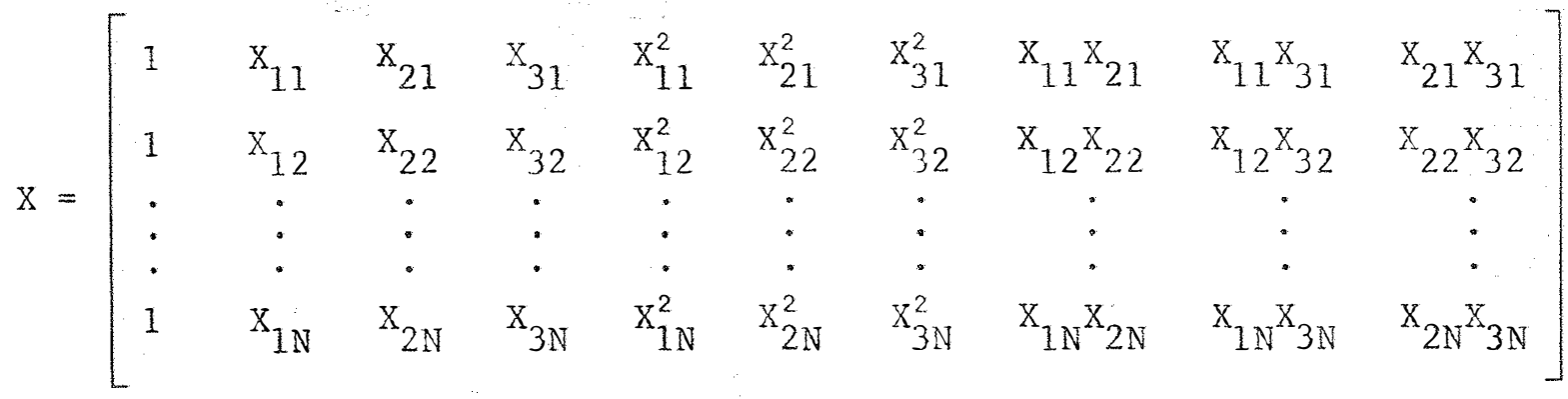


A submatriz de $X$ formada pelas colunas dois, três e quatro, é a matriz $D$ de ordem $N \times 3$, onde a u-esima linha representa o tratamento $\underset{\sim}{\mathrm{X}_{u}^{\prime}}=\left(\mathrm{X}_{1 \mathrm{u}}, \mathrm{X}_{2 \mathrm{u}}, \mathrm{X}_{3 \mathrm{u}}\right), \mathrm{u}=1,2, \ldots, \mathrm{N}$. A matriz $\mathrm{D}$ e denominala a matriz do delineamento.

3.3. A determinação e a anāilise do ponto crítico

$$
\begin{aligned}
& \text { Uma vez obtido o vetor } \\
& \qquad \underset{\sim}{\widehat{\beta}}=\left(\widehat{\beta}_{0}, \widehat{\beta}_{1}, \widehat{\beta}_{2}, \widehat{\beta}_{3}, \widehat{\beta}_{11}, \widehat{\beta}_{22}, \widehat{\beta}_{33}, \widehat{\beta}_{12}, \widehat{\beta}_{13}, \widehat{\beta}_{23}\right)^{\prime}
\end{aligned}
$$

como a estimativa do vetor $\underset{\sim}{\beta}$, tem-se então a superfície de resposta $\hat{\eta}$ da da por

$$
\begin{aligned}
\hat{n}= & \widehat{\beta}_{0}+\widehat{\beta}_{1} X_{1}+\widehat{\beta}_{2} X_{2}+\widehat{\beta}_{3} X_{3}+\widehat{\beta}_{11} X_{1}^{2}+\widehat{\beta}_{22} X_{2}^{2}+\widehat{\beta}_{33} X_{3}^{2}+ \\
& +\widehat{\beta}_{12} X_{1} X_{2}+\widehat{\beta}_{13} X_{1} X_{3}+\widehat{\beta}_{23} X_{2} X_{3}
\end{aligned}
$$

Colocando-se

$$
\begin{aligned}
& \underset{\sim}{b}=\left(\widehat{\beta}_{1}, \hat{\beta}_{2}, \widehat{\beta}_{3}\right)^{\prime}, \quad x=\left(x_{1}, x_{2}, x_{3}\right)^{\prime} \quad e \\
& B=\left[\begin{array}{ccc}
\hat{\beta}_{11} & \frac{1}{2} \widehat{\beta}_{12} & \frac{1}{2} \widehat{\beta}_{13} \\
\text { sim. } & \widehat{\beta}_{22} & \frac{1}{2} \widehat{\beta}_{23} \\
\text { sim. } & \text { sim. } & \widehat{\beta}_{33}
\end{array}\right]
\end{aligned}
$$

tem-se que

$$
\widehat{\eta}=\widehat{\beta}_{0}+\underset{\sim}{X^{\prime} b}+\underset{\sim}{X^{\prime}}{\underset{\sim}{X}}^{X}
$$

A diferencial primeira da $\widehat{n} \vec{e}$ dada por

$$
\mathrm{d} \hat{n}=\left[b_{\sim}^{\prime}+\underset{\sim}{2 \mathrm{X}^{\prime}} B\right] d \underset{\sim}{\mathrm{X}}
$$

onde $\underset{\sim}{\mathrm{dX}}=\left(\mathrm{dx}_{1}, \mathrm{dx}_{2}, \mathrm{dx}_{3}\right)^{\prime}$. Para se obter o ponto crític $\bullet$ considera-se a identidade $\mathrm{d} \hat{n} \equiv 0$, o que equivale dizer que

$$
\stackrel{\mathrm{b}}{\prime}^{\prime}+\underset{\sim}{2 \mathrm{X}^{\prime} \mathrm{B}}=\underset{\sim}{0} \mathbf{\sim}^{\prime}
$$

Assim, $\underset{\sim}{X^{*}}=\left(X_{1}^{*}, X_{2}^{*}, X_{3}^{*}\right)^{\prime}$ e um ponto crítico do domínio da função $\hat{\eta}$ se é solução do sistema de equações (3.3.1). 
Teoricamente, dependendo do vetor $b$ e da matriz $B$, esse sis tema pode não ter solução, pode ter uma unica solução ou ter infinitas so luções. No caso de uma ünica solução $X^{*}$, existe a matriz inversa $B^{-1}$ de B e, então, a solução é dada por

$$
\mathrm{X}^{*}=-\frac{1}{2} \mathrm{~B}^{-1} \stackrel{\mathrm{b}}{\sim}
$$

Na prática, onde b e B são obtidos atravēs de dados experimentais, é mui to raro ter-se uma situação exata de não existência de solução ou mesmo de infinitas soluções.

A natureza de um ponto crítico $\underset{\sim}{X} * \bar{e}$ estudada pela diferen cial segunda $d^{2} \hat{n}$ de $\hat{n}$. Tem-se

$$
d^{2} \hat{n}=2(\underset{\sim}{d X})^{\prime} B(\underset{\sim}{d X})
$$

e então a natureza (se de máximo, mínimo, de sela ou indeterminação) de $X^{*}$ será determinada por una forma diagonalizada da matriz $B$.

Uma forma diagonalizada da matriz B é uma matriz $\Delta$ de mesma ordem que $B$, obtida de modo que cada operação elementar efetuada nas 1 i nhas de B é seguida da mesma operação elementar efetuada nas colunas da matriz obtida na etapa anterior. Isso equivale a pré-multiplicar $B$ por uma matriz M' (resultante das aplicações das operações elementares suces sivas nas linhas) e pós-multiplicar M'B por $M$, obtendo-se

$$
M^{\prime} B M=\Delta=\operatorname{diag}\left\{d_{1}, d_{2}, d_{3}\right\}
$$

Assim, têm-se:

a) Se $d_{1}, d_{2}$ e $d_{3}$ são positivos, então $\underset{\sim}{X *}$ e ponto de mínimo;

b) Se $\mathrm{d}_{1}, \mathrm{~d}_{2}$ e $\mathrm{d}_{3}$ são negativos, então $\underset{\sim}{\mathrm{X}}$ é ponto de máximo;

c) Se $d_{1}, d_{2}$ e $d_{3}$ têm sinais diferentes, então $\underset{\sim}{X *}$ é ponto

de sela;

d) Se algum dos $d_{i}, i=1,2,3$, for nulo, então tem-se uma indeterminação.

Quando ocorre uma indeterminação, isto significa que o sis tema (3.3.1) tem infinitas soluções. No presente trabalho, quando numa anālise ocorrer uma indeterminação, o procedimento seráa apenas registrare contar tal ocorrência para controle, passando-se então, para a anālise se guinte com um novo conjunto de dados. 


\subsection{A forma canônica da superfície de resposta}

Seja $\hat{n}$ a superfície de resposta e $X^{*}$ um ponto crítico. Como pode ser visto em MYERS (1971, päg. 72-74), pode-se escrever

$$
\left.\left.\vec{\eta}=\mathrm{Y}_{0}+\underset{\sim}{\left(\underset{\sim}{\mathrm{X}}-\mathrm{X}^{*}\right.}\right)^{\prime} \mathrm{B} \underset{\sim}{\mathrm{X}}-\underset{\sim}{\mathrm{X}} *\right)
$$

onde $\mathrm{Y}_{0}$ ë o valor de $\hat{\eta}$ em $\mathrm{X}_{\sim}^{*}$. Agora, sendo B uma matriz real e simétrica, existe uma transformação ortogonal definida por

$$
\underset{\sim}{X-X *}=\underset{\sim}{M W}
$$

onde $\underset{\sim}{\mathbb{W}}=\left(W_{1}, W_{2}, W_{3}\right)^{\prime}$, tal que

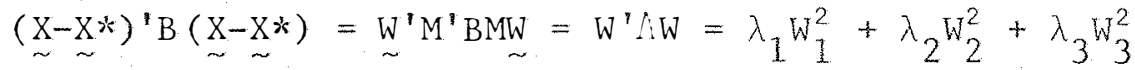

onde $\lambda_{1}, \lambda_{2}$ e $\lambda_{3}$ são os autovalores da matriz B. Os autovalores são núme ros reais e a matriz $M$ é de ordem $3 \times 3$, tal que $M^{\prime} M=I_{3}$.

Assim, pode-se escrever

$$
\widehat{n}=Y_{0}+\lambda_{1} W_{1}^{2}+\lambda_{2} W_{2}^{2}+\lambda_{3} W_{3}^{2}
$$

que é denominada a forma canônica da superfície de resposta polinomial qua drática.

A transformação ortogonal dada pela equação (3.4.1) define uma mudança de coordenadas de $\underset{\sim}{X}$ para $\underset{\sim}{W}$, onde o novo sistema de coordenadas retangulares $\underset{\sim}{W}$ tem origem $\underset{\sim}{W}=\underset{\sim}{0}$ em $\underset{\sim}{X}=\underset{\sim}{X}$. A posição dos eixos do novo sistema é obtida por uma rotação (definida por $M$ ) dos eixos $X_{1}, X_{2}$ e $X_{3}$ e por uma translação dos mesmos, caracterizada por uma mudança de origem de $\underset{\sim}{\mathrm{X}}=\underset{\sim}{0} \operatorname{para} \underset{\sim}{\mathrm{X}}=\underset{\sim}{*}$.

$$
\begin{aligned}
& \text { A matriz } \\
& \Lambda=\mathrm{M}^{\prime} \mathrm{BM}=\operatorname{diag}\left\{\lambda_{1}, \lambda_{2}, \lambda_{3}\right\}
\end{aligned}
$$

para a obtenção da forma canônica é uma forma particular da matriz $\Delta=\operatorname{diag}\left\{\mathrm{d}_{1}, \mathrm{~d}_{2}, \mathrm{~d}_{3}\right\}$ da seção 3.3. Assim, para se determinar a natureza do ponto crítico pela forma canônica, pode-se utilizar a mesma regra ante riormente estabelecida, bastando considerar $\lambda_{1}, \lambda_{2}$ e $\lambda_{3}$ em lugar de $d_{1}$, $\mathrm{d}_{2}$ e $\mathrm{d}_{3}$.

Além de indicarem a natureza do ponto crítico, os autovalo res $\lambda_{1}, \lambda_{2}$ e $\lambda_{3}$, ainda permitem a avaliação da diferença de sensibilida 
de da resposta $\hat{n}$ nas direções dos eixos $W_{1}$, $W_{2}$ e $W_{3}$. Por exemplo, num ca so onde se tem um ponto de máximo e $\lambda_{2}$ tem valor absoluto muito maior que $\lambda_{1}$ e $\lambda_{3}$, a direção do eixo $\omega_{2}$ é aquela onde a resposta $\hat{\eta}$ decresce mais ra pidamente quando se afasta da origem $\underset{\sim}{W}=\underset{\sim}{0}$, em qualquer sentido.

\subsection{Construção de um modelo de superfície polinomial quadrätica em $x_{1}, x_{2}$ e $x_{3}$, a partir de uma forma canônica dada}

Um problema, cuja solução é aplicada neste trabalho, é o da obtenção de uma forma particular polinomial quadrática em $x_{1}, x_{2}$ e $x_{3}$, a partir de uma forma canônica dada. E claro que esse problema, em sua for ma geral, tem infinitas soluções, mas o interesse aqui é na solução obti da por uma rotação particular dos eixos canônicos $W_{1}, W_{2}$ e $W_{3}$, e uma trans lação destes, de modo que a origem $\underset{\sim}{W}=\underset{\sim}{0}$ coincida com um ponto dado $\underset{\sim 0}{X_{0}}$ no sistema em $\mathrm{X}$.

De modo analítico, isso pode ser obtido por uma transforma ção linear ortogonal definida por

$$
\underset{\sim}{\mathrm{X}}=\underset{\sim}{\mathrm{MW}}+\underset{\sim 0}{\mathrm{X}}
$$

ou, de modo equivalente,

$$
\left.\underset{\sim}{W}=\mathrm{M}^{\gamma} \underset{\sim}{\left(\mathrm{X}-\mathrm{X}_{0}\right.}\right)
$$

onde $M$ é uma matriz tal que $M^{\prime}=M^{\prime} M=I_{3}$. A matriz $M$ é de ordem $3 \times 3$ cu ja linha i é o vetor de ordem $1 \times 3$ dado por

$$
\left(\cos \alpha_{i 1}, \cos \alpha_{i 2}, \cos \alpha_{i 3}\right), \quad i=1,2,3
$$

onde $\alpha_{i j}$ é igual ao ângulo que o eixo $x_{i}$ forma com o eixo $W_{j}, j=1,2,3$. Neste trabalho, essa técnica é utilizada na construção de modelos particulares de superfície de resposta polinomial quadrätica que tenham máximo e cujo ponto de mäximo seja um ponto dado $\underset{\sim 0}{X_{0} E A, ~} 0$ proble ma é, então, realizar a volta de uma forma econômica dada para uma forma polinomial quadrática, dentro de condições particulares de interesse. Co mo será visto, essas condições são tais que garantem uma solução ünica pa ra o problema e os modelos obtidos serão assumidos como os modelos verda deiros de resposta, sendo então utilizados para a simulação de dados de produção. 


$$
\begin{aligned}
& \text { Seja, então, a forma canônica } \\
& n=Y_{0}+\lambda_{1} W_{1}^{2}+\lambda_{2} W_{2}^{2}+\lambda_{3} W_{3}^{2}
\end{aligned}
$$

onde $\lambda_{1}, \lambda_{2}$ e $\lambda_{3}$ são números reais negativos dados. Então, $Y_{0}=$ máx $\eta$ que é atingido em $\underset{\sim}{W}=\underset{\sim}{0}$. Lembrando que

$$
\Lambda=\operatorname{diag}\left\{\lambda_{1}, \lambda_{2}, \lambda_{3}\right\}
$$

tem-se

$$
\eta=\mathrm{Y}_{0}+\underset{\sim}{\mathrm{W}^{\prime} \Lambda \mathrm{W}}
$$

Para que $\mathrm{Y}_{0}=\max n$ seja atingido em $\mathrm{X}_{0}=\left(\mathrm{X}_{01}, \mathrm{X}_{02}, \mathrm{X}_{03}\right)^{\prime}$ nas novas coordenadas, considera-se, então, a transformação linear (3.5.1), onde $M$ é uma matriz de rotação escolhida. Com isso, tem-se

$$
\underset{\sim}{W}=M^{\prime}\left(\underset{\sim}{X}-X_{0}\right)
$$

e a equação de produção fica

$$
\eta=Y_{0}+\left(\underset{\sim}{X}-X_{0}\right)^{\prime} M \Lambda M^{\prime}\left(\underset{\sim}{X}-X_{0}\right)
$$

Colocando-se

$$
\mathrm{Q}=\mathrm{M} \Lambda \mathrm{M}^{\prime}
$$

tem-se

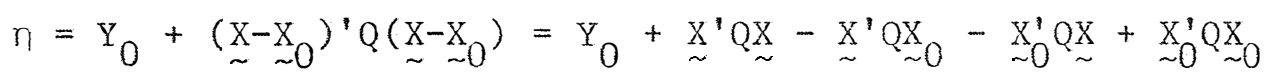

is to $\vec{e}$,

$$
\eta=\left[\mathrm{Y}_{0}+\underset{\sim 0}{\mathrm{X}_{0}^{\prime}} \mathrm{QX}_{\sim 0}\right]-\underset{\sim 0}{2 \mathrm{X}_{0}^{\prime} \mathrm{QX}}+\underset{\sim}{\mathrm{X}^{\prime}} \mathrm{QX}_{\sim}^{\mathrm{X}}
$$

Para atender aos interesses do presente trabalho foi tomado o vetor $\underset{\sim 0}{\mathrm{X}_{0}}=(4,4,4)^{\prime}$ e considerada a matriz $\mathrm{M}$ igual a $\mathrm{M}_{1}$ ou $\mathrm{M}_{2}$, onde

$$
\begin{aligned}
& M_{1}=I_{3} \quad \text { e } \\
& M_{2}=\left[\begin{array}{ccc}
\frac{2}{3} & \frac{1}{3} & \frac{2}{3} \\
-\frac{3}{\sqrt{17}} & \frac{2}{\sqrt{17}} & \frac{2}{\sqrt{17}} \\
-\frac{2}{\sqrt{153}} & -\frac{10}{\sqrt{153}} & \frac{7}{\sqrt{153}}
\end{array}\right]
\end{aligned}
$$


Com isso, pode-se estabelecer dois resultados de verificação imediata que facilitam a determinação da equação de produção (3.5.2) para $\lambda_{1}, \lambda_{2}$ e $\lambda_{3}$ dados.

Resultado 1: Se $M=M_{1}=I_{3}$ e $\underset{\sim 0}{X_{0}}=(4,4,4)^{\prime}$, então
a) $Q=\Lambda$
b) $-2 \underset{\sim}{2 X_{0}^{\prime} Q}=\left(-8 \lambda_{1},-8 \lambda_{2},-8 \lambda_{3}\right)$
c) $\underset{\sim 0}{\mathrm{X}_{0}^{1}}{\underset{\sim 0}{0}}_{0}=16\left(\lambda_{1}+\lambda_{2}+\lambda_{3}\right)$

Resultado 2: Se $M=M_{2}$ e $\underset{\sim 0}{X}=(4,4,4)^{\prime}$, então

$$
\begin{aligned}
& \text { a) } Q=\left[\begin{array}{ccc}
\frac{4 \lambda_{1}+\lambda_{2}+4 \lambda_{3}}{9} & \frac{-6 \lambda_{1}+2 \lambda_{2}+4 \lambda_{3}}{\sqrt{153}} & \frac{-4 \lambda_{1}-10 \lambda_{2}+14 \lambda_{3}}{\sqrt{1377}} \\
\operatorname{sim.} & \frac{9 \lambda_{1}+4 \lambda_{2}+4 \lambda_{3}}{17} & \frac{6 \lambda_{1}-20 \lambda_{2}+14 \lambda_{3}}{\sqrt{2601}} \\
\operatorname{sim} . & \operatorname{sim.} & \frac{4 \lambda_{1}+100 \lambda_{2}+49 \lambda_{3}}{153}
\end{array}\right] \\
& \text { b) }-2 \underset{\sim 0}{2 x_{0}^{\prime} Q}=\left(-8 \sum_{i=1}^{3} q_{i 1},-8 \sum_{i=1}^{3} q_{i 2},-8 \sum_{i=1}^{3} q_{i 3}\right) \\
& \text { c) } \underset{\sim 0}{X_{0}^{\prime}} \mathrm{QX}_{\sim 0}=16 \sum_{i=1}^{3} \sum_{j=1}^{3} q_{i j}
\end{aligned}
$$

onde $q_{i j}=$ elemento da linha $i$ e coluna $j$ da matriz $q$.

A consideração da matriz $M=M_{1}=I_{3}$ na transformação (3.5.1) permite que se obtenha modelos em $x_{1}, X_{2}$ e $x_{3}$ onde os coeficientes $\beta_{12}$, $\beta_{13}$ e $\beta_{23}$ são nulos, o que caracteriza una situação onde não há interação entre os fatores. Por outro lado, a consideração de $M=M_{2}$ permite que se obtenha modelos de produção em $x_{1}, x_{2}$ e $x_{3}$ com $\beta_{12}, \beta_{13}$ e $\beta_{23}$ não to dos nulos, criando-se assim uma situação onde hä interação entre os fato res, no caso onde $\lambda_{1}, \lambda_{2}$ e $\lambda_{3}$ não são todos iguais. Quando $M=M_{1}=I$, a transformação (3.5.1) equivale a realizar apenas uma translação dos eixos, 
ou melhor, uma translação dos eixos e uma rotação de ângulos $\alpha_{i j}=0, \forall i, j$ e quando $M=M_{2}$, essa transformação equivale a realizar uma translação e uma rotação de ângulos $\alpha_{i j}$, dados aproximadamente por:

$$
\begin{aligned}
& \alpha_{11}=48,19^{\circ}, \quad \alpha_{12}=70,53^{\circ}, \quad \alpha_{13}=48,19^{\circ} \\
& \alpha_{21}=136,69^{\circ}, \quad \alpha_{22}=60,98^{\circ}, \alpha_{23}=60,98^{\circ} \\
& \alpha_{31}=99,31^{\circ}, \quad \alpha_{32}=143,94^{\circ}, \quad \alpha_{33}=55,53^{\circ}
\end{aligned}
$$

Para concluir esta seção, vale apresentar aqui a justificą tiva da escolha da matriz $M=M_{2}$, bem como a sua determinação. Essa ma triz foi escolhida porque atende aos interesses da pesquisa, ou seja, pos sibilita a obtenção dos eixos $x_{1}, x_{2}$ e $x_{3}$ numa posição conveniente em re lação aos eixos $W_{1}, W_{2}$ e $W_{3}$, tendo em vista a se obter um modelo de produ ção $n$ em $x_{1}, x_{2}$ e $x_{3}$ com $\beta_{12}, \beta_{13}$ e $\beta_{23}$ não todos nulos, caracterizando assim uma situação teórica com interação entre os fatores. Na realidade, existe um número infinito de matrizes $M$ que poderiam ser utilizadas com a mesma finalidade.

Para a obtenção de $M=M_{2}$ foram determinados primeiramente, três vetores ortogonais com origem em $\underset{\sim}{W}=\underset{\sim}{0}$ e em posições convenientes, tendo em vista a posição que se queria para os eixos $x_{1}, x_{2}$ e $x_{3}$. Esses vetores são:

$$
\underset{\sim 1}{v}=\left(t, \frac{t}{2}, t\right)^{\prime}, \quad v_{2}=\left(-\frac{3}{2} t, t, t\right)^{\prime} \quad \text { e } \underset{\sim 3}{v_{3}}=\left(-\frac{2}{7} t,-\frac{10}{7} t, t\right)^{\prime}
$$

onde $t$ é um nümero real positivo. Sendo $\alpha_{i j}$ igual ao ângulo que o vetor

$$
\underset{\sim i}{v}=\left(v_{i 1}, v_{i 2}, v_{i 3}\right)^{i}
$$

forma com o eixo $W_{j}$, tem-se

$$
\cos \alpha_{i j}=\frac{v_{i j}}{\left\|v_{i}\right\|}, \quad i, j=1,2,3
$$

onde $\left\|{\underset{\sim}{\mathrm{i}}}_{\mathrm{i}}\right\| \overline{\mathrm{e}}$ a norma euclidiana do vetor ${\underset{\sim}{\mathrm{v}}}_{\mathfrak{i}}$. A matriz $\mathrm{M}=\mathrm{M}_{2}$ de rotação foi, então, tomada como sendo

$$
M=\left(m_{i j}\right)_{3 \times 3}
$$

onde $m_{i j}=\cos \alpha_{i j}, \quad i, j=1,2,3$. 


\section{6. o ponto de máximo fronteira}

\subsubsection{Definição}

A região experimental A de interesse $\vec{e}$ um subconjunto de $R^{3}$ definido por

$$
\begin{aligned}
A= & \left(x_{1}, x_{2}, x_{3}\right) \in R^{3} ; a_{1} \leq x_{1} \leq b_{1}, a_{2} \leq x_{2} \leq b_{2}, \\
& \left.a_{3} \leq x_{3} \leq b_{3}, \text { onde } a_{i}, b_{i} \text { são reais, } i=1,2,3\right\}
\end{aligned}
$$

A representação gráfica no espaço $R^{3}$ é um paralelepípedo retangular como indicado na Figura 3.6.1, no caso particular em que $a_{1}=a_{2}=a_{3}=0$ e $b_{1}=b_{2}=b_{3}=b$.

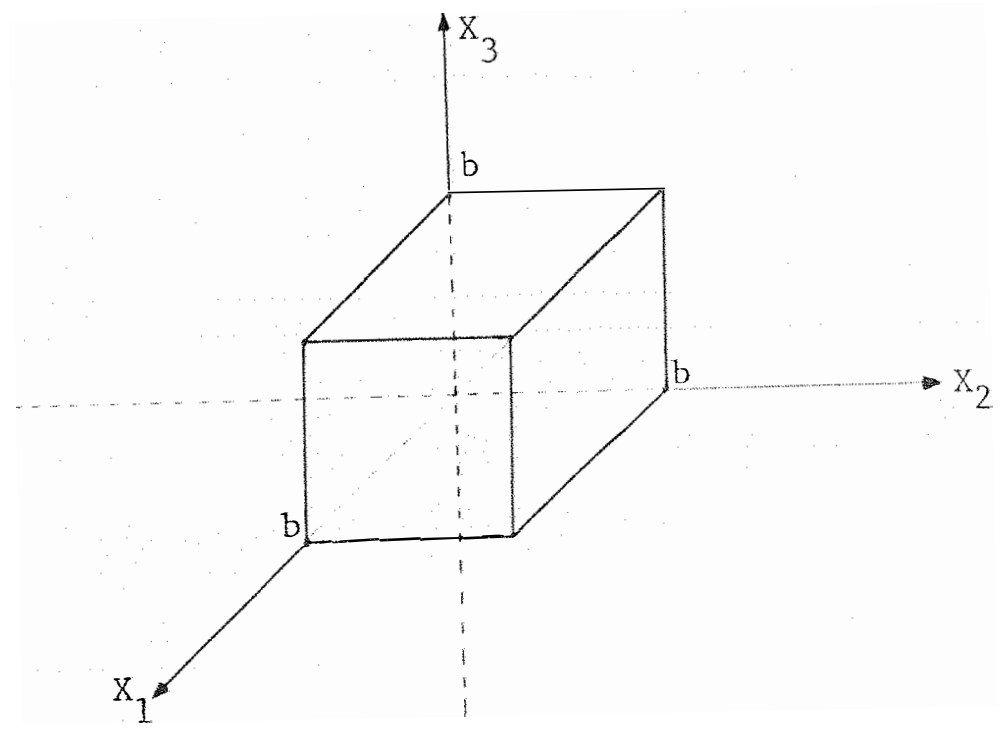

FIGURA 3.6.1 - Representação gráeica da região experimental.

A fronteira de A é a reunião das seis faces

$$
\begin{aligned}
& \mathrm{F}_{1}=\left\{\left(\mathrm{a}_{1}, \mathrm{x}_{2}, \mathrm{x}_{3}\right) ; \mathrm{a}_{2} \leq \mathrm{x}_{2} \leq \mathrm{b}_{2} \text { e } \mathrm{a}_{3} \leq \mathrm{x}_{3} \leq \mathrm{b}_{3}\right\} \\
& \mathrm{F}_{2}=\left\{\left(\mathrm{b}_{1}, \mathrm{x}_{2}, \mathrm{x}_{3}\right) ; \mathrm{a}_{2} \leq \mathrm{x}_{2} \leq \mathrm{b}_{2} \text { e } \mathrm{a}_{3} \leq \mathrm{x}_{3} \leq \mathrm{b}_{3}\right\} \\
& \mathrm{F}_{3}=\left\{\left(\mathrm{x}_{1}, \mathrm{a}_{2}, \mathrm{x}_{3}\right) ; \mathrm{a}_{1} \leq \mathrm{x}_{1} \leq \mathrm{b}_{1} \text { e } \mathrm{a}_{3} \leq \mathrm{x}_{3} \leq \mathrm{b}_{3}\right\} \\
& \mathrm{F}_{4}=\left\{\left(\mathrm{x}_{1}, \mathrm{~b}_{2}, \mathrm{x}_{3}\right) ; \mathrm{a}_{1} \leq \mathrm{x}_{1} \leq \mathrm{b}_{1} \text { e } \mathrm{a}_{3} \leq \mathrm{x}_{3} \leq \mathrm{b}_{3}\right\} \\
& \mathrm{F}_{5}=\left\{\left(\mathrm{x}_{1}, \mathrm{x}_{2}, \mathrm{a}_{3}\right) ; \mathrm{a}_{1} \leq \mathrm{x}_{1} \leq \mathrm{b}_{1} \text { e } \mathrm{a}_{2} \leq \mathrm{x}_{2} \leq \mathrm{b}_{2}\right\} \\
& \mathrm{F}_{6}=\left\{\left(\mathrm{x}_{1}, \mathrm{x}_{2}, \mathrm{~b}_{3}\right) ; \mathrm{a}_{1} \leq \mathrm{x}_{1} \leq \mathrm{b}_{1} \text { e } \mathrm{a}_{2} \leq \mathrm{x}_{2} \leq \mathrm{b}_{2}\right\}
\end{aligned}
$$


onde a variável fixa é $x_{i}$ nas faces $F_{2 i-1}$ e $F_{2 i}$, sendo $x_{i}=a_{i}$ na face $F_{2 i-1}$ e $x_{i}=b_{i}$ na face $F_{2 i}, i=1,2,3$.

Quando o ponto crítico de $\widehat{n}$ é um ponto de sela, um problema de interesse neste trabalho é encontrar o ponto $\underset{\sim}{X}$ em $A$ de maior valor pa ra $\hat{n}$. Esse ponto será encontrado na fronteira de A e, por essa razão, se rá denominado o ponto de máximo fronteira.

Para se determinar esse ponto, a procura deverá ser feita nas seis faces do paralelepípedo. Denominando-se por $M_{S}$ o maior valor de $\hat{n}$ na face $\mathrm{F}_{\mathrm{S}}$, isto $\overrightarrow{\mathrm{e}}$

$$
M_{s}=\underset{F_{S}}{\max } \hat{n}, \quad s=1,2,3,4,5,6,
$$

o valor máximo $\widehat{Y}_{M F}$ de $\hat{n}$ na fronteira de A seră, então,

$$
\widehat{\mathrm{Y}}_{M F}=\max \left\{M_{1}, M_{2}, M_{3}, M_{4}, M_{5}, M_{6}\right\}
$$

0 ponto $\underset{\sim}{\mathrm{X}}=\left(\mathrm{X}_{1}, \mathrm{X}_{2}, \mathrm{X}_{3}\right)^{\prime}$ em $\mathrm{A}$, onde $\hat{\eta}=\widehat{\mathrm{Y}}_{M F}$, é o ponto de mäximo frontei ra procurado.

O valor $M_{S}$ poderá ser atingido num ponto interior da face $F_{S}$ ou num ponto da fronteira dessa face. Quando é atingido na fronteira da face, isto é, num dos quatro lados (arestas) da face, deve-se fazer a pesquisa nesses segmentos. Aí, serão encontrados quatro valores reais que serão os máximos de $\hat{n}$ nesses quatro lados, sendo, então, ${ }_{s}$ igual ao máximo desses valores.

\subsubsection{Considerações importantes na determinação do ponto de máximo fronteira}

A procura do ponto de máximo fronteira envolve a pesquisa em faces e arestas do paralelepípedo que é a região experimental A. Para se estar numa face é necessário fixar uma das variáveis $x_{1}$ ou $x_{2}$ ou $x_{3}$ em um dos valores extremos de seu intervalo de variação na região experimen tal. Por outro lado, para se estar numa aresta é preciso fixar duas va riáveis em tais valores extremos. Assim, na pesquisa do maior valor de $\hat{n}$ numa face ou numa aresta, tem-se que trabalhar com funções obtidas de $\hat{n}$ fixando-se uma ou duas das variáveis, respectivamente. 
Sejam, então, as variáveis $x_{1}, x_{2}$ e $x_{3}$ denominadas generica mente por $x_{i}, x_{j} e x_{k}, i, j, k=1,2,3, j \neq i, k \neq i, j<k$. Com isso, define-se as funções

$\widehat{n}_{i}=$ função obtida de $\hat{\eta}$ quando se fixa a variāvel $x_{i}$

$\hat{n}_{i j}=$ função obtida de $\hat{\eta}$ quando se fixam as variäveis $x_{i}$ e $x_{j}$

$\widehat{n}_{i k}=$ função obtida de $\hat{n}$ quando se fixam as variäveis $x_{i}$ e $x_{k}$

Tem-se:

$$
\begin{aligned}
& \hat{n}_{i}=\left[\widehat{\beta}_{0}+\widehat{\beta}_{i} x_{i}+\widehat{\beta}_{i i} x_{i}^{2}\right]+\left[\widehat{\beta}_{j}+\widehat{\beta}_{i j} x_{i}\right] x_{j}+\left[\widehat{\beta}_{k}+\widehat{\beta}_{i k} x_{i}\right] x_{k}+ \\
& +\hat{B}_{j j} X_{j}^{2}+\hat{\beta}_{k k} X_{k}^{2}+\widehat{B}_{j k} X_{j} X_{k} \\
& \widehat{n}_{i j}=\left[\widehat{\beta}_{0}+\widehat{\beta}_{i} X_{i}+\widehat{\beta}_{j} X_{j}+\widehat{\beta}_{i i} X_{i}^{2}+\widehat{\beta}_{j j} X_{j}^{2}+\widehat{\beta}_{i j} X_{i} X_{j}\right]+ \\
& +\left[\widehat{\beta}_{k}+\widehat{\beta}_{i k} X_{i}+\widehat{\beta}_{j k} x_{j}\right] x_{k}+\widehat{\beta}_{k k} x_{k}^{2} \\
& \hat{\eta}_{i k}=\left[\widehat{\beta}_{0}+\hat{\beta}_{i} X_{i}+\hat{\beta}_{k} X_{k}+\hat{\beta}_{i i} X_{i}^{2}+\hat{\beta}_{k k} X_{k}^{2}+\hat{\beta}_{i k} X_{i} X_{k}\right]+ \\
& +\left[\widehat{B}_{j}+\widehat{B}_{i j} X_{i}+\widehat{\beta}_{j k} X_{k}\right] x_{j}+\widehat{B}_{j j} X_{j}^{2}
\end{aligned}
$$

onde os termos agrupados entre colchetes são constantes determinadas para os valores fixados de $x_{i}, x_{j}$ e $x_{k}$. Tem-se também que $\hat{n}_{i j}=\hat{\eta}_{j i}$ e $\hat{\eta}_{i k}=\hat{\eta}_{k i}$.

Como pode-se ver, para cada valor considerado de $x_{i}$, obtémse uma função $\hat{n}_{i}$ correspondente. No entanto, como será visto a seguir, a natureza do ponto crítico é a mesma para qualquer função $\hat{n}_{i}$ obtida. Fato semelhante ocorre com as diferentes funções $\hat{\eta}_{i j}$ e $\hat{\eta}_{i k}$ obtidos de $\hat{n}$ valores particulares de $x_{i}, x_{j}$ e $x_{k}$.

Seja, então, d $\hat{n}_{i}$ a diferencial primeira de $\hat{\eta}_{i}$, isto é,

$$
\begin{aligned}
d \hat{n}_{i}= & {\left[\hat{\beta}_{j}+\hat{\beta}_{i j} x_{i}+\hat{\beta}_{j k} x_{k}+2 \hat{\beta}_{j j} x_{j}\right] d x_{j}+} \\
& +\left[\hat{\beta}_{k}+\hat{\beta}_{i k} x_{i}+\hat{\beta}_{j k} x_{j}+2 \hat{\beta}_{k k} x_{k}\right] d x_{k}
\end{aligned}
$$

Então,

$$
d \hat{n}_{i} \equiv 0 \Leftrightarrow\left\{\begin{array}{l}
\hat{\beta}_{j}+\hat{\beta}_{i j} x_{i}+\hat{\beta}_{j k} x_{k}+2 \widehat{\beta}_{j j} x_{j}=0 \\
\hat{\beta}_{k}+\hat{\beta}_{i k} x_{i}+\hat{\beta}_{j k} x_{j}+2 \widehat{\beta}_{k k} x_{k}=0
\end{array}\right.
$$


e o ponto crítico de $\widehat{\eta}_{i}$ é solução do sistema

$$
\left[\begin{array}{ll}
\hat{\beta}_{j j} & \frac{\hat{B}_{j k}}{2} \\
\operatorname{sim} & \widehat{\beta}_{k k}
\end{array}\right]\left[\begin{array}{l}
x_{j} \\
x_{k}
\end{array}\right]=\left[\begin{array}{cc}
-\frac{\widehat{B}_{j}}{2} & -\frac{\widehat{B}_{i j}}{2} x_{i} \\
-\frac{\widehat{B}_{k}}{2} & -\frac{\widehat{B}_{i k}}{2} x_{i}
\end{array}\right]
$$

A diferencial segunda fica

$$
\begin{aligned}
d^{2} \hat{\eta}_{i} & =2 \widehat{\beta}_{j j} d x_{j}^{2}+2 \widehat{\beta}_{j k} d x_{j} d x_{k}+2 \widehat{\beta}_{k k} d x_{k}^{2} \\
& =2\left[d x_{j}, d x_{k}\right]\left[\begin{array}{cc}
\widehat{\beta}_{j j} & \frac{\hat{\beta}_{j k}}{2} \\
\text { sim. } & \widehat{\beta}_{k k}
\end{array}\right]\left[\begin{array}{c}
d x_{j} \\
d x_{k}
\end{array}\right]
\end{aligned}
$$

Como se vê, a natureza do ponto crítico não depende do va lor fixado de $\mathrm{x}_{i}$ e serä dada pela forma diagonal

$$
\Delta_{i}=\operatorname{diag}\left\{\widehat{\mathrm{d}}_{j \mathrm{j}}, \widehat{\mathrm{d}}_{\mathrm{kk}}\right\}
$$

da matriz

$$
B_{i}=\left[\begin{array}{cc}
\hat{\beta}_{j j} & \frac{\hat{\beta}_{j k}}{2} \\
\text { sim. } & \widehat{\beta}_{k k}
\end{array}\right]
$$

do seguinte modo:
a) Se $\widehat{d}_{j j}$ e $\widehat{d}_{k k}$ são positivos, o ponto é de mínimo;
b) Se $\widehat{d}_{j j} e \widehat{d}_{k k}$ são negativos, o ponto $\vec{e}$ de mäximo;
c) Se $\widehat{\mathrm{d}}_{j \mathrm{j}}$ e $\widehat{\mathrm{d}}_{k \mathrm{k}}$ têm sinais contrários, o ponto é de sela;
d) Se algum desses elementos diagonais é nulo, tem-se uma indeterminação.

Uma indeterminação como em (d) ser $\overline{\mathbf{a}}$ denominada de indetermi nação numa face e equivale à situação onde o sistema (3.6.2.1) tem infini tas soluções. Tal situação é muito particular e, embora teoricamente pos 
sível, é difícil de ocorrer nos problemas práticos de superfície polino mial quadrática. Em vista disso, se numa análise ocorcer uma tal situa ção, esta será apenas registrada e contada para efeito de controle no pre sente trabalho, não se determinando o ponto de máximo fronteira nessa aná 1ise.

$$
\begin{aligned}
& \text { Considerando-se agora a diferencial primeira de } \widehat{\eta}_{i j} \text { tem-se } \\
& \mathrm{d} \hat{n}_{i j}=\left[\widehat{B}_{k}+\widehat{B}_{i k} x_{i}+\widehat{B}_{j k} x_{j}+2 \widehat{B}_{k k} x_{k}\right] d X_{k}
\end{aligned}
$$

Então,

$$
\mathrm{d} \hat{n}_{i j} \equiv 0 \Leftrightarrow \widehat{\beta}_{k}+\hat{\beta}_{i k} x_{i}+\hat{\beta}_{j k} x_{j}+2 \hat{\beta}_{k k} x_{k}=0
$$

e o ponto crítico de $\hat{n}_{i . j}$ é solução da equaçäo

$$
\widehat{\beta}_{k k} X_{k}=-\left[\frac{\hat{\beta}_{k}}{2}+\frac{\hat{\beta}_{i k}}{2} x_{i}+\frac{\widehat{\beta}_{j k}}{2} x_{j}\right]
$$

A diferencial segunda fica

$$
\mathrm{d}^{2} \widehat{\eta}_{i j}=2 \widehat{\beta}_{k k} d x_{k}^{2}
$$

e como também pode-se ver, a natureza do ponto crîtico de $\hat{\eta}_{i j}$ não depende dos valores fixados de $X_{i}$ e $X_{j}$ e será dada pelo valor de $\widehat{\beta}_{k k}$, do seguinte modo:

a) Se $\widehat{\beta}_{k k}>0$, o ponto é de mínimo;

b) Se $\widehat{B}_{k k}<0$, o ponto é de mäximo.

De modo anālogo ao que foi feito para a função $\hat{n}_{i j}$, o ponto crítico de $\hat{n}_{i k}$ é solução da equação

$$
\widehat{\beta}_{j j} X_{j}=-\left[\frac{\widehat{\beta}_{j}}{2}+\frac{\widehat{\beta}_{i j}}{2} x_{i}+\frac{\widehat{\beta}_{j k}}{2} x_{k}\right]
$$

e a natureza do ponto crítico de $\widehat{n}_{i k}$ seră dada pelo valor de $\widehat{\beta}_{j j}$, isto é,
a) Se $\widehat{\beta}_{j j}>0$, o ponto é de mínimo;
b) Se $\widehat{B}_{j j}<0$, o ponto é de mäximo.

Como também pode-se ver, a natureza do ponto crítico de $\hat{\eta}_{i k}$ não depende dos valores de $X_{i}$ e $X_{k}$ fixados. 


\section{Observações :}

i) Na denominação genérica dos coeficientes $\widehat{B}_{i j}$ e $\widehat{B}_{i k}$, de ve-se entender que $\widehat{B}_{i j}=\widehat{B}_{j i}$ senpre que se tiver $i>j$ e $\widehat{B}_{i k}=\widehat{B}_{k i}$, quan do $i>k$;

ii) A matriz $B_{i}$, onde $i$ é o indice da variável fixada, po de ser facilmente obtida como uma submatriz de $B$, suprimindo-se a linha $i$ e a coluna i;

iii) Se $\widehat{\beta}_{k k}=0$, então $\widehat{n}_{i j}$ é uma função linear da variāvel $x_{k}$. Nesse caso, se $\hat{\eta}_{i j} \bar{e}$ constante, então, todo valor de $x_{k}$ é tanto pon to de máximo como ponto de mínimo; se $\widehat{n}_{i j}$ não é constante, não existe va lor de $x_{k}$, onde a derivada primeira de $\hat{n}_{i j}$ se anula. Fato análogo è vảili. do para a função $\hat{\eta}_{i k}$, no caso que $\widehat{\beta}_{j j}=0$.

\subsection{3. o método}

Seja a equação de produção

$\hat{n}$ ou $\hat{n}\left(x_{\sim}\right)$ ou $\hat{n}\left(x_{1}, x_{2}, x_{3}\right)=\hat{\beta}_{0}+\hat{\beta}_{1} x_{1}+\hat{\beta}_{2} x_{2}+\hat{\beta}_{3} X_{3}+\hat{\beta}_{11} X_{1}^{2}+\hat{\beta}_{22} x_{2}^{2}+$

$$
+\widehat{B}_{33} X_{3}^{2}+\widehat{B}_{12} X_{1} X_{2}+\widehat{B}_{13} X_{1} X_{3}+\widehat{B}_{23} X_{2} X_{3}
$$

para a qual se tenha obtido um ponto de sela. Para maior clareza na apre sentação do método, sejam também as Figuras 3.6 .3 .1 e 3.6 .3 .2 , que são re presentações gräficas típicas das faces $F_{2 i-1}$ e $F_{2 i}$ nos planos paralelos determinados por $x_{i}=a_{i}$ e $x_{i}=b_{i}$, respectivamente.

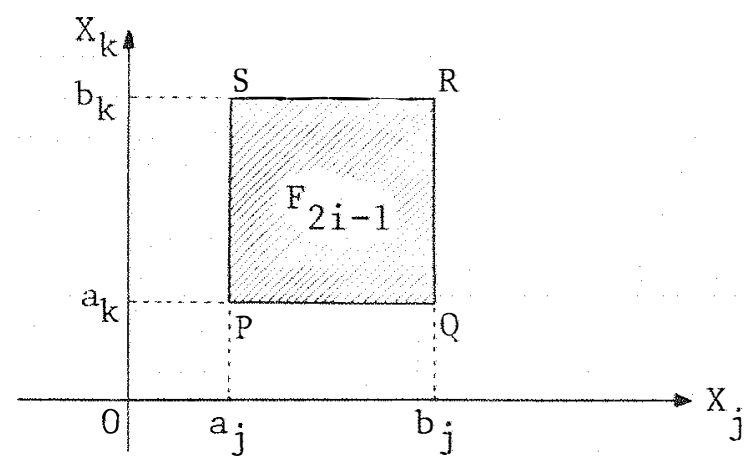

FIGURA 3.6.3.1 - Representação grạ fica de $\mathrm{F}_{2 i-1}$.

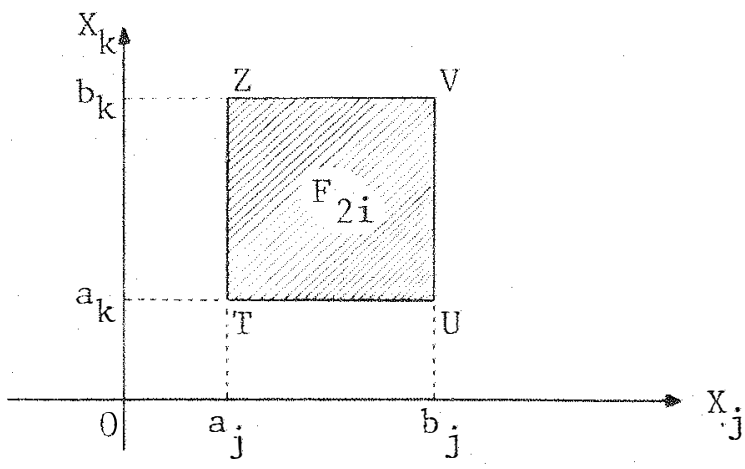

FIGURA 3.6.3.2 - Representação grä fica de $\mathrm{F}_{2 i}$. 
0 método a ser descrito consiste em se pesquisar nas faces $\mathrm{F}_{2 i-1}$ e $\mathrm{F}_{2 i}$, considerando-se sucessivamente $i=1,2,3$. Para cada $i$ con siderado, toma-se $j, k=1,2,3, j \neq i, k \neq i$ e $j<k$, realizando-se os passos adequados a cada situação, conforme os itens e subitens seguintes:

1) Determina-se a natureza do ponto critico de $\hat{\eta}_{i}$ pela for ma diag•nal

$$
\Delta_{i}=\operatorname{diag}\left\{\widehat{d}_{j j}, \widehat{d}_{k k}\right\}
$$

da matriz

$$
B_{i}=\left[\begin{array}{cc}
\hat{\beta}_{j j} & \frac{\hat{\beta}_{j k}}{2} \\
\operatorname{sim} . & \widehat{\beta}_{k k}
\end{array}\right]
$$

A natureza é a mesma, tanto para $x_{i}=a_{i}$ como para $x_{i}=b_{i}$.

2) Pesquisa na face $F_{2 i-1}: X_{i}=a_{i}$

2.1) Se $\hat{n}_{i}$ tem máximo, obtẻm-se a solução $\left(\bar{x}_{j}, \bar{x}_{k}\right)$ do

sistema

$$
\left[\begin{array}{cc}
\hat{\beta}_{j j} & \frac{\hat{\beta}_{j k}}{2} \\
\operatorname{sim} . & \hat{\beta}_{k k}
\end{array}\right]\left[\begin{array}{l}
x_{j} \\
x_{k}
\end{array}\right]=\left[\begin{array}{cc}
-\frac{\hat{\beta}_{j}}{2} & -\frac{\hat{\beta}_{i j}}{2} a_{i} \\
-\frac{\hat{\beta}_{k}}{2} & -\frac{\hat{B}_{i k}}{2} a_{i}
\end{array}\right]
$$

e se $\left(\bar{x}_{j}, \bar{x}_{k}\right) \in\left[a_{j}, b_{j}\right] \times\left[a_{k}, b_{k}\right]$, calcula-se

$$
\operatorname{máx}_{F_{2 i-1}} \hat{n}=M_{2 i-1}=\hat{n}\left(a_{i}, \bar{x}_{j}, \bar{x}_{k}\right)
$$

2.2) Se $\hat{\eta}_{i}$ tem máximo e $\left(\bar{x}_{j}, \bar{x}_{k}\right) \notin\left[a_{j}, b_{j}\right] \times\left[a_{k}, b_{k}\right]$ ou se $\hat{n}_{i}$ tem mínimo ou ponto de sela, faz-se:

2.2.1) Pesquisa no lado $\overline{\mathrm{PS}}: \mathrm{X}_{j}=a_{j}$

Se $\hat{n}_{i j}$ tem mäximo $\left(\widehat{\beta}_{k k}<0\right)$, calcula-se

$\overline{\bar{X}}_{k}=-\frac{1}{\hat{\beta}_{k k}}\left[\frac{\hat{\beta}_{k}}{2}+\frac{\hat{\beta}_{i k}}{2} a_{i}+\frac{\hat{\beta}_{j k}}{2} a_{j}\right]$ 
obtendo-se

$$
\begin{aligned}
\frac{\max }{\hat{\mathrm{PS}}} \hat{\eta} m_{(2 i-1) j l} & \hat{\eta}\left(a_{i}, a_{j}, \bar{x}_{k}\right) \text { se } \bar{x}_{k} \in\left[a_{k}, b_{k}\right] \\
= & \max \left\{\hat{\eta}\left(a_{i}, a_{j}, a_{k}\right), \hat{n}\left(a_{i}, a_{j}, b_{k}\right)\right\} \text { se } \bar{x}_{k} \notin\left[a_{k}, b_{k}\right]
\end{aligned}
$$

Se $\widehat{n}_{i j}$ tem mínimo $\left(\widehat{B}_{k k}>0\right)$ ou se $\hat{\beta}_{k k}=0$, calcula-se:

$\frac{\operatorname{máx}}{\operatorname{PS}} \hat{n}=m_{(2 i-1) j 1}=\operatorname{máx}\left\{\hat{n}\left(a_{i}, a_{j}, a_{k}\right), \hat{n}\left(a_{i}, a_{j} b_{k}\right)\right\}$

\subsection{2) Pesquisa no lado $\overline{Q R}: X_{j}=b_{j}$}

Se $\hat{r}_{i j}$ tem máximo $\left(\widehat{B}_{k k}<0\right)$, calcula-se

$$
\overline{\bar{X}}_{k}=-\frac{1}{\widehat{\beta}_{k k}}\left[\frac{\widehat{\beta}_{k}}{2}+\frac{\widehat{\beta}_{i k}}{2} a_{i}+\frac{\hat{\beta}_{j k}}{2} b_{j}\right]
$$

obtendo-se

$$
\begin{aligned}
& \frac{\operatorname{ma} x}{(Q R} \hat{\eta}=m_{(2 i-1) j 2}=\hat{n}\left(a_{i}, b_{j}, \overline{\bar{X}}_{k}\right) \text { se } \overline{\bar{x}}_{k} \in\left[a_{k}, b_{k}\right] \\
& \left.=\max \left\{\hat{\eta}_{\left(a_{i}\right.}, b_{j}, a_{k}\right), \hat{\eta}\left(a_{i}, b_{j}, b_{k}\right)\right\} \text { se } \overline{\bar{x}}_{k} \notin\left[a_{k}, b_{k}\right]
\end{aligned}
$$

Se $\widehat{r}_{i j}$ tem minimo $\left(\widehat{B}_{k \mathrm{k}}>0\right)$ ou se $\widehat{\beta}_{k \mathrm{k}}=0$, calcula-se:

$\operatorname{maxx}_{\overline{Q R}} \hat{n}=m_{(2 i-1)}{ }^{2}=\operatorname{maxx}\left\{\hat{n}\left(a_{i}, b_{j}, a_{k}\right), \hat{n}\left(a_{i}, b_{j}, b_{k}\right)\right\}$

\subsection{3) Pesquisa no 1 ado $\overline{\mathrm{PQ}}: \mathrm{x}_{k}=a_{k}$}

Se $\widehat{\eta}_{i k}$ tem mäximo $\left(\widehat{\beta}_{j j}<0\right)$, calcula-se

$$
\overline{\bar{X}}_{j}=-\frac{1}{\widehat{B}_{j j}}\left[\frac{\hat{B} j}{2}+\frac{\hat{B}_{i j}}{2} a_{i}+\frac{\hat{B} j k}{2} a_{k}\right]
$$

obtendo-se

$$
\begin{aligned}
& \frac{\operatorname{máx}}{\overline{P Q}} \hat{\eta}=m_{(2 i-1) k 1}=\hat{\eta}\left(a_{i}, \overline{\bar{x}}_{j}, a_{k}\right) \text { se } \overline{\bar{x}}_{j} \in\left[a_{j}, b_{j}\right] \\
& =\max \left\{\hat{\eta}\left(a_{i}, a_{j}, a_{k}\right), \hat{\eta}\left(a_{i}, b_{j}, a_{k}\right)\right\} \text { se } \overline{\bar{x}}, \notin\left[a_{j}, b_{j}\right]
\end{aligned}
$$

Se $\widehat{\eta}_{i k}$ tem minimo $\left(\widehat{B}_{j j}>0\right)$ ou se $\widehat{B}_{j j}=0$, calcula-se: 
$\frac{\max }{\overline{P Q}} \hat{n}=m(2 i-1) k 1=\max \left\{\hat{n}\left(a_{i}, a_{j}, a_{k}\right), \hat{n}\left(a_{i}, b_{j}, a_{k}\right)\right\}$

2.2.4) Pesquisa no lado $\overline{\mathrm{SR}}$ : $\mathrm{X}_{\mathrm{k}}=\mathrm{b}_{\mathrm{k}}$

Se $\widehat{\eta}_{i k}$ tem mäximo $\left(\widehat{\beta}_{j j}<0\right)$, calcula-se

$\overline{\bar{X}}_{j}=-\frac{1}{\hat{\beta}_{j j}}\left[\frac{\hat{\beta}_{j}}{2}+\frac{\hat{B}_{i j}}{2} a_{i}+\frac{\hat{B}_{j k}}{2} b_{k}\right]$

obtendo-se

$$
\begin{aligned}
\frac{\max }{\operatorname{sR}} \hat{n}=m_{(2 i-1) k 2} & =\hat{n}\left(a_{i}, \overline{\bar{x}}_{j}, b_{k}\right) \text { se } \overline{\bar{x}}_{j} \in\left[a_{j}, b_{j}\right] \\
& =\operatorname{maxx}\left\{\hat{n}\left(a_{i}, a_{j}, b_{k}\right), \hat{n}\left(a_{i}, b_{j}, b_{k}\right)\right\} \text { se } \overline{\bar{x}}_{j} E\left[a_{j}, b_{j}\right]
\end{aligned}
$$

Se $\hat{n}_{i k}$ tem minimo $\left(\hat{\beta}_{j j}>0\right)$ ou $\widehat{B}_{j j}=0$, calcula-se

$\operatorname{māx}_{\overline{\mathrm{SR}}} \hat{n}=\mathrm{m}_{(2 i-1) k 2}=\operatorname{maxx}\left\{\hat{n}\left(a_{i}, a_{j}, b_{k}\right), \hat{n}\left(a_{i}, b_{j}, b_{k}\right)\right\}$

\subsection{5) Cá1culo de $M_{2 i-1}$}

Tem-se

$\left.\operatorname{máx} \hat{n}=M_{2 i-1}=\operatorname{máx} m_{(2 i-1) j 1}, m_{(2 i-1) j 2}, m_{(2 i-1) k 1}, m_{(2 i-1) k 2}\right\}$ $\mathrm{F}_{2 i-1}$

\section{3) Pesquisa na face $F_{2 i}: x_{i}=b_{i}$}

Faz-se de modo análogo ao que está descrito no item 2 e sub itens, com $b_{i}, 2 i, \overline{\mathrm{TZ}}, \overline{\mathrm{UV}}$, $\overline{\mathrm{TU}}$ e $\overline{\mathrm{ZV}}$, no lugar de $a_{i}, 2 i-1, \overline{\mathrm{PS}}, \overline{\mathrm{QR}}, \overline{\mathrm{PQ}}$ e $\overline{\mathrm{SR}}$, respectivamente, obtendo-se

$\max \hat{\eta}=M_{2 i}=\hat{n}\left(b_{i}, \bar{x}_{j}, \bar{x}_{k}\right)$ se $\hat{n}_{i}$ tem máximo e $\left(\bar{x}_{j}, \bar{x}_{k}\right) \in\left[a_{j}, b_{j}\right] \times\left[a_{k}, b_{k}\right]$ $F_{2 i}$

$$
\begin{aligned}
& =\operatorname{mäx}\left[m_{(2 i) j 1},{ }^{m}(2 i) j 2, m(2 i) k 1, m(2 i) k 2\right\} \\
& \quad \text { se }\left(\bar{x}_{j}, \bar{x}_{k}\right) \notin\left[a_{j}, b_{j}\right] \times\left[a_{k}, b_{k}\right] \\
& \text { ou se } \widehat{n}_{i} \text { tem mínimo ou ponto de sela }
\end{aligned}
$$




\section{Observações:}

i) $\mathrm{Na}$ notação $m_{\text {srt }}$ para o mäximo de $\vec{n}$ numa aresta do para lelepípedo, o índice $s$ indica a face, o indice $r$ indica a segunda variä vel fixada e o indice $t$ indica o valor fixado da segunda variável. Assim, $s=2 i-1$ ou 2i, $r=j$ ou $k$ e $t=1$ ou 2 ( 1 se $x_{r}=a_{r}$ e 2 se $\left.x_{r}=b_{r}\right)$;

ii) Teoricamente, e possivel ocorrer a igualda entre dois valores $m_{\text {srt }}$ de uma mesma face ou mesmo a igualdade entre dois $M_{s}$ nas seis faces. No entanto, tais situações dificilmente ocorrem ern problemas práticos.

\subsubsection{Um exemplo}

Seja

$$
\hat{\eta}=5+8 x_{1}+6 x_{2}+4 x_{3}-6 x_{i}^{2}-4 x_{2}^{2}+4 x_{3}^{2}+x_{1} x_{2}
$$

onde $0 \leq x_{1} \leq 2,0 \leq x_{2} \leq 2$ e $0 \leq x_{3} \leq 2$. Tem-se, então, $\widehat{\beta}_{0}=5, \widehat{B}_{1}=8$, $\widehat{\beta}_{2}=6, \widehat{\beta}_{3}=4, \widehat{\beta}_{11}=-6, \widehat{\beta}_{22}=-4, \widehat{\beta}_{33}=4, \widehat{\beta}_{12}=1, \widehat{\beta}_{13}=0$ e $\widehat{B}_{23}=0$. Assim, a matriz B $\vec{e}$

$$
B=\left[\begin{array}{ccc}
-6 & 0,5 & 0 \\
0,5 & -4 & 0 \\
0 & 0 & 4
\end{array}\right]
$$

Em B, trocando-se a 2a 1 inha por $12 \times(2$ a 1 inha $)+(1$ a 1 inha $)$ e a 2 a coluna da matriz obtida por $12 \times(2$ a coluna $)+(1$ a coluna $)$, obtém-se uma forma diagonalizada $\Delta$ de $B$ onde

$$
\Delta=\operatorname{diag}\{-6,-570,4\}
$$

Logo, $\hat{n}$ tem ponto de sela. Passando-se, então, à procura do maior valor de $\hat{n}$ na fronteira da região experimental, tem-se:

\section{1) Natureza do ponto critico de $\hat{n}_{1}$ :}

$$
B_{1}=\left[\begin{array}{cc}
-4 & 0 \\
0 & 4
\end{array}\right]
$$

Logo, $\hat{\eta}_{1}$ tem ponto de sela para $x_{1}=0$ e $x_{1}=2$. 
2) Pesquisa em $F_{1}: X_{1}=0$

Para $x_{1}$ e $x_{2}$ fixos, tem-se:

$\widehat{\beta}_{33}=4>0 \Rightarrow \hat{n}_{12}$ tem ponto de mínimo. Então,

$m_{121}=\operatorname{máx}\{\hat{n}(0,0,0), \hat{n}(0,0,2)\}=\operatorname{máx}\{5 ; 29\}=29$

$\mathrm{m}_{122}=\operatorname{máx}\{\widehat{n}(0,2,0), \hat{n}(\bullet, 2,2)\}=\operatorname{māx}\{1 ; 25\}=25$

Por outro lado, para $x_{1}$ e $x_{3}$ fixos, tem-se:

$\widehat{B}_{22}=-4<0 \Rightarrow \widehat{\eta}_{13}$ tem ponto de mäximo. Então,

para $x_{3}=0$, tem-se

$$
\overline{\bar{X}}_{2}=-\frac{1}{\widehat{\beta}_{22}}\left[\frac{\hat{\beta}_{2}}{2}+\frac{\widehat{\beta}_{12}}{2} 0+\frac{\widehat{\beta}_{23}}{2} 0\right]=\frac{1}{4} \frac{6}{2}=0,75
$$

Como $\overline{\mathrm{x}}_{2}=0,75 \in[0,2]$, tem-se

$$
\mathrm{m}_{131}=\hat{n}(0 ; 0,75 ; 0)=7,25
$$

Para $x_{3}=2$, tem-se

$$
\overline{\bar{X}}_{2}=-\frac{1}{\widehat{\beta}_{22}}\left[\frac{\widehat{\beta}_{2}}{2}+\frac{\hat{\beta}_{12}}{2} 0+\frac{\widehat{B}_{23}}{2} 2\right]=\frac{1}{4} \frac{6}{2}=0,75
$$

Como $\overline{\bar{x}}_{2}=0,75 \in[0,2]$, tem-se

$$
\mathrm{m}_{132}=\hat{n}(0 ; 0,75 ; 2)=31,25
$$

Portanto,

$$
M_{1}=\underset{F_{1}}{\operatorname{maxx}} \hat{n}=\operatorname{máx}\{29 ; 25 ; 7,25 ; 31,25\}=31,25
$$

3) Pesquisa em $F_{2}: X_{1}=2$

Como para $x_{1}$ e $x_{2}$ fixos, $\widehat{\eta}_{12}$ tem ponto de mínimo, tem-se:

$\mathrm{m}_{221}=\operatorname{māx}\{\hat{\eta}(2,0,0), \hat{\eta}(2,0,2)\}=\operatorname{máx}\{-3 ; 21\}=21$

$\mathrm{m}_{222}=\max \{\hat{n}(2,2,0), \widehat{\eta}(2,2,2)\}=\max \{-3 ; 21\}=21$ 
Como para $x_{1}$ e $x_{3}$ fixos, $\hat{n}_{13}$ tem ponto de máximo, tem-se:

$$
\begin{aligned}
x_{3}=0 \Rightarrow \bar{x}_{2} & =-\frac{1}{\hat{\beta}_{22}}\left[\frac{\widehat{\beta}_{2}}{2}+\frac{\widehat{\beta}_{12}}{2} 2+\frac{\hat{\beta}_{23}}{2} 0\right]= \\
& =\frac{1}{4}\left[\frac{6}{2}+1\right]=1 \Theta[0,2]
\end{aligned}
$$

Logo,

$$
\begin{aligned}
& \mathrm{m}_{231}=\hat{\eta}(2,1,0)=1 \\
& \mathrm{x}_{3}=2 \Rightarrow \overline{\bar{x}}_{2}=-\frac{1}{\widehat{\beta}_{22}}\left[\frac{\widehat{\beta}_{2}}{2}+\frac{\widehat{\beta}_{12}}{2} 2+\frac{\widehat{\beta}_{23}}{2} 2\right]= \\
&=\frac{1}{4}\left[\frac{6}{2}+1\right]=1 \in[0,2]
\end{aligned}
$$

Logo ,

$$
\mathrm{m}_{232}=\hat{n}(2,1,2)=25
$$

Portanto,

$$
M_{2}=\underset{F_{2}}{\max } \hat{\eta}=\operatorname{máx}\{21 ; 21 ; 1 ; 25\}=25
$$

\section{4) Natureza do ponto crítico de $\widehat{\eta}_{2}$}

Tem-se:

$$
B_{2}=\left[\begin{array}{cc}
-6 & 0 \\
0 & 4
\end{array}\right]
$$

Logo, $\hat{n}_{2}$ tem ponto de sela para $x_{2}=0$ e $x_{2}=2$.

\section{5) Pesquisa em $F_{3}: X_{2}=0$}

Para $x_{2}$ e $x_{1}$ fixos, obtém-se $\hat{n}_{21}$ (igual a $\hat{n}_{12}$ ) que, como já foi visto, tem ponto de mínimo, pois $\widehat{B}_{33}=4>0$. Então,

$$
\begin{aligned}
& \mathrm{m}_{311}=\operatorname{máx}\{\hat{n}(0,0,0), \hat{n}(0,0,2)\}=\operatorname{máx}\{5 ; 29\}=29 \\
& m_{312}=\operatorname{máx}\{\hat{n}(2,0,0), \hat{n}(2,0,2)\}=\operatorname{máx}\{-3 ; 21\}=21
\end{aligned}
$$


Para $x_{2}$ e $x_{3}$ fixos, obtêm-se $\hat{\eta}_{23}$ que tem ponto de mäximo, pois $\hat{\beta}_{11}=-6<0$. Então, para $x_{3}=0$, tem-se

$$
\bar{X}_{1}=-\frac{1}{\widehat{B}_{11}}\left[\frac{\widehat{B}_{1}}{2}+\frac{\widehat{\beta}_{21}}{2} 0+\frac{\widehat{B}_{13}}{2} 0\right]=\frac{1}{6} \frac{8}{2} \cong 0,6667
$$

Como $\overline{\bar{x}}_{1} \in[0,2]$, tem-se

$$
\begin{aligned}
& m_{331}=\hat{n}(0,6667 ; 0 ; 0)=7,6667 \\
& \text { Para } x_{3}=2 \text {, tem-se } \\
& \overline{\bar{x}}_{1}=-\frac{1}{\hat{\beta}_{11}}\left[\frac{\hat{\beta}_{1}}{2}+\frac{\widehat{B}_{21}}{2} 0+\frac{\widehat{\beta}_{13}}{2} 2\right]=\frac{1}{6} \frac{8}{2}=0,6667
\end{aligned}
$$

Como $\overline{\overline{\mathrm{X}}}_{1} \in[0,2]$, tem-se

$$
\mathrm{m}_{332}=\widehat{\eta}(0,6667 ; 0 ; 2)=31,6667
$$

Portanto,

$$
M_{3}=\underset{F_{3}}{\max } \hat{n}=\max \{29 ; 21 ; 7,6667 ; 31,6667\}=31,6667
$$

\section{6) Pesquisa em $\mathbf{F}_{4}: X_{2}=2$}

Como para $x_{2}$ e $x_{1}$ fixos, $\hat{n}_{21}$ tem ponto de mínimo $\left(\widehat{B}_{33}=4>0\right)$,

tem-se

$$
\begin{aligned}
& \mathrm{m}_{411}=\max \{\hat{n}(0 ; 2 ; 0), \hat{\eta}(0 ; 2 ; 2)\}=\max \{1 ; 25\}=25 \\
& \mathrm{~m}_{412}=\operatorname{maxx}\{\hat{n}(2 ; 2 ; 0), \hat{n}(2 ; 2 ; 2)\}=\max \{-3 ; 21\}==1
\end{aligned}
$$

Para $x_{2}$ e $x_{3}$ fixos, jâ foi visto que $\hat{n}_{23}$ tem ponto de mäxi mo, pois $\widehat{\beta}_{11}=-6<0$. Então, para $x_{3}=0$, tem-se

$$
\overline{\bar{X}}_{1}=-\frac{1}{\hat{\beta}_{11}}\left[\frac{\hat{\beta}_{1}}{2}+\frac{\hat{\beta}_{21}}{2} 2+\frac{\hat{\beta}_{13}}{2} 0\right]=\frac{1}{6}\left[\frac{8}{2}+\frac{1}{2} 2\right] \cong 0,8333
$$

Como $\overline{\overline{\mathrm{x}}}_{1} \in[0,2]$, tem-se

$$
\mathrm{m}_{431}=\widehat{n}(0,8333 ; 2 ; 0) \cong 5,1667
$$




$$
\begin{aligned}
& \operatorname{Para} x_{3}=2, \text { tem-se } \\
& \overline{\bar{X}}_{1}=-\frac{1}{\widehat{B}_{11}}\left[\frac{\widehat{B}_{1}}{2}+\frac{\widehat{B}_{21}}{2} 2+\frac{\widehat{B}_{13}}{2} 2\right]=\frac{1}{6}\left[\frac{8}{2}+\frac{1}{2} 2\right] \cong 0,8333
\end{aligned}
$$

Como $\overline{\bar{x}}_{1} \in[0,2]$, tem-se

$$
\mathrm{m}_{432}=\hat{\eta}(0,8333 ; 2 ; 2)=29,1667
$$

Portanto,

$$
M_{4}=\underset{\mathrm{F}_{4}}{\max } \hat{\eta}=\max \{25 ; 21 ; 5,1667 ; 29,1667\}=29,1667
$$

\section{7) Natureza do ponto critic de $\hat{n}_{3}$}

Fixando-se a variävel $x_{3}$, tem-se

$$
B_{3}=\left[\begin{array}{cc}
-6 & 0,5 \\
0,5 & -4
\end{array}\right]
$$

Substituind•-se a 2 a Iinha de $B_{3}$ por $(1 \stackrel{a}{a}$ linha $)+12 \times\left(2^{\text {a }}\right.$. linha $)$ e substi tuindo-se, na matriz obtida, a 2 a celuna pox (1a coluna) + $12 \times(2$ a coluna), obtem-se a forma diagonalizada

$$
\Delta_{3}=\operatorname{diag}\{-6 ;-570\}
$$

Logo, $\widehat{n}_{3}$ tem ponto de máximo para $x_{3}=0$ e $x_{3}=2$.

\section{8) Pesquisa em $\mathrm{F}_{5}: \mathrm{X}_{3}=0$}

Como a variāvel fixada $\vec{e} x_{3}$, ou seja, $i=3$, tem-se $j=1$ e $k=2$, conforme o método descrito. Então, resolvendo-se o sistema

$$
\left[\begin{array}{cc}
\hat{\beta}_{11} & \frac{\hat{\beta}_{12}}{2} \\
\sin & \hat{\beta}_{22}
\end{array}\right]\left[\begin{array}{l}
x_{1} \\
x_{2}
\end{array}\right]=\left[\begin{array}{cc}
-\hat{\beta}_{1} & -\frac{\hat{\beta}_{31}}{2} \\
-\frac{\hat{B}_{2}}{2} & -\frac{\hat{\beta}_{32}}{2}
\end{array}\right]
$$

is to $\vec{e}$,

$$
\left[\begin{array}{cc}
-6 & 0,5 \\
0,5 & -4
\end{array}\right]\left[\begin{array}{l}
x_{1} \\
x_{2}
\end{array}\right]=\left[\begin{array}{c}
-4 \\
-3
\end{array}\right]
$$


obtërn-se

$$
\begin{aligned}
& \bar{x}_{1}=\frac{\left|\begin{array}{ll}
-4 & 0,5 \\
-3 & -4
\end{array}\right|}{23,75}=\frac{17,5}{23,75} \cong 0,7368 \\
& \bar{x}_{2}=\frac{\left|\begin{array}{ll}
-6 & -4 \\
0,5 & -3
\end{array}\right|}{23,75}=\frac{20}{23,75} \cong 0,8421
\end{aligned}
$$

Como $\left(\bar{x}_{1}, \bar{x}_{2}\right) \in[0,2] \times[0,2]$, tem-se

$$
M_{5}=\max _{F_{5}} \hat{\eta}=\hat{n}(0,7368 ; \bullet, 8421 ; 0) \cong 10,4737
$$

9) Pesquisa em $F_{6}: X_{3}=2$

Resolvendo-se o sistema

$$
\left[\begin{array}{cc}
\widehat{\beta}_{11} & \frac{\widehat{B}_{12}}{2} \\
\operatorname{sim} . & \widehat{B}_{22}
\end{array}\right]\left[\begin{array}{l}
x_{1} \\
x_{2}
\end{array}\right]=\left[\begin{array}{cc}
-\frac{\widehat{B}_{1}}{2} & -\frac{\hat{B}_{31}}{2} 2 \\
-\frac{\hat{B}_{2}}{2} & -\frac{\widehat{B}_{32}}{2} 2
\end{array}\right]
$$

is to $\overline{\mathrm{e}}$,

$$
\left[\begin{array}{cc}
-6 & 0,5 \\
0,5 & -4
\end{array}\right]\left[\begin{array}{l}
x_{1} \\
x_{2}
\end{array}\right]=\left[\begin{array}{c}
-4 \\
-3
\end{array}\right]
$$

obtēm-se

$$
\bar{x}_{1} \cong 0,7368 \text { e } \bar{x}_{2} \cong 0,8421
$$

Como $\left(\overline{\mathrm{X}}_{1}, \overline{\mathrm{X}}_{2}\right) \in[0,2] \times[0,2]$, obtêm-se

$$
M_{6}=\underset{F_{6}}{\max } \hat{n}=\hat{n}(0,7368 ; 0,8421 ; 2) \cong 34,4737
$$


10) Ponto de máximo fronteira

Tem-se

$$
\begin{aligned}
\hat{Y}_{M F} & =\max \left\{M_{1}, M_{2}, M_{3}, M_{4}, M_{5}, M_{6}\right\}= \\
& =\max \{31,25 ; 25 ; 31,6667 ; 29,1667 ; 10,4737 ; 34,4737\} \\
& =34,4737
\end{aligned}
$$

Assim, o ponto de mäximo fronteira em $A \bar{e}$

$$
\underset{\sim}{X}=\left(X_{1}, x_{2}, x_{3}\right)^{\prime}=(0,7368 ; 0,8421 ; 2)
$$

onde $\hat{\eta} \underset{\sim}{\mathrm{X}})=\widehat{\mathrm{Y}}_{\mathrm{MF}}=34,4737$

\subsection{Comparação de delineamentos}

Na literatura sobre superfícies de resposta existem muitos trabalhos de pequisa que tratam da construção de delineamentos de trata mentos (ou delineamento de regressão, segundo alguns autores), principal mente apös o trabalho de BOX e WILSON (1951). Foram, então, propostos mui tos critérios para se obter os chamados delineamentos ótimos, como podese ver em MEAD e PIKE (1975), JOHN e DRAPER (1975), JORDAN (1979) e ROJAS (1982), entre outros .

Como se sabe da literatura, a matriz $V=\operatorname{Var}(\underset{\sim}{\widehat{B}})=\left(\mathrm{X}^{\prime} \mathrm{X}\right)^{-1} \sigma^{2}$ depende somente dos $\mathrm{N}$ pontos experimentais (tratamentos) e não de qual quer conjunto particular de observações $\mathrm{Y}_{1}, \mathrm{Y}_{2}, \ldots, \mathrm{Y}_{\mathrm{N}}$ feitas nesses pon tos. Portanto, a matriz $\mathrm{V}$ fornece uma base concreta para se definir cri térios visando a otimização de delineamentos ou mesmo para comparar deli neamentos.

Uma maneira de se comparar dois delineamentos $E_{1}$ e $E_{2}$ é pe lo critério da eficiência por parâmetro. Considerando-se os parâmetros $\beta_{i}, \beta_{i i}, i=1,2,3$ e $\beta_{i j}, i, j=1,2,3, j>i$ da superfície de res posta polinomial quadrática, define-se a eficiência (por parâmetro) do de lineamento $E_{2}$ em relação ao delineamento $E_{1}$ como 


$$
\begin{aligned}
& E_{f}\left(\hat{\beta}_{i}\right)=\frac{\operatorname{Var}_{1}\left(\hat{\beta}_{i}\right)}{\operatorname{Var}_{2}\left(\hat{\beta}_{i}\right)} \times \frac{s_{i}\left(E_{1}\right) N_{1}}{s_{i}\left(E_{2}\right) N_{2}} \\
& E_{f}\left(\widehat{B}_{i i}\right)=\frac{\operatorname{Var}_{1}\left(\hat{\beta}_{i i}\right)}{\operatorname{Var}_{2}\left(\hat{\beta}_{i i}\right)} \times \frac{\left[s_{i}\left(E_{1}\right)\right]^{2} N_{1}}{\left[s_{i}\left(E_{2}\right)\right]^{2} N_{2}} \\
& E_{f}\left(\hat{\beta}_{i j}\right)=\frac{\operatorname{Var}_{1}\left(\hat{\beta}_{i j}\right)}{\operatorname{Var}_{2}\left(\hat{\beta}_{i j}\right)} \times \frac{s_{i}\left(E_{1}\right) s_{j}\left(E_{2}\right) N_{1}}{s_{i}\left(E_{2}\right) s_{j}\left(E_{2}\right) N_{2}}
\end{aligned}
$$

onde $\operatorname{Var}_{d}\left(\hat{\beta}_{i}\right), \operatorname{Var}_{d}\left(\widehat{\beta}_{i j}\right)$ e $\operatorname{Var}_{d}\left(\widehat{\beta}_{i j}\right)$ são as variâncias das estimativas $\widehat{\beta}_{i}$, $\widehat{\boldsymbol{\beta}}_{i i}$ e $\widehat{\beta}_{i j}$, respectivamente, no delineamento $\mathrm{E}_{\mathrm{d}}, \mathrm{N}_{\mathrm{d}}=$ número de tratamen tos do delineamento $E_{d}$ e

$$
s_{t}\left(E_{d}\right)=\left\{\frac{1}{N_{d}} \sum_{u=1}^{N}\left(x_{t u}-\bar{x}_{t}\right)^{2}\right\}^{1 / 2}
$$

que é denominada a variação da variävel $x_{t}, t=1,2,3$, no delineamento $E_{d}, d=1,2$. Diz-se, então, que $E_{2} \bar{e}$ melhor do que $E_{1}$ para se estimar um parâmetro genërico $\beta$, quando se obtém um valor maior que 1 para $E_{f}(\widehat{B})$, onde $\widehat{\beta} \bar{e}$ uma estimativa de $\beta$.

o segundo fator que aparece multiplicando a razão das va riâncias nas fórmulas (3.7.1) é um fator de correção que é colocado sem pre que os delineamentos $E_{1}$ e $E_{2}$ tem $N_{1} \neq N_{2}$ ou $s_{t}\left(E_{1}\right) \neq s_{t}\left(E_{2}\right)$. Isso fundamenta-se nas idéias de BOX e WILSON (1951) sobre a comparação de dois delineamentos com base na precisão das estimativas e, por essa razão, o critério da eficiência por parâmetro é denominado por muitos autores como o critério de Box.

Um outro modo de comparar dois delineamentos $E_{1}$ e $E_{2}$ foi apresentado por CAMPOS (1967), também com base na precisão das estimati vas. Na comparação das variâncias das estimativas leva-se em conta o nü mero de tratamentes dos delineamentos e a redução à mesma escala é feita reduzindo-se os níveis das variäveis à intervalos de mesma amplitude para ambos os delineamentos.

CAMPoS (1967) apresentou o método na comparação do delinea mento fatorial $3^{3}$ com níveis igualmente espaçados com o delineamento de Box com 15 pontos e $\alpha=\sqrt{3}$. Em termos mais gerais, o método pode ser des 
crito assim: Sejam a e b dois nümeros reais positivos e a < b. Se em $E_{1}$ os nỉveis variam de -a até a e em $\mathrm{E}_{2} \mathrm{de}-\mathrm{b}$ até b, deve-se comparar as va riâncias corrigidas

$$
\begin{aligned}
& \operatorname{Var}_{1}\left(\hat{B}_{i}\right) \operatorname{com} \frac{N_{2}}{N_{1}}\left(\frac{b}{a}\right)^{2} \operatorname{Var}_{2}\left(\hat{B}_{i}\right) \\
& \operatorname{Var}_{1}\left(\widehat{B}_{i i}\right) \operatorname{com} \frac{N_{2}}{N_{1}}\left(\frac{b}{a}\right)^{4} \operatorname{Var}_{2}\left(\hat{B}_{i j}\right) \\
& \operatorname{Var}_{1}\left(\hat{B}_{i j}\right) \operatorname{com} \frac{N_{2}}{N_{1}}\left(\frac{b}{a}\right)^{4} \operatorname{Var}_{2}\left(\hat{B}_{i j}\right)
\end{aligned}
$$

Diz-se, então, que o delineamento $E_{2}$ é melhor do que o delineamento $E_{1}$ pa ra se estimar um parâmetro genérico $\beta$ quando a variância corrigida de $\widehat{\beta}$ for menor para $\mathrm{E}_{2}$.

Tanto o critério de Box como o outro apresentado por CAMPOS (1967), não são critérios globais, isto ê, não define, no geral, uma pre ferência completa por um ou outro entre dois delineamentos $E_{1}$ e $E_{2}$ sob comparação. Assim, por exemplo, $E_{2}$ pode ser melhor do que $E_{1}$ para se es timar os coeficientes $\beta_{i}$ e $\beta_{i i}$ e $E_{1}$ pode ser melhor do que $E_{2}$ para se es timar os coeficientes $\beta_{i j}$. Entre os critérios globais mais conhecidos da literatura, podem ser citados o critério do $|V|$ (determinante de $V$ ), do tr $V$ (traço de $V$ ) e o critério da variância máxima da resposta estimada $\hat{\eta}(\underset{\sim}{X}), X \in A$.

Com base nesses critérios globais, pode-se definir outros critérios para se comparar dois delineamentos. Sejam, então, $V_{1}$ e $V_{2}$ as matrizes de dispersão de $\underset{\sim}{\widehat{B}}, \operatorname{Var}_{1}[\hat{\eta}(\underset{\sim}{X})]$ e $\operatorname{Var}_{2}[\hat{\eta}(\underset{\sim}{X})]$ as variâncias da res posta estimada em um ponto qualquer $\underset{\sim}{X} \in A$, para os delineamentos $E_{1}$ e $E_{2}$, respectivamente. Assim, a preferência de $E_{2}$ sobre $E_{1}$ ( $E_{2}$ melhor que $E_{1}$ ) pode ser determinada por um dos critérios seguintes:

$$
\begin{aligned}
& \text { 1) }\left|v_{2}\right|<\left|v_{1}\right| \\
& \text { 2) } \operatorname{tr} V_{2}<\operatorname{tr} V_{1} \\
& \text { 3) } \max _{\underset{\sim}{\mathrm{XEA}}} \operatorname{Var}_{2}[\hat{\eta}(\underset{\sim}{\mathrm{X}})]<\underset{\sim}{\mathrm{XEA}} \operatorname{Var}_{1}[\hat{\eta}(\underset{\sim}{\mathrm{X}})]
\end{aligned}
$$


Neste trabalho, a comparação de delineamentos sexá feita pe lo critério da porcentagem de ocorrência de um evento de interesse. Por exemplo, se o que se deseja num problema é encontrar a combinação de ni veis que dá a produção máxima, então, a ocorrência do evento de interesse pode ser a ocorrência de um máximo da função de produção. Sendo assim, dentro das hipóteses básicas do presente trabalho, um delineamento serä dito melhor, dentre dois ou em um conjunto de delineamentos utilizáveis na prática, se produz maior porcentagem de pontos de máximo, sempre que a situação real è de máximo.

\subsection{Delineamentos de tratamentos com três fatores}

Neste trabalho são utilizados para estudo, delineamentos de tratamentos com 3 fatores em 3, 5, 7 e 9 níveis que têm sido utilizados em pesquisas em ensaios de adubação. A região experimental será previa mente fixada como

$$
A=\left\{\left(x_{1}, x_{2}, X_{3}\right) \in R^{3} \text { tal que } 0 \leq x_{i} \leq 5, i=1,2,3\right\}
$$

e a definição dos níveis dos fatores em todos os delineamentos, sera fei ta de modo que ao nível mais baixo corresponda o valor 0 (zero) e ao ní vel mais alto corresponda o valor 5. Desse modo, todos os delineamentos terão os níveis dos fatores (variáveis) reduzidos a intervalos de mesma amplitude.

A composição de cada delineamento, bem como a matriz D' (a matriz transposta da matriz D do delineamento) são apresentadas a seguir.

\subsubsection{Delineamento fatorial $3^{3}$}

Denominando por 0 = nível baixo, 1 = nível intermediário e 2 = nível alto, o delineamento fatorial $3^{3}$ é composto pelos 27 tratamen tos seguintes:

$$
\begin{array}{lllllllll}
(0,0,0) & (0,1,0) & (0,2,0) & (1,0,0) & (1,1,0) & (1,2,0) & (2,0,0) & (2,1,0) & (2,2,0) \\
(0,0,1) & (0,1,1) & (0,2,1) & (1,0,1) & (1,1,1) & (1,2,1) & (2,0,1) & (2,1,1) & (2,2,1) \\
(0,0,2) & (0,1,2) & (0,2,2) & (1,0,2) & (1,1,2) & (1,2,2) & (2,0,2) & (2,1,2) & (2,2,2)
\end{array}
$$


3.8.1.1. Delineamento fatorial $3^{3} \mathrm{com}$ niveis igualmente espaçados

Fazendo-se 0, 1 e 2 corresponder a $0,2,5$ e 5, respectiva mente, tem-se

$$
\begin{gathered}
D^{\prime}=\left[\begin{array}{lllllllllllllllll}
0 & 0 & 0 & 0 & 0 & 0 & 0 & 0 & 0 & 2,5 & 2,5 & 2,5 & 2,5 & 2,5 \\
0 & 0 & 0 & 2,5 & 2,5 & 2,5 & 5 & 5 & 5 & 0 & 0 & 0 & 2,5 & 2,5 \\
0 & 2,5 & 5 & 0 & 2,5 & 5 & 0 & 2,5 & 5 & 0 & 2,5 & 5 & 0 & 2,5 \\
2,5 & 2,5 & 2,5 & 2,5 & 5 & 5 & 5 & 5 & 5 & 5 & 5 & 5 & 5 \\
2,5 & 5 & 5 & 5 & 0 & 0 & 0 & 2,5 & 2,5 & 2,5 & 5 & 5 & 5 \\
5 & 0 & 2,5 & 5 & 0 & 2,5 & 5 & 0 & 2,5 & 5 & 0 & 2,5 & 5
\end{array}\right]
\end{gathered}
$$

\subsubsection{Delineamento fatorial com niveis} do tipo $0, q$ e $3 q, q>0$

Fazendo-se 0, 1 e 2 corresponder a $0, \frac{5}{3}$ e 5, respectivamen te, tem-se:

$$
\mathrm{D}^{\prime}=\left[\begin{array}{llllllllllllll}
0 & 0 & 0 & 0 & 0 & 0 & 0 & 0 & 0 & \frac{5}{3} & \frac{5}{3} & \frac{5}{3} & \frac{5}{3} & \frac{5}{3} \\
0 & 0 & 0 & \frac{5}{3} & \frac{5}{3} & \frac{5}{3} & 5 & 5 & 5 & 0 & 0 & 0 & \frac{5}{3} & \frac{5}{3} \\
0 & \frac{5}{3} & 5 & 0 & \frac{5}{3} & 5 & 0 & \frac{5}{3} & 5 & 0 & \frac{5}{3} & 5 & 0 & \frac{5}{3} \\
& \frac{5}{3} & \frac{5}{3} & \frac{5}{3} & \frac{5}{3} & 5 & 5 & 5 & 5 & 5 & 5 & 5 & 5 & 5 \\
\frac{5}{3} & 5 & 5 & 5 & 0 & 0 & 0 & \frac{5}{3} & \frac{5}{3} & \frac{5}{3} & 5 & 5 & 5 \\
5 & 0 & \frac{5}{3} & 5 & 0 & \frac{5}{3} & 5 & 0 & \frac{5}{3} & 5 & 0 & \frac{5}{3} & 5
\end{array}\right]
$$




\subsubsection{Delineamento de Box com 15 pontos}

Este delineamento, também denominado de composto central, é obtido a partir do delineamento fatorial $2^{3}$, pela adição de 7 outros tra tamentos, totalizando 15 tratamentos. Denominando os níveis do fatorial $2^{3}$ por -1 (nível baixo) e 1 (nível alto), os tratamentos são os seguintes:

$$
\begin{array}{rrrrr}
(-1,-1,-1) & (-1,1,-1) & (1,-1,-1) & (1,1,-1) \\
(-1,-1,1) & (-1,1,1) & (1,-1,1) & (1,1,1) \\
& & (0,0,0) \\
& (-\alpha, 0,0) & (0,-\alpha,-\infty) & (0,0,-\alpha) \\
& (\alpha, 0,0) & (0, \alpha, 0) & (0,0, \alpha)
\end{array}
$$

Os 8 primeiros são do fatorial $2^{3}$, o tratamento $(0,0,0)$ é o ponto cen tral do delineamento e os ültimos são denominados os pontos axiais.

o valor de $\alpha$ è um nümero real escolhido pelo experimentador e uma das escolhas possíveis é $\alpha=2$, obtendo-se, então, cinco níveis igualmente espaçados para cada variável. Outra escolha possível è aquela que satisfaz a condição de ortogonalidade

$$
N \cdot n_{f}=\left(n_{f}+2 \alpha^{2}\right)^{2}
$$

como pode-se ver em JOHN (1971, pág. 204), onde $\mathrm{N}=$ nümero de tratamentos do delineamento e $\mathrm{n}_{\underline{f}}=$ nümero de tratamentos do fatorial. No caso, como se tem $N=15$ e $n_{f}=8$, encontra-se $\alpha=1,21541169$, obtendo-se o chamado delineamento composto central ortogonal. 
3.8.2.1. Delineamento de Box com 15 pontos $\operatorname{com} \alpha=1,21541169$

Fazendo-se $-\alpha,-1,0,1$ e $\alpha$ corresponder a $0 ; 0,443083796$; 2,5; 4,556916204 e 5, respectivamente, tem-se:

$$
\begin{aligned}
& D^{\prime}=\left[\begin{array}{llll}
0,443083796 & 0,443083796 & 0,443083796 & 0,443083796 \\
0,443083796 & 0,443083796 & 4,556916204 & 4,556916204 \\
0,443083796 & 4,556916204 & 0,443083796 & 4,556916204
\end{array}\right. \\
& 4,556916204 \quad 4,556916204 \quad 4,556916204 \quad 4,556916204 \\
& 0,443083796 \quad 0,443083796 \quad 4,556916204 \quad 4,556916204 \\
& 0,443083796 \quad 4,556916204 \quad 0,443083796 \quad 4,556916204 \\
& \left.\begin{array}{ccccccc}
2,5 & 0 & 5 & 2,5 & 2,5 & 2,5 & 2,5 \\
2,5 & 2,5 & 2,5 & 0 & 5 & 2,5 & 2,5 \\
2,5 & 2,5 & 2,5 & 2,5 & 2,5 & 0 & 5
\end{array}\right]
\end{aligned}
$$

3.8.2.2. Delineamento de Box com 15 pontos $\operatorname{com} \alpha=2$

Fazendo-se $-\alpha,-1,0,1$ e $\alpha$ corresponder a $0 ; 1,25 ; 2,5$;

3,75 e 5 , respectivamente, tem-se:

$$
\begin{aligned}
D^{\prime}=\left[\begin{array}{llllllll}
1,25 & 1,25 & 1,25 & 1,25 & 3,75 & 3,75 & 3,75 & 3,75 \\
1,25 & 1,25 & 3,75 & 3,75 & 1,25 & 1,25 & 3,75 & 3,75 \\
1,25 & 3,75 & 1,25 & 3,75 & 1,25 & 3,75 & 1,25 & 3,75 \\
2,5 & 0 & 5 & 2,5 & 2,5 & 2,5 & 2,5 \\
2,5 & 2,5 & 2,5 & 0 & 5 & 2,5 & 2,5 \\
2,5 & 2,5 & 2,5 & 2,5 & 2,5 & 0 & 5
\end{array}\right]
\end{aligned}
$$




\subsubsection{Delineamento $(1 / 5) 5^{3}$}

Com o objetivo de obter delineamentos para o estudo de su perfícies de resposta em experimentos com fertilizantes, com maíor nümero de níveis ou maior distância entre os niveis de cada fator, CoNAGIN e JOR GE (1977) construíram três fatoriais fracionärios (1/5) $5^{3}$ gerados pela su perposição de três quadrados latinos ortogonais. As frações foram desig nada de tipo I, II, III, tipo I, II, IV e tipo I, III, IV e os autores des tacam que esses delineamentos têm um tamanho bastante adequado e apresen tam um nümero suficiente de níveis para pesquisa com fertilizantes.

Com esse mesmo objetivo, PERECIN et aliz (1982) construíram as 155 frações regulares (1/5) $5^{3}$, geradas pelo confundimento de componen tes ortogonais, derivados da teoria de "Corpos de Galois", mostrando que as 3 frações de CONAGIN e JORGE (1977) e outras 37 apresentam proprieda des semelhantes para serem utilizadas como delineamentos para superfície de resposta em experimentos de adubação. Nesse trabalho, os autores clas sificaram essas 40 frações em três tipos denominados tipos $Y$, Z e W, em quantidades assim distribuídas: 12 no tipo $Y, 4$ no tipo $Z$ e 24 no tipo W. As três frações estudadas por CONAGIN e JORGE (1977) são do tipo Y, segun do a classificação de PERECIN et aliz (1982).

Um delineamento $(1 / 5) 5^{3}$ e um delineamento fatorial Fracioná rio e é constituído de 25 tratamentos dos 125 do fatorial completo $5^{3}$. Ca da fator é considerado em cínco níveis igualmente espaçados que serão de nominados por $0,1,2,3$ e 4 .

\subsubsection{Delineamento $(1 / 5) 5^{3}$ tipo \\ I, III, IV ou tipo $\mathrm{Y}$}

Este delineamento é composto dos 25 tratamentos seguintes:

$\begin{array}{lllll}(0,0,0) & (1,3,4) & (2,1,3) & (3,4,2) & (4,2,1) \\ (1,1,1) & (2,4,0) & (3,2,4) & (4,0,3) & (0,3,2) \\ (2,2,2) & (3,0,1) & (4,3,0) & (0,1,4) & (1,4,3) \\ (3,3,3) & (4,1,2) & (0,4,1) & (1,2,0) & (2,0,4) \\ (4,4,4) & (0,2,3) & (1,0,2) & (2,3,1) & (3,1,0)\end{array}$


Fazendo-se $0,1,2,3$ e 4 corresponder a $0 ; 1,25 ; 2,5 ; 3,75$ e 5 , respecti vamente, tem-se:

$D^{\prime}=\left[\begin{array}{ccccccccc}0 & 1,25 & 2,5 & 3,75 & 5 & 1,25 & 2,5 & 3,75 & 5 \\ 0 & 1,25 & 2,5 & 3,75 & 5 & 3,75 & 5 & 0 & 1,25 \\ 0 & 1,25 & 2,5 & 3,75 & 5 & 5 & 0 & 1,25 & 2,5 \\ 0 & 2,5 & 3,75 & 5 & 0 & 1,25 & 3,75 & 5 \\ 2,5 & 1,25 & 2,5 & 3,75 & 5 & 0 & 5 & 0 \\ 3,75 & 3,75 & 5 & 0 & 1,25 & 2,5 & 2,5 & 3,75 \\ 0 & 1,25 & 2,5 & 5 & 0 & 1,25 & 2,5 & 3,75 \\ 1,25 & 2,5 & 3,75 & 2,5 & 3,75 & 5 & 0 & 1,25 \\ 5 & 0 & 1,25 & 1,25 & 2,5 & 3,75 & 5 & 0\end{array}\right]$

3.8.3.2. Delineamento $(1 / 5) 5^{3}$ tipo $w$

Este delineamento ë constiturido dos 25 tratamentos seguin tes:

$$
\begin{array}{lllll}
(0,0,0) & (1,0,2) & (2,0,4) & (3,0,1) & (4,0,3) \\
(0,1,2) & (1,1,4) & (2,1,1) & (3,1,3) & (4,1,0) \\
(0,2,4) & (1,2,1) & (2,2,3) & (3,2,0) & (4,2,2) \\
(0,3,1) & (1,3,3) & (2,3,0) & (3,3,2) & (4,3,4) \\
(0,4,3) & (1,4,0) & (2,4,2) & (3,4,4) & (4,4,1)
\end{array}
$$

Sendo 0,1,2, 3 e 4, correspondentes a $0 ; 1,25 ; 2,5 ; 3,75$ e 5, respecti vamente, tem-se: 


$D^{\prime}=\left[\begin{array}{cccccccccc}0 & 0 & & 0 & 0 & 0 & 1,25 & 1,25 & 1,25 & 1,25 \\ 0 & 1,25 & 2,5 & 3,75 & 5 & 0 & 1,25 & 2,5 & 3,75 \\ 0 & 2,5 & 5 & 1,25 & 3,75 & 2,5 & 5 & 1,25 & 3,75 \\ 1,25 & 2,5 & 2,5 & 2,5 & 2,5 & 2,5 & 3,75 & 3,75 \\ 5 & 0 & 1,25 & 2,5 & 3,75 & 5 & 0 & 1,25 \\ 0 & 5 & 1,25 & 3,75 & 0 & 2,5 & 1,25 & 3,75 \\ 3,75 & 3,75 & 3,75 & 5 & 5 & 5 & 5 & 5 \\ 2,5 & 3,75 & 5 & 0 & 1,25 & 2,5 & 3,75 & 5 \\ 0 & 2,5 & 5 & 3,75 & 0 & 2,5 & 5 & 1,25\end{array}\right]$

\subsubsection{Delineamento composto central com duas estrelas}

Este delineamento, na sua forma geral para $k$ fatores, foi proposto por CONAGIN (1982) como sendo um delineamento do tipo simétrico, com um número $\mathrm{N}$ de pontos (tratamentos) dado por

$$
N=2^{k-f}+2 k+2 k+n
$$

onde: $2^{k-f}=$ número de pontos da parte fatorial, sendo $f$ o indice de fra cionamento;

$2 k+2 k=$ nümero de pontos axiais;

$\mathrm{n}=$ número de pontos centrais.

Os pontos axiais estão situados nos eixos coordenados dos fatores nas distâncias $\pm \alpha$ e $\pm \gamma \alpha$ do centro do delineamento. CONAGIN (1982) mostrou que para se ter o delineamento ortogonal deve-se ter a relação

$$
\alpha^{4}\left(1+\gamma^{2}\right)^{2}+W^{2} F \alpha^{2}\left(1+\gamma^{2}\right)-W^{4} \frac{F}{4}(N-F)=0
$$

onde $F$ é o nümero de pentos de fatorial e W é tal que $\pm W$ são os nĩveis do fatorial.

No caso de $k=3$ fatores e valores de $\mathrm{f}=0, \mathrm{n}=1, \gamma=2 \mathrm{e}$ $\mathrm{W}=1$, o autor obteve o delineamento composto central com duas estrelas ortogonal. Esse delineamento é constituído de $N=21$ pontos que são: 


$$
\begin{array}{llll}
(-1,-1,-1) & (-\alpha, 0,0) & (-2 \alpha, 0,0) & (0,0,0) \\
(-1,-1,1) & (\alpha, 0,0) & (2 \alpha, 0,0) \\
(-1,1,-1) & (0,-\alpha, 0) & (0,-2 \alpha, 0) \\
(-1,1,1) & (0, \alpha, 0) & (0,2 \alpha, 0) \\
(1,-1,-1) & (0,0,-\alpha) & (0,0,-2 \alpha) \\
(1,-1,1) & (\mathbf{0}, 0, \alpha) & (\mathbf{0}, 0,2 \alpha) \\
(1,1,-1) & \\
(1,1,1)
\end{array}
$$

onde $\alpha=0,704377838$. Cada fator é, portanto, considerado em 7 níveis.

Fazendo-se $-2 \alpha,-1,-\alpha, 0, \alpha, 1$ e $2 \alpha$ corresponder a 0 ; 0,$725384257 ; 1,25 ; 2,5 ; 3,75 ; 4,274615743$ e 5, respectivamente, tem-se:

$$
\begin{aligned}
& D^{\prime}=\left[\begin{array}{lllll}
0,725384257 & 0,725384257 & 0,725384257 & 0,725384257 & 4,274615743 \\
0,725384257 & 0,725384257 & 4,274615743 & 4,274615743 & 0,725384257 \\
0,725384257 & 4,274615743 & 0,725384257 & 4,274615743 & 0,725384257
\end{array}\right. \\
& 4,274615743 \quad 4,274615743 \quad 4,274615743 \quad 2,5 \quad 1,25 \quad 3,75 \quad 2,5 \\
& 0,725384257 \quad 4,274615743 \quad 4,274615743 \quad 2,5 \quad 2,5 \quad 2,5 \quad 1,25 \\
& 4,274615743 \quad 0,725384257 \quad 4,274615743 \quad 2,5 \quad 2,5 \quad 2,5 \quad 2,5 \\
& \left.\begin{array}{lllllllll}
2,5 & 2,5 & 2,5 & 0 & 5 & 2,5 & 2,5 & 2,5 & 2,5
\end{array}\right] \\
& \begin{array}{lllllllll}
3,75 & 2,5 & 2,5 & 2,5 & 2,5 & 0 & 5 & 2,5 & 2,5
\end{array}
\end{aligned}
$$

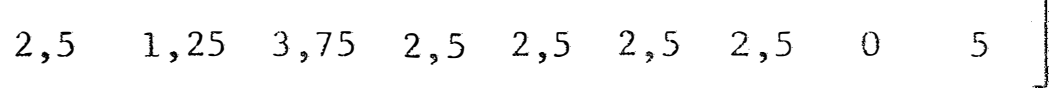




\subsubsection{Delineamento duplo central composto com 29 pontos}

CONAGIN et aiti (1969) propuseram o uso do delineamento du plo central composto com 29 pontos, visando obter melhor estimativa da curvatura da função de resposta. Este delineamento compöe-se dos 8 pon tos do fatorial $2^{3}$ com níveis -1 e 1 , mais 8 pontos do fatorial $2^{3}$ com ní veis -2 e 2 , mais 1 ponto centra1, mais 12 pontos axiais, sendo 6 nas dis tâncias $\pm \alpha$ e outros 6 nas distâncias $\pm 2 \alpha$ do centro do delineamento. Logo, os 29 tratamentos são:

$$
\begin{array}{lllll}
(-1,-1,-1) & (-2,-2,-2) & (0,0,0) & (-2 \alpha, 0,0) \\
(-1,-1,1) & (-2,-2,2) & (-\alpha, 0,0) & (2 \alpha, 0,0) \\
(-1,1,-1) & (-2,2,-2) & (\alpha, 0,0) & (0,-2 \alpha, 0) \\
(-1,1,1) & (-2,2,2) & (0,-\alpha, 0) & (0,2 \alpha, 0) \\
(1,-1,-1) & (2,-2,-2) & (0, \alpha, 0) & (0,0,-2 \alpha) \\
(1,-1,1) & (2,-2,2) & (0,0,-\alpha) & (0,0,2 \alpha) \\
(1,1,-1) & (2,2,-2) & (0,0, \alpha) & \\
(1,1,1) & (2,2,2) &
\end{array}
$$

Segundo CONAGIN e JORGE (1979), esse delineamento foi-consi derado, em sua forma original, com $\alpha=1 \mathrm{e}$, nesse caso, cada fator era analisado em cinco níveis, a saber, $-2,-1,0,1$ e 2 . o tipo ortogonal é obtido considerando-se $a=1,5100$ e nesse caso, cada um dos três fatores é analisado em nove niveis, quais sejam:

$$
-3,02 ;-2 ;-1,5100 ;-1 ; 0 ; 1 ; 1,5100 ; 2 ; 3,02
$$




\subsubsection{Delineamento duplo central composto com $\alpha=1,51$}

Fazendo-se $-3,02 ;-2 ;-1,51 ;-1 ; 0 ; 1,1,51 ; 2$ e 3,02 cor responder a $0 ; 0,844370862 ; 1,25 ; 1,672185431 ; 2,5 ; 3,327814569 ; 3,75$; 4,155629138 e 5, tem-se:

$$
\begin{aligned}
& D^{\prime}=\left[\begin{array}{lllll}
1,672185431 & 1,672185431 & 1,672185431 & 1,672185431 & 3,327814569 \\
1,672185431 & 1,672185431 & 3,327814569 & 3,327814569 & 1,672185431 \\
1,672185431 & 3,327814569 & 1,672185431 & 3,327814569 & 1,672185431
\end{array}\right. \\
& 3,327814569 \quad 3,327814569 \quad 3,327814569 \quad 0,844370862 \quad 0,844370862 \\
& 1,672185431 \quad 3,327814569 \quad 3,327814569 \quad 0,844370862 \quad 0,844370862 \\
& 3,327814569 \quad 1,672185431 \quad 3,327814569 \quad 0,844370862 \quad 4,155629138 \\
& 0,844370862 \quad 0,844370862 \quad 4,155629138 \quad 4,155629138 \quad 4,155629138 \\
& 4,155629138 \quad 4,155629138 \quad 0,844370862 \quad 0,844370862 \quad 4,155629138 \\
& 0,844370862 \quad 4,155629138 \quad 0,844370862 \quad 4,155629138 \quad 0,844370862
\end{aligned}
$$

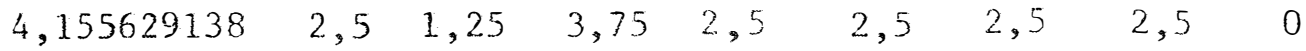

$$
\begin{aligned}
& \begin{array}{lllllllll}
4,155629138 & 2,5 & 2,5 & 2,5 & 1,25 & 3,75 & 2,5 & 2,5 & 2,5
\end{array} \\
& \begin{array}{lllllllll}
4,155629138 & 2,5 & 2,5 & 2,5 & 2,5 & 2,5 & 1,25 & 3,75 & 2,5
\end{array} \\
& \left.\begin{array}{ccccc}
5 & 2,5 & 2,5 & 2,5 & 2,5 \\
2,5 & 0 & 5 & 2,5 & 2,5 \\
2,5 & 2,5 & 2,5 & 0 & 5
\end{array}\right]
\end{aligned}
$$


3.8.5.2. Delineamento duplo central composto com $\alpha=1$

Fazendo-se $-2,-1,0,1$ e 2 corresponder a $0,1,25,2,5$, 3,75 e 5, tem-se:

$D^{\prime}=\left[\begin{array}{llllllll}1,25 & 1,25 & 1,25 & 1,25 & 3,75 & 3,75 & 3,75 & 3,75 \\ 1,25 & 1,25 & 3,75 & 3,75 & 1,25 & 1,25 & 3,75 & 3,75 \\ 1,25 & 3,75 & 1,25 & 3,75 & 1,25 & 3,75 & 1,25 & 3,75\end{array}\right.$

$\begin{array}{llllllllllll}0 & 0 & 0 & 0 & 5 & 5 & 5 & 5 & 2,5 & 1,25 & 3,75 & 2,5\end{array}$

$\begin{array}{llllllllllll}0 & 0 & 5 & 5 & 0 & 0 & 5 & 5 & 2,5 & 2,5 & 2,5 & 1,25\end{array}$

$\begin{array}{llllllllllll}0 & 5 & 0 & 5 & 0 & 5 & 0 & 5 & 2,5 & 2,5 & 2,5 & 2,5\end{array}$

$\left.\begin{array}{ccccccccc}2,5 & 2,5 & 2,5 & 0 & 5 & 2,5 & 2,5 & 2,5 & 2,5 \\ 3,75 & 2,5 & 2,5 & 2,5 & 2,5 & 0 & 5 & 2,5 & 2,5 \\ 2,5 & 1,25 & 3,75 & 2,5 & 2,5 & 2,5 & 2,5 & 0 & 5\end{array}\right]$




\section{METODOLOGIA}

\subsection{O método utilizado}

Para atender aos objetivos da pesquisa, foi utilizado o me todo de simulação. Todo o trabalho de simulação e análise dos dados foi executado num microcomputador eletrônico EGO XT, compatível com o IBM-PC, na Unidade de Processamento de Dados a Faculdade de Ciências Agrärias e Veterinārias - UNESP, Campus de Jaboticaba1.

Os dados foram simulados para os delineamentos de tratamen tos com três fatores em $3,5,7$ e 9 níveis, descritos na seção 3.8 , utili zando-se funções de resposta que tem máximo. As funções de resposta uti lizadas para a simulação dos dados foram as mesmas para todos os delinea mentos e constituíram um conjunto de 21 funções de produção em três variā veis $x_{1}, x_{2}$ e $x_{3}$ do tipo

$$
\begin{aligned}
\eta= & \beta_{0}+\beta_{1} x_{1}+\beta_{2} x_{2}+\beta_{3} x_{3}+\beta_{11} x_{1}^{2}+\beta_{22} x_{2}^{2}+\beta_{33} x_{3}^{2}+ \\
& +\beta_{12} x_{1} x_{2}+\beta_{13} x_{1} x_{3}+\beta_{23} x_{2} x_{3}
\end{aligned}
$$

Nas 21 funções, os valores dos coeficientes foram determina dos de modo a produzir diferentes situações reais de interesse, sob as quais a pesquisa seria desenvolvida. A técnica utilizada na construção desses modelos de resposta, admitidos como verdadeiros na simulação, foi desenvolvida na seção 3.5 e o ponto de partida é uma forma canônica

$$
\eta=Y_{0}+\lambda_{1} W_{1}^{2}+\lambda_{2} W_{2}^{2}+\lambda_{3} W_{3}^{2}
$$

onde $\lambda_{i}<0, i=1,2,3$ e $Y_{0}=\operatorname{mäx} n$ em $R^{3}$. 


\subsection{Os modelos de resposta para simulação}

Com o objetivo de se definir modelos de resposta pröximos daqueles que podem ser obtidos na prática, foi feito, inicialmente, um es tudo sobre a função de produção polinomial quadrätica utilizada por JoRGE e CONAGIN (1977) que nas variāveis $x_{1}, x_{2}$ e $x_{3}$ é

$$
\begin{aligned}
n= & 480+561 x_{1}+691 x_{2}+378 x_{3}-42 x_{1}^{2}-55 x_{2}^{2}-28 x_{3}^{2}- \\
& -25 x_{1} x_{2}-18 x_{1} x_{3}-12 x_{2} x_{3}
\end{aligned}
$$

Com esse modelo, segundo os autores, procura-se caracter $\underline{i}$ zar uma situação de produção de milho, em quilogramas por hectare, susce tível de ser encontrada para os ensaios de adubação dessa cultura no Esta do de São Paulo. Nos estudos realizados pelos autores, trabalhou-se com um coeficiente de variação de $8,5 \%$ para uma produção média de milho em torno de $3500 \mathrm{~kg} / \mathrm{ha}$, aproximadamente, o que dá um valor aproximado $\sigma=300$ para o desvio padrão do erro em cada observação.

os autovalores da matriz B desse modelo são iguais a $-65,2$, $-36,2$ e $-23,6$, aproximadamente, sendo então, $\sum_{i=1}^{3} \lambda_{i}=-125$, que è igual a tr B. Essa função de produção $n$ tem máximo aproximadamente igual a 4176,60 no ponto $\left(\mathrm{X}_{1}, \mathrm{x}_{2}, \mathrm{X}_{3}\right)=(4,31,4,83,4,33)$.

Com base nesses resultados, foi tomado para toda a pesquisa, o valor $\sigma=300$ e os 21 modelos de produção foram obtidos a partir da for ma canônica 4.1 , nas seguintes condições:

1) Condições sobre $\sum_{i=1}^{3} \lambda_{i}$ :

$$
\begin{aligned}
& \text { 1.1) } \sum_{i=1}^{3} \lambda_{i}=-0,50=-150 \\
& \text { 1.2) } \sum_{i=1}^{3} \lambda_{i}=-0,30=-90 \\
& \text { 1.3) } \sum_{i=1}^{3} \lambda_{i}=-0,85 \sigma=-255
\end{aligned}
$$

2) Condições sobre $\lambda_{1}, \lambda_{2}$ e $\lambda_{3}$ :

Para cada uma das condições sobre $\sum_{i}^{3} \lambda_{i}$ foram consideradas as seguintes outras condições: 


\section{1) $\lambda_{1}=\lambda_{2}=\lambda_{3}$}

2.2) $\lambda_{1}$ grande e $\lambda_{2}=\lambda_{3}$ pequenos

2.3) $\lambda_{1}=\lambda_{2}$ grandes e $\lambda_{3}$ pequeno

2.4) $\lambda_{1}$ grande, $\lambda_{2}$ mëdio e $\lambda_{3}$ pequeno

Observação: A caracterização de um autovalor pequeno, mëdio ou grande é em termos do valor absoluto.

3) Condições sobre o máximo de $\eta(\underset{\sim}{X})$

Para todas as funções $\eta \underset{\sim}{(X)}$ o interesse foi em se ter $\operatorname{máx} \eta(\underset{\sim}{X})=4100$ no ponto $\underset{\sim 0}{x_{0}}=\left(x_{01}, x_{02}, x_{03}\right)^{\prime}=(4,4,4)^{\prime}$.

0 ponto $\underset{\sim 0}{X_{0}}$ foi escolhido assim porque se desejava estudar uma situação on de $\underset{\sim 0}{X_{0}}$ estivesse dentro da região experimental A e tal que as coordenadas estivessem próximas do maior nível possível. No caso, a variação de cada $x_{i}, i=1,2,3$ é no intervalo $[0,5]$ e $\operatorname{com} x_{01}=x_{02}=x_{03}=4$, tem-se es sas doses situadas $80 \%$ à direita da menor dose, o que é uma situação fá cil de ser encontrada em ensaios de adubação.

Os 21 modelos de produção, as condiçöes sob as quais foram determinados, bem como o cálculo de cada um, conforme a seção 3.5 , são apresentados a seguir, sendo os modelos de números 1 a 7 com a condição $\sum_{i=1}^{3} \lambda_{i}=-150$, os modelos de números 8 a $14 \operatorname{com}_{3}$ a condição $\sum_{i=1}^{3} \lambda_{i}=-90$ e os modelos de números 15 a 21 com a condição $\sum_{i=1}^{3} \lambda_{\dot{I}}=-255$. A matriz M é a matriz de rotação e como foi visto na seção 3.5 , será $M=I$ para se ob ter um modelo sem interação e $M=M_{2}$ para se obter um modelo com intera ção. O valor pequeno para $\lambda_{i}$ foi tomado como-18, o médio como a média aritmética dos três e o grande por diferença, jä que a soma dos três é fi xa.

MODELO 1: $\lambda_{1}=\lambda_{2}=\lambda_{3}=-50$ e $\mathrm{M}=\mathrm{I}$

Tem-se:

$$
\begin{aligned}
& Q=\operatorname{diag}\{-50,-50,-50\} \\
& -2 \mathrm{X}_{0}^{\prime} \mathrm{Q}=(400 ; 400 ; 400) \\
& \underset{\sim 0}{\mathrm{X}_{\sim}^{\prime}} \mathrm{X}_{0}=16(-150)=-2400
\end{aligned}
$$


Portanto,

$$
\eta=1700+400 x_{1}+400 x_{2}+400 x_{3}-50 x_{1}^{2}-50 x_{2}^{2}-50 x_{3}^{2}
$$

MODELO 2: $\lambda_{1}=-114, \lambda_{2}=-18, \lambda_{3}=-18$ e $M=I$

Tem-se:

$$
\begin{aligned}
& Q-\operatorname{diag}\{-114,-18,-18\} \\
& -\underset{\sim 0}{2 X_{0}^{\prime} Q=(912 ; 144 ; 144)} \\
& \underset{\sim 0}{X_{0}^{\prime}} X_{0}=16(-150)=-2400
\end{aligned}
$$

Então,

$$
\eta=1700+912 x_{1}+144 x_{2}+144 x_{3}-114 x_{1}^{2}-18 x_{2}^{2}-18 x_{3}^{2}
$$

MODELO 3: $\lambda_{1}=-114, \lambda_{2}=-18, \lambda_{3}=-18$ e $M=M_{2}$

Tem-se:

$$
\begin{aligned}
& \mathrm{Q}=\left[\begin{array}{ccc}
-60,67 & 46,57 & 10,35 \\
\operatorname{sim} . & -68,82 & -11,29 \\
\operatorname{sim} . & \text { sim. } & -20,51
\end{array}\right] \\
& -2 \underset{\sim 0}{X_{0}^{\prime} Q}=(30 ; 268,32 ; 171,6) \\
& \underset{\sim 0}{X_{0}^{\prime} Q X_{\sim 0}=16(-58,74)=-939,84}
\end{aligned}
$$

Logo,

$$
\begin{aligned}
\eta= & 3160,16+30 x_{1}+268,32 x_{2}+171,6 x_{3}-60,67 x_{1}^{2} \\
& -68,82 x_{2}^{2}-20,51 x_{3}^{2}+93,14 x_{1} x_{2}+20,7 x_{1} x_{3}-22,58 x_{2} x_{3}
\end{aligned}
$$

MODELO 4: $\lambda_{1}=-66, \lambda_{2}=-66, \lambda_{3}=-18$ e $M=I$

Tem-se:

$$
\begin{aligned}
& Q=\operatorname{diag}\{-66,-66,-18\} \\
& -\underset{\sim 0}{2} X_{0}^{\prime} Q=(528 ; 528 ; 144) \\
& \underset{\sim 0}{X_{\sim}^{\prime}} \mathbb{X}_{0}=16(-150)=-2400
\end{aligned}
$$


Então,

$$
n=1700+528 x_{1}+528 x_{2}+144 x_{3}-66 x_{1}^{2}-66 x_{2}^{2}-18 x_{3}^{2}
$$

MODELO 5: $\lambda_{1}=-66, \lambda_{2}=-66, \lambda_{3}=-18$ e $M=M_{2}$

Tem-se:

$$
\begin{aligned}
& Q=\left[\begin{array}{ccc}
-44,67 & 15,52 & 18,11 \\
\operatorname{sim} . & -54,70 & 13,18 \\
\text { sim. } & \text { sim. } & -50,63
\end{array}\right] \\
& \underset{\sim 0}{-2 X_{0}^{\prime} Q}=(88,32 ; 208 ; 154,72) \\
& \underset{\sim}{X_{0}^{\prime} X_{0}}=16(-56,38)=-902,08
\end{aligned}
$$

Portanto,

$$
\begin{aligned}
\eta= & 3197,92+88,32 x_{1}+208 x_{2}+154,72 x_{3}-44,67 x_{1}^{2}- \\
& -54,70 x_{2}^{2}-50,63 x_{3}^{2}+31,04 x_{1} x_{2}+36,22 x_{1} x_{3}+26,36 x_{2} x_{3}
\end{aligned}
$$

MODELO 6: $\lambda_{1}=-82, \lambda_{2}=-50, \lambda_{3}=-18$ e $M=I$

Tem-se:

$$
\begin{aligned}
& Q=\operatorname{diag}\{-82,-50,-18\} \\
& -\underset{\sim 0}{2 X_{0}^{\prime} Q=(656 ; 400 ; 144)} \\
& \underset{\sim 0}{X_{\sim}^{\prime} Q X_{0}}=16(-150)=-2400
\end{aligned}
$$

Logo,

$$
n=1700+656 x_{1}+400 x_{2}+144 x_{3}-82 x_{1}^{2}-50 x_{2}^{2}-18 x_{3}^{2}
$$

MODELO 7: $\lambda_{1}=-82, \lambda_{2}=-50, \lambda_{3}=-18$ e $M=M_{2}$

Tem-se:

$$
\begin{aligned}
& Q=\left[\begin{array}{crr}
-50 & 25,87 & 15,52 \\
\text { sim. } & -59,41 & 5,02 \\
\text { sim. } & \text { sim. } & -40,49
\end{array}\right] \\
& -\underset{\sim 0}{-2 X_{0}^{\prime} Q=(68,88 ; 228,16 ; 160,4)} \\
& \underset{\sim 0}{X_{0}^{\prime} Q X_{0}=16(-57,18)=-914,88}
\end{aligned}
$$


Assim,

$$
\begin{aligned}
n= & 3185,12+68,88 x_{1}+228,16 x_{2}+160,4 x_{3}-50 x_{1}^{2}- \\
& -59,41 x_{2}^{2}-40,59 x_{3}^{2}+51,74 x_{1} x_{2}+31,04 x_{1} x_{3}+10,04 x_{2} x_{3}
\end{aligned}
$$

MODELO 8: $\lambda_{1}=-30, \lambda_{2}=-30, \lambda_{3}=-30$ e $M=1$

Tem-se:

$$
\begin{aligned}
& Q=\operatorname{diag}\{-30,-30,-30\} \\
& -\underset{\sim 0}{2 X_{0}^{\prime} Q}=(240 ; 240 ; 240) \\
& \underset{\sim 0}{\mathrm{X}}{ }_{0}^{\prime} \mathrm{QX}_{\sim 0}=16(-90)=-1440
\end{aligned}
$$

Então,

$$
\eta=2660+240 x_{1}+240 x_{2}+240 x_{3}-30 x_{1}^{2}-30 x_{2}^{2}-30 x_{3}^{2}
$$

MODELO 9: $\lambda_{1}=-54, \lambda_{2}=-18, \lambda_{3}=-18$ e $M=I$

Tem-se:

$$
\begin{aligned}
& Q=\operatorname{diag}\{-54,-18,-18\} \\
& -2 \underset{\sim 0}{X_{0}^{\prime} Q}=(432 ; 144 ; 144) \\
& \underset{\sim 0}{X_{0}^{\prime}} \underset{\sim 0}{X_{0}}=16(-90)=-1440
\end{aligned}
$$

Logo,

$$
\eta=2660+432 x_{1}+144 x_{2}+144 x_{3}-54 x_{1}^{2}-18 x_{2}^{2}-18 x_{3}^{2}
$$

MODELO 10: $\lambda_{1}=-54, \lambda_{2}=-18, \lambda_{3}=-18$ e $M=M_{2}$

Tem-se:

$$
\begin{aligned}
& Q=\left[\begin{array}{ccr}
-34 & 17,46 & 3,88 \\
\operatorname{sim} . & -37,06 & -4,24 \\
\text { sim. } & \text { sim. } & -18,94
\end{array}\right] \\
& -2 \mathrm{X}_{0}^{\prime} \mathrm{Q}=(101,28 ; 190,72 ; 154,4) \\
& \underset{\sim 0}{\mathrm{X}_{\sim}^{\prime} \mathrm{QX}}=16(-55,8)=-892,8
\end{aligned}
$$


Logo,

$$
\begin{aligned}
\eta= & 3207,2+101,28 x_{1}+190,72 x_{2}+154,4 x_{3}-34 x_{1}^{2}- \\
& -37,06 x_{2}^{2}-18,94 x_{3}^{2}+34,92 x_{1} x_{2}+7,76 x_{1} x_{3}-8,48 x_{2} x_{3}
\end{aligned}
$$

MODELO 11: $\lambda_{1}=-36, \lambda_{2}=-36, \lambda_{3}=-18$ e $M=I$

Tem-se:

$$
\begin{aligned}
& Q=d i a g\{-36,-36,-18\} \\
& -2 X_{\sim 0}^{\prime} Q=(288 ; 288 ; 144) \\
& \underset{\sim 0}{X_{\sim}^{\prime} Q X_{0}=16(-90)=-1440}
\end{aligned}
$$

Então,

$$
\eta=2660+288 x_{1}+288 x_{2}+144 x_{3}-36 x_{1}^{2}-36 x_{2}^{2}-18 x_{3}^{2}
$$

MODELO 12: $\lambda_{1}=-36, \lambda_{2}=-36, \lambda_{3}=-18$ e $M=M_{2}$

Tem-se:

$$
\begin{aligned}
& Q=\left[\begin{array}{crr}
-28 & 5,82 & 6,79 \\
\text { sim. } & -31,76 & 4,94 \\
\text { sim. } & \text { sim. } & -30,24
\end{array}\right] \\
& -2 \underset{\sim 0}{2 X_{0}^{\prime} Q=(123,12 ; 168 ; 148,08)} \\
& \underset{\sim}{X_{0}^{\prime}}{\underset{\sim O}{O}}_{0}=16(-54,9)=-878,4
\end{aligned}
$$

Portanto,

$$
\begin{aligned}
\eta= & 3221,6+123,12 x_{1}+168 x_{2}+148,08 x_{3}-28 x_{1}^{2}- \\
& -31,76 x_{2}^{2}-30,24 x_{3}^{2}+11,64 x_{1} x_{2}+13,58 x_{1} x_{3}+9,88 x_{2} x_{3}
\end{aligned}
$$

MODELO 13: $\lambda_{1}=-42, \lambda_{2}=-30, \lambda_{3}=-18$ e $M=I$

Tem-se:

$$
\begin{aligned}
& Q=\operatorname{diag}\{-42,-30,-18\} \\
& -2 \underset{\sim}{2} \mathbf{0}^{\prime} Q=(336 ; 240 ; 144) \\
& \underset{\sim 0}{\mathrm{X}} \mathrm{QX}_{\sim} \mathrm{X}_{0}=16(-90)=-1440
\end{aligned}
$$


Logo,

$$
\eta=2660+336 x_{1}+240 x_{2}+144 x_{3}-42 x_{1}^{2}-30 x_{2}^{2}-18 x_{3}^{2}
$$

MODELO 14: $\lambda_{1}=-42, \lambda_{2}=-30, \lambda_{3}=-18$ e $M=M_{2}$

Tem-se:

$$
\begin{aligned}
& Q=\left[\begin{array}{rrr}
-30 & 9,70 & 5,82 \\
\operatorname{sim} . & -33,53 & 1,88 \\
\operatorname{sim} . & \text { sim. } & -26,47
\end{array}\right] \\
& -2 \mathrm{X}_{0}^{\prime} \mathrm{Q}=(115,84 ; 175,6 ; 150,16) \\
& \underset{\sim}{\mathrm{X}_{0}^{\prime} \mathrm{QX}}=16(-55,2)=-883,2
\end{aligned}
$$

Portanto,

$$
\begin{aligned}
\eta= & 3216,8+115,84 x_{1}+175,6 x_{2}+150,16 x_{3}-30 x_{1}^{2}- \\
& -33,53 x_{2}^{2}-26,47 x_{3}^{2}+19,4 x_{1} x_{2}+11,64 x_{1} x_{3}+3,76 x_{2} x_{3}
\end{aligned}
$$

MODELO 15: $\lambda_{1}=-85, \lambda_{2}=-85, \lambda_{3}=-85$ e $M=I$

Tem-se:

$$
\begin{aligned}
& Q=\operatorname{diag}\{-85,-85,-85\} \\
& \underset{\sim 0}{-2 \mathrm{X}_{0}^{\prime} \mathrm{Q}=(680 ; 680 ; 680)} \\
& \underset{\sim 0}{\mathrm{X}}{ }_{\sim 0}^{\prime} \mathrm{X}_{0}=16(-255)=-4080
\end{aligned}
$$

Então,

$$
\eta=20+680 x_{1}+680 x_{2}+680 x_{3}-85 x_{1}^{2}-85 x_{2}^{2}-85 x_{3}^{2}
$$

MODELO 16: $\lambda_{1}=-219, \lambda_{2}=-18, \lambda_{3}=-18$ e $M=I$

Tem-se:

$$
\begin{aligned}
& Q=\operatorname{diag}\{-219,-18,-18\} \\
& -\underset{\sim 0}{-2 X_{0}^{\prime} Q=(1752 ; 144 ; 144)} \\
& \underset{\sim 0}{X_{0}^{\prime}} \sim_{0}=16(-255)=-4080
\end{aligned}
$$


Assim,

$$
\eta=20+1752 x_{1}+144 x_{2}+144 x_{3}-219 x_{1}^{2}-18 x_{2}^{2}-18 x_{3}^{2}
$$

MODELO 17: $\lambda_{1}=-219, \lambda_{2}=-18, \lambda_{3}=-18$ e $M=M_{2}$

Tem-se:

$$
\begin{aligned}
& Q=\left[\begin{array}{ccc}
-107,33 & 97,50 & 21,67 \\
\operatorname{sim} . & -124,21 & -23,65 \\
\text { sim. } & \text { sim. } & -23,26
\end{array}\right] \\
& -2 \mathrm{X}_{0}^{\prime} Q=(-94,72 ; 404,48 ; 201,92) \\
& \underset{\sim 0}{X_{\sim}^{\prime} Q X_{0}=16(-63,96)=-1023,36}
\end{aligned}
$$

Løgo,

$$
\begin{aligned}
\eta= & 3076,64-94,72 x_{1}+404,48 x_{2}+201,92 x_{3}-107,33 x_{1}^{2}- \\
& -124,41 x_{2}^{2}-23,26 x_{3}^{2}+195 x_{1} x_{2}+43,34 x_{1} x_{3}-47,3 x_{2} x_{3}
\end{aligned}
$$

MODELO 18: $\lambda_{1}=-118,5, \lambda_{2}=-118,5, \lambda_{3}=-18$ e $M=I$

Tem-se:

$$
\begin{aligned}
& Q=\operatorname{diag}\{-118,5 ;-118,5 ;-18\} \\
& -2 \underset{\sim 0}{X_{0}^{\prime} Q=(948 ; 948 ; 144)} \\
& \underset{\sim 0}{X_{\sim}^{\prime}} \underset{\sim 0}{X}=16(-255)=-4080
\end{aligned}
$$

Logo,

$$
n=20+948 x_{1}+948 x_{2}+144 x_{3}-118,5 x_{1}^{2}-118,5 x_{2}^{2}-18 x_{3}^{2}
$$

MODELO 19: $\lambda_{1}=-118,5, \lambda_{2}=-118,5, \lambda_{3}=-18$ e $M=M_{2}$

Tem-se:

$$
\begin{aligned}
& Q=\left[\begin{array}{ccc}
-73,83 & 32,50 & 37,92 \\
\operatorname{sim} . & -94,86 & 27,60 \\
\operatorname{sim} . & \operatorname{sim} . & -86,31
\end{array}\right] \\
& -2 \mathrm{X}_{0}^{\prime} Q=(27,28 ; 278,08 ; 166,32) \\
& \underset{\sim 0}{X_{0}^{\prime} Q X_{0}=16(-58,96)=-943,36}
\end{aligned}
$$


Portanto,

$$
\begin{aligned}
n= & 3156,64+27,28 x_{1}+278,08 x_{2}+166,32 x_{3}-73,83 x_{1}^{2}- \\
& -94,86 x_{2}^{2}-86,31 x_{3}^{2}+65 x_{1} x_{2}+75,84 x_{1} x_{3}+55,2 x_{2} x_{3}
\end{aligned}
$$

MODELO 20: $\lambda_{1}=-152, \lambda_{2}=-85, \lambda_{3}=-18$ e $M=1$

Tem-se:

$$
\begin{aligned}
& Q=\operatorname{diag}\{-152,-85,-18\} \\
& -2 \mathrm{X}_{0}^{\prime} Q=(1216 ; 680 ; 144) \\
& \underset{\sim 0}{X_{0}^{\prime} Q X_{\sim}=16(-255)=-4080}
\end{aligned}
$$

Entäo,

$$
n=20+1216 x_{1}+680 x_{2}+144 x_{3}-152 x_{1}^{2}-85 x_{2}^{2}-18 x_{3}^{2}
$$

MODELO 21: $\lambda_{1}=-152, \lambda_{2}=-85, \lambda_{3}=-18$ e $M=M_{2}$

Tem-se :

$$
\begin{aligned}
& Q=\left[\begin{array}{ccc}
-85 & 54,17 & 32,50 \\
\operatorname{sim} . & -104,71 & 10,51 \\
\operatorname{sim} . & \text { sim. } & -65,29
\end{array}\right] \\
& -2 \mathrm{X}_{0}^{\prime} Q=(-13,36 ; 320,24 ; 178,24) \\
& \underset{\sim 0}{X_{\sim}^{\prime} Q X_{0}}=16(-60,64)=-970,24
\end{aligned}
$$

Então,

$$
\begin{aligned}
n= & 3129,76-13,36 x_{1}+320,24 x_{2}+178,24 x_{3}-85 x_{1}^{2}- \\
& -104,71 x_{2}^{2}-65,29 x_{3}^{2}+108,34 x_{1} x_{2}+65 x_{1} x_{3}+21,02 x_{2} x_{3}
\end{aligned}
$$

\subsection{Critério para a escolha de um $\lambda_{i}$ pequeno}

Numa forma canônica

$$
n=Y_{0}+\lambda_{1} W_{1}^{2}+\lambda_{2} W_{2}^{2}+\lambda_{3} W_{3}^{2}
$$

de um modelo de resposta, pode-se observar que para um $\lambda_{i}$ pequeno em valor absoluto, tem-se pouca sensibilidade na resposta na direção do eixo canô 
nico $W_{i}$, isto é, as alteraçöes na resposta $\eta$ são relativamente pequenas quando se desloca no eixo canônico $W_{i}$, afastando-se da origern em qualquer sentido. Com isso em mente, considerou-se uma posição particular dos ei xos e utilizou-se a variação da resposta $n$ na ireção do eixo $W_{i}$, dentro da região experimental, para se definir o que poderia ser um $\lambda_{i}$ pequeno para a construção de alguns dos modelos da seção 4.2.

Para isso, tomou-se os eixos canônicos $w_{1}, w_{2}$ e $w_{3}$ parale los aos eixos $X_{1}, X_{2}$ e $X_{3}$, respectivamente e de mesmas orientações que es tes. A seguir, considerou-se a curva

$$
\stackrel{*}{n}=\mathrm{Y}_{0}+\lambda_{i} \mathrm{~W}_{i}^{2}
$$

obtida da forma canônica de $\eta$ quando se coloca 0 (zero) para as outras va riáveis canônicas.

Definiu-se, então, como sendo um $\lambda_{i}$ pequeno, aquele que sa tisfaz a condição

$$
\max _{w_{i}} \stackrel{*}{\eta}-\min _{i} \stackrel{*}{\eta} \leq \sigma
$$

para $W_{i}$ dentro da região experimental. Considerando-se a posição relati va particular dos eixos $w_{i}$ e $x_{i}$ e que $x_{0}=\left(x_{01}, x_{02}, x_{03}\right)^{\prime}=(4,4,4)^{\prime}$ corresponde à origem $\underset{\sim}{W}=\underset{\sim}{0}$ do sistema canônico, uma ilustração gráfica tí pica da curva (4.3.1) na condição (4.3.2) é dada pela Figura 4.1.

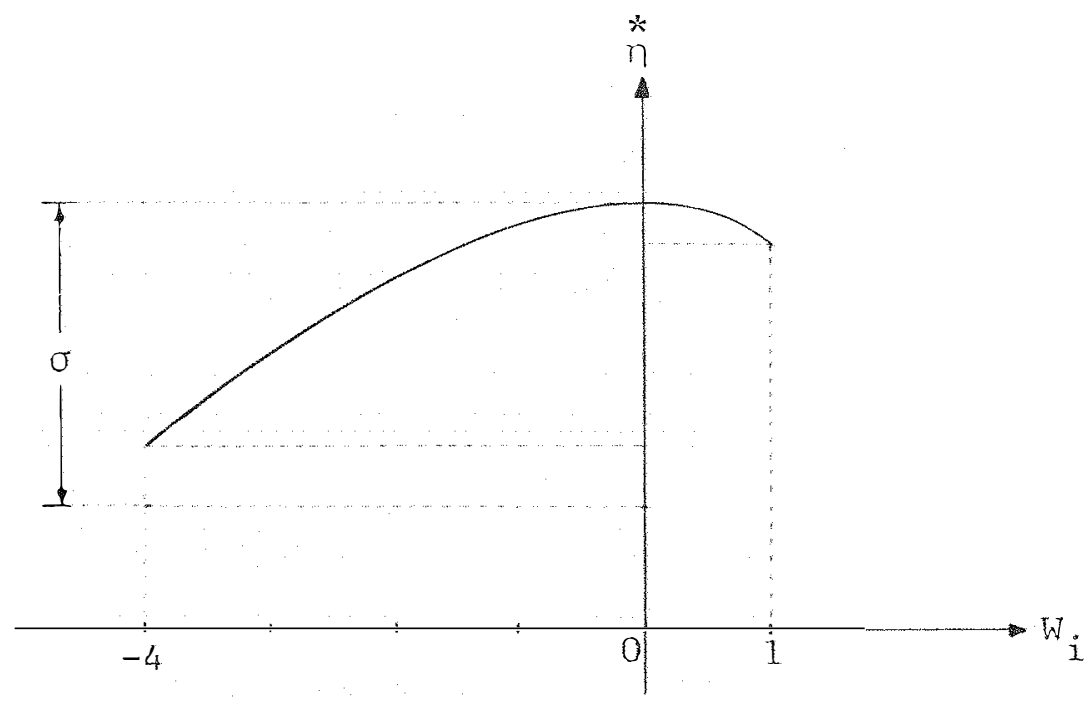

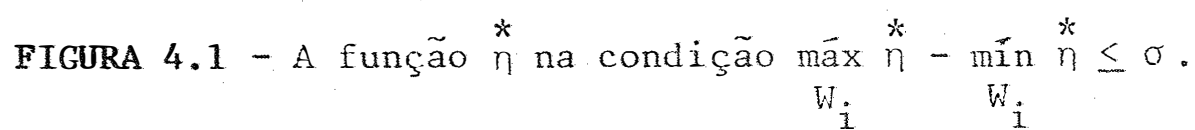


Conforme se nota na Figura 4.1 , a variação de $W_{i}$ dentro da região experimental é de -4 até 1 , pois se está considerando que $x_{i} E[0,5]$. Isso não é difícil de se concluir porque na situação particular já descri ta, dos eixos, a relação entre $\underset{\sim}{X}$ e $\underset{\sim}{W}$ é dada por

$$
\underset{\sim}{X}=\underset{\sim 0}{X}+\underset{\sim}{W}
$$

onde I é a matriz (de rotação) identidade de ordem 3. Sendo assim, para $i=1,2,3$, tem-se

$$
w_{i}=x_{i}-x_{0 i}
$$

e, portanto,

$$
0 \leq x_{i} \leq 5 \Leftrightarrow-4 \leq w_{i} \leq 1
$$

Como a função $\stackrel{*}{\eta}$ é simétrica em relação a $w_{i}=0$, pode-se con cluir que $\min _{W_{i}} \stackrel{\dot{k}^{*}}{n}=\mathrm{Y}_{0}+16 \lambda_{i}$, is to é, o minimo de $\stackrel{*}{\eta}$ para $W_{i} \in[-4,1]$ é atin gido em $W_{i} \stackrel{W_{i}}{=}-4$. Sendo máx $\stackrel{*}{n}=x_{0}$ nesse intervalo, tem-se

$$
0 \leq \max _{W_{i}} \stackrel{*}{\eta}-\min _{i} \stackrel{*}{n} \leq \sigma \Leftrightarrow 0 \leq-16 \lambda_{i} \leq \sigma
$$

isto $\overline{\mathrm{e}}$,

$$
-\frac{\sigma}{16} \leq \lambda_{i} \leq 0
$$

Portanto, para $\sigma=300$, tem-se que $\lambda_{i}$ é um valor pequeno em valor absolu to se satisfaz $-18,75 \leq \lambda_{i} \leq 0$.

Em princípio, qualquer valor de $\lambda_{i}$ nesse intervalo poderia ser utilizado como pequeno, pois todos satisfazem a condição (4.3.2). No entanto, para não se criar situações quase extremas, isto é, de muito pou ca sensibilidade na resposta, optou-se por um valor de $\lambda_{i}$ o mais próximo possível do extremo inferior desse intervalo. Sendo assim, para simplifi car os cálculos, tomou-se o valor inteiro $\lambda_{i}=-18$.

\subsection{O material utilizado e a obtenção dos resultados}

O material utilizado na pesquisa constituiu-se de dados ex perimentais obtidos por simulação, utilizando-se a sub-rotina indicada no 
Apêndice, onde o método utilizado para a simulação de variáveis aleatórias com distribuição normal unidimensional é fundamentado no trabalho de BoX (1958). Para cada delineamento d com $N_{d}$ tratamentos, $d=1,2, \ldots, 9$ e para cada um dos 21 modelos de resposta, foram simulados 1000 ensaios in teiramente casualizados de $\mathrm{N}_{\mathrm{d}}$ tratamentos com $\sigma=300$, o desvio padrão do erro em cada observação.

O programa para o computador foi elaborado de modo que quan do um delineamento era informado, através da matriz D, os resultados eram obtidos para o conjunto dos 21 modelos, num total de 21000 ensaios gera dos, sendo 1000 a partir de cada modelo de resposta. Para cada ensaio, de cada conjunto de 1000, foi obtida pelo método dos mínimos quadrados, a su perfície de resposta

$$
\begin{aligned}
\hat{n}= & \widehat{\beta}_{0}+\widehat{\beta}_{1} X_{1}+\widehat{\beta}_{2} X_{2}+\widehat{\beta}_{3} X_{3}+\widehat{\beta}_{11} X_{1}^{2}+\widehat{\beta}_{22} X_{2}^{2}+\widehat{\beta}_{33} X_{3}^{2}+ \\
& +\widehat{\beta}_{12} X_{1} X_{2}+\widehat{\beta}_{13} X_{2} X_{3}+\widehat{\beta}_{23} X_{2} X_{3}
\end{aligned}
$$

A seguir foi feito o estudo da natureza do ponto crítico de $\hat{\eta}$, sendo este classificado em um dos quatro tipos possíveis que são: ponto de mäximo, de mínimo, de sela e indeterminação.

As ocorrências de máximo, mỉnimo, sela ou indeterminação fo ram contadas e depois apresentadas em porcentagens sobre 1000 ensaios. Em cada ensaio, quando o ponto crítico era de máximo ou de sela, eram calcu ladas as coordenadas desse ponto e o valor de $\hat{n}$ nesse ponto. Os casos de mínimo ou indeterminação eram apenas contados, não se efetuando nenhum ou tro cálculo nesses casos.

Nos ensaios onde o ponto crítico era de sela e, somente nes ses, eram calculados também o ponto de máximo experimental e o ponto de máximo fronteira na região experimental, bem como o valor de $\widehat{\eta}$ nesses pon tos. O ponto de máximo experimental è o ponto na região experimental, ca racterizado pela combinação de níveis $\underset{\sim}{\mathrm{X}}=\left(\mathrm{X}_{1}, \mathrm{X}_{2}, \mathrm{X}_{3}\right)^{\prime}$ do delineamento que corresponde $\grave{a}$ maior observação $Y$ do ensaỉo simulado.

Conforme foi dito na seção 3.6 .2 , existe a possibilidade de ocorrer uma indeterminação numa face quando se vai calcular o ponto de má ximo fronteira, Num caso desses, o programa elaborado encerrava o proces so de cálculo do ponto de máximo fronteira e registrava tal ocorrência pa ra efeito de controle. 


\section{RESULTADOS E DISCUSSÃO}

Os resultados obtidos estão apresentados nas tabelas numera das de 1 a 12 . Nas tabelas foram utilizadas siglas para designar os deli neamentos que foram as seguintes:

FIE:-Fatorial $3^{3}$ com níveis igualmente espaçados

FN: Fatorial $3^{3}$ com níveis do tipo 0 , $q$ e $3 q$

BO: Box com 15 pontos e $\alpha=1,21541169$

BN: Box com 15 pontos e $\alpha=2$

Y: $\quad(1 / 5) 5^{3}$ tipo I, III, IV ou tipo $Y$

W: $\quad(1 / 5) 5^{3}$ tipo $W$

CC: Composto central com duas estrelas

DCO: Duplo central composto com 29 pontos e $\alpha=1,51$

DCN : Duplo central composto com 29 pontos e $\alpha=1$

Os resultados foram obtidos em duas etapas. Na primeira fo ram utilizados todos os 21 modelos descritos na seção 4.2 e os resultados de interesse estão nas tabelas numeradas de 1 a 6 . Na segunda etapa fo ram utilizados apenas os modelos de resposta de nümeros 6, 14 e 18 e os resultados estão nas tabelas numeradas de 7 a 12 .

\subsection{Porcentagens de pontos de máximo}

A Tabela 1 contëm as porcentagens de pontos le mäximo em 1000 ensaios gerados a partir de cada modelo e delineamento. Em cada li nha, correspondente a cada modelo de resposta, aparecem os delineamentos 
seguidos das porcentagens de pontos de mäximo, colocadas entre parênteses. A seqüência de delineamentos, em cada linha, está colocada en ordem de crescente quanto a porcentagem de pontos de máximo.

Como se pode notar, os resultados na Tabela 1 mostram uma nítida vantagem dos dois delineamentos fatoriais $3^{3}$ sobre os demais, quan to à capacidade de produzir pontos de máximo quando a situação real é de máximo. Entre os dois delineamentos $3^{3}$ hä uma ligeira vantagem para o de lineamento fatorial $3^{3}$ com níveis igualmente espaçados.

$\mathrm{Na}$ comparação dos nove delineamentos entre si, através dos resultados da Tabela 1 , deve-se destacar o excelente desempenho dos dois delineamentos $3^{3}$ em confronto, principalmente, com os delineamentos de 7 e 9 níveis que são o composto central com duas estrelas e o duplo central composto com 29 pontos do tipo ortogonal, respectivamente. De modo geral, considerando-se as 21 situações estudadas através dos 21 modelos de res posta, os resultados na Tabela 1 indicam uma classificação conjunta dos nove delineamentos, em ordem decrescente de preferência, da seguinte for ma: fatorial $3^{3}$ com níveis igualmente espaçados, fatorial $3^{3}$ com níveis tipo $0, q$ e $3 q,(1 / 5) 5^{3}$ tipo $w,(1 / 5) 5^{3}$ tipo $Y$, duplo central composto com 29 pontos e $\alpha=1$, Box com 15 pontos e $\alpha=1,215$, composto central com estrelas, duplo central composto com 29 pontos e $\alpha=1,51$ e Box com 15 pon tos e $\alpha=2$.

Conforme se nota por essa classificação, o nümero maior de níveis não é causa que por si só determina uma maior porcentagem de pon tos de máximo. Uma afirmativa que se sugere aqui, e que pode ser investi gada, é que o aumento do número de níveis dos três fatores pouco resolve, se isso não resultar em uma distribuição adequada de pontos na região ex perimental.

A possível influência da interação entre os fatores nos re sultados, foi referida na introdução deste trabalho como um ponto a ser investigado. Isso pode ser feito, analisando-se os resultados da Tabela 1 correspondentes a cada par de modelos de resposta, entre os pares $(2,3)$, $(4,5),(6,7),(9,10),(11,12),(13,14),(16,17),(18,19)$ e $(20,21)$, onde o primeiro elemento do par indica o nümero do modelo sem interação e o segundo elemento indica o nümero do modelo com interação. 


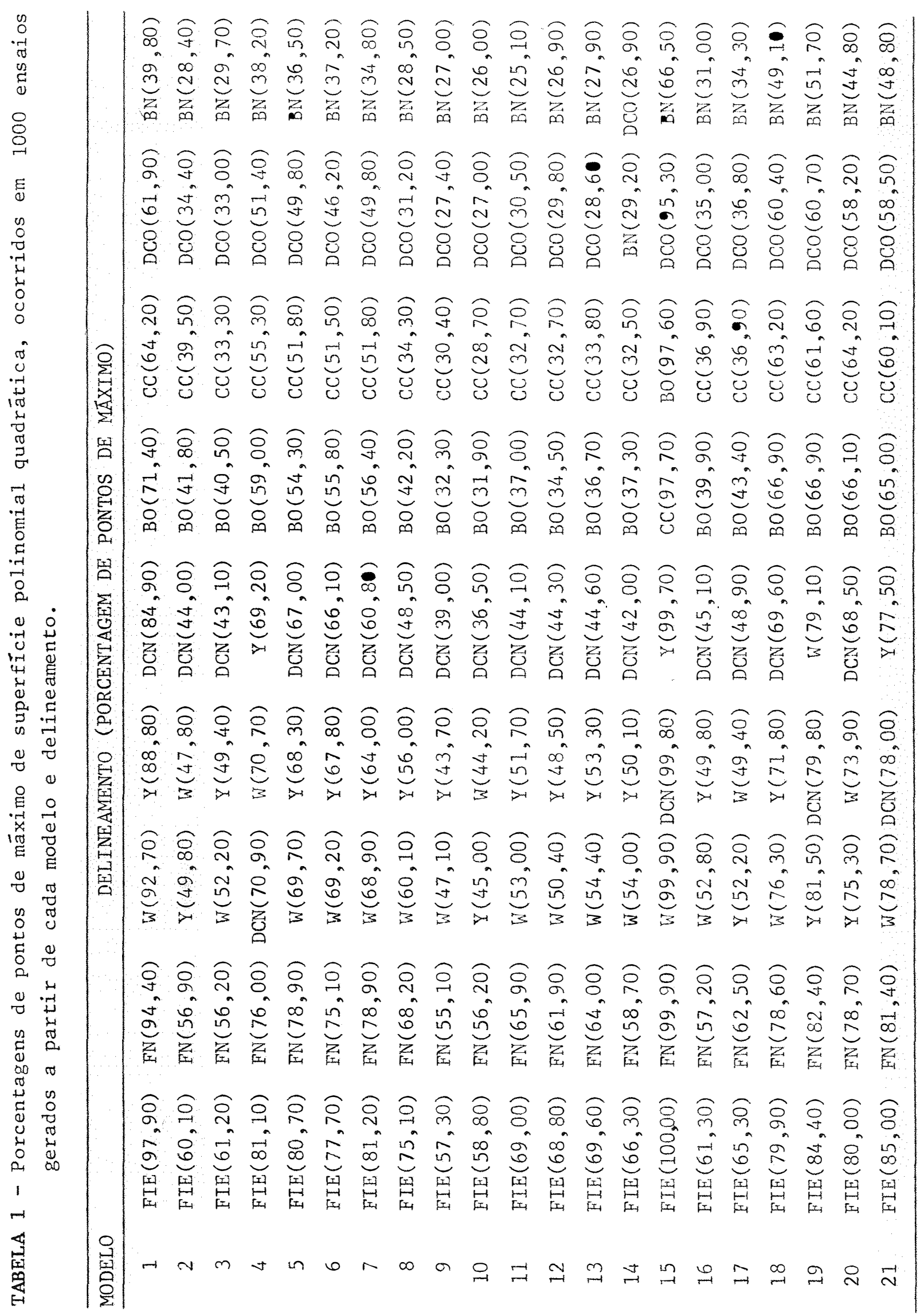


Pode-se notar que para cada um desses pares, as alterações na ordem de preferência (pela maior porcentagem de máximos) são poucas. Há pares, por exemplo $(6,7)$ e $(11,12)$ que não exibiram alterações na ordem de preferência dos delineamentos. Os pares que apresentaram alte rações na ordem de preferência foram os seguintes:

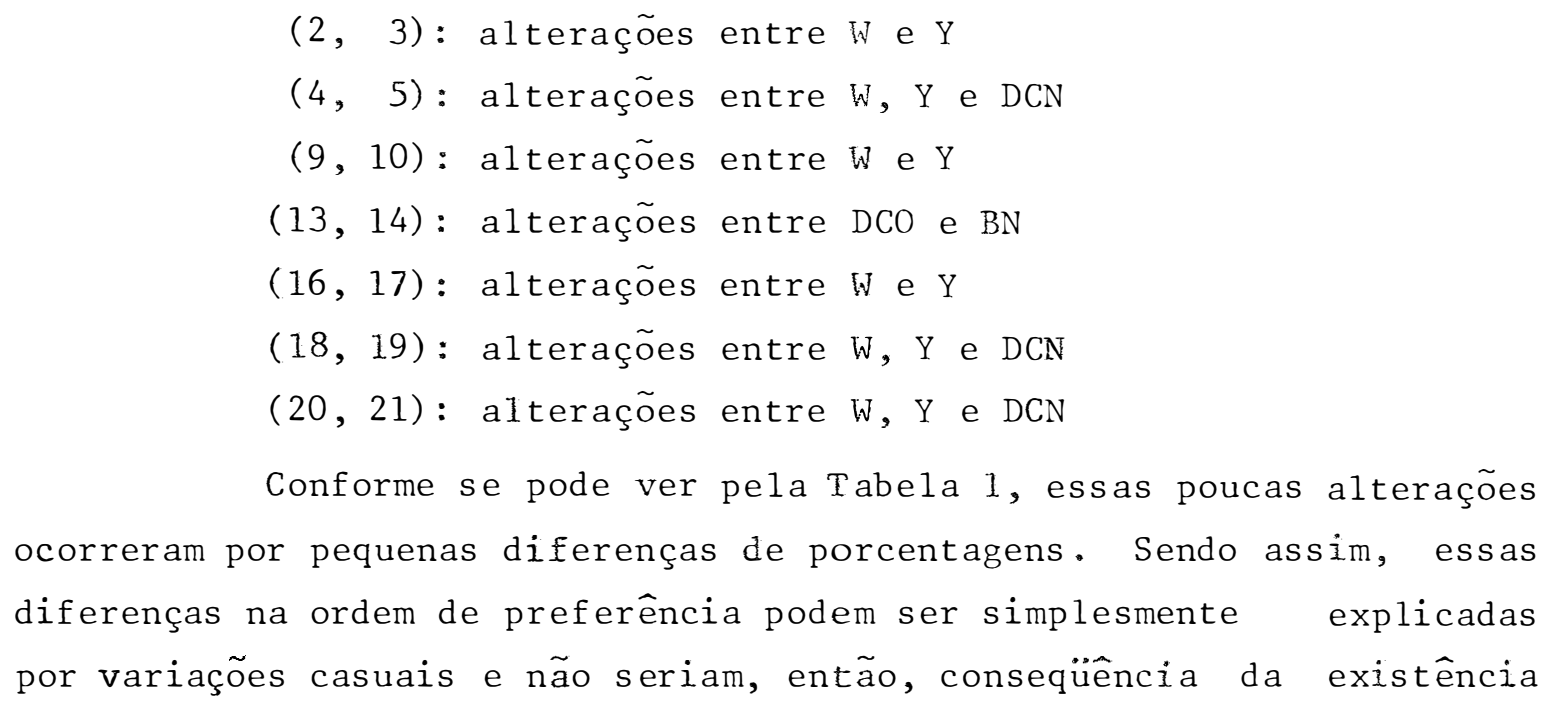

\subsection{Porcentagens de pontos de sela}

A Tabela 2 apresenta as porcentagens de pontos de sela em 1000 ensaios gerados a partir de cada modelo e delineamento. A finalida de desta tabela é completar as informações sobre a natureza dos pontos críticos das funções de produção estimadas $\hat{\eta}$ nos 189000 ensaios gerados, bem como auxiliar na construção de outras tabelas. Para que essas infor mações fiquem completas, é necessärio salientar que não ocorreram inde terminações nos 189000 ensaios gerados. Sendo assim, as diferenças en tre os 100 por cento e as somas dos totais de porcentagens das Tabelas 1 e 2 para cada modelo e delineamento, correspondem às porcentagens de pon tos de mínimo em 1000 ensaios.

Conforme se pode deduzir, foram baixas as porcentagens de mínimo. O delineamento que mais produziu pontos de mínimo, ainda que poucos, foi o delineamento de Box com 15 pontos e $\alpha=2$. 


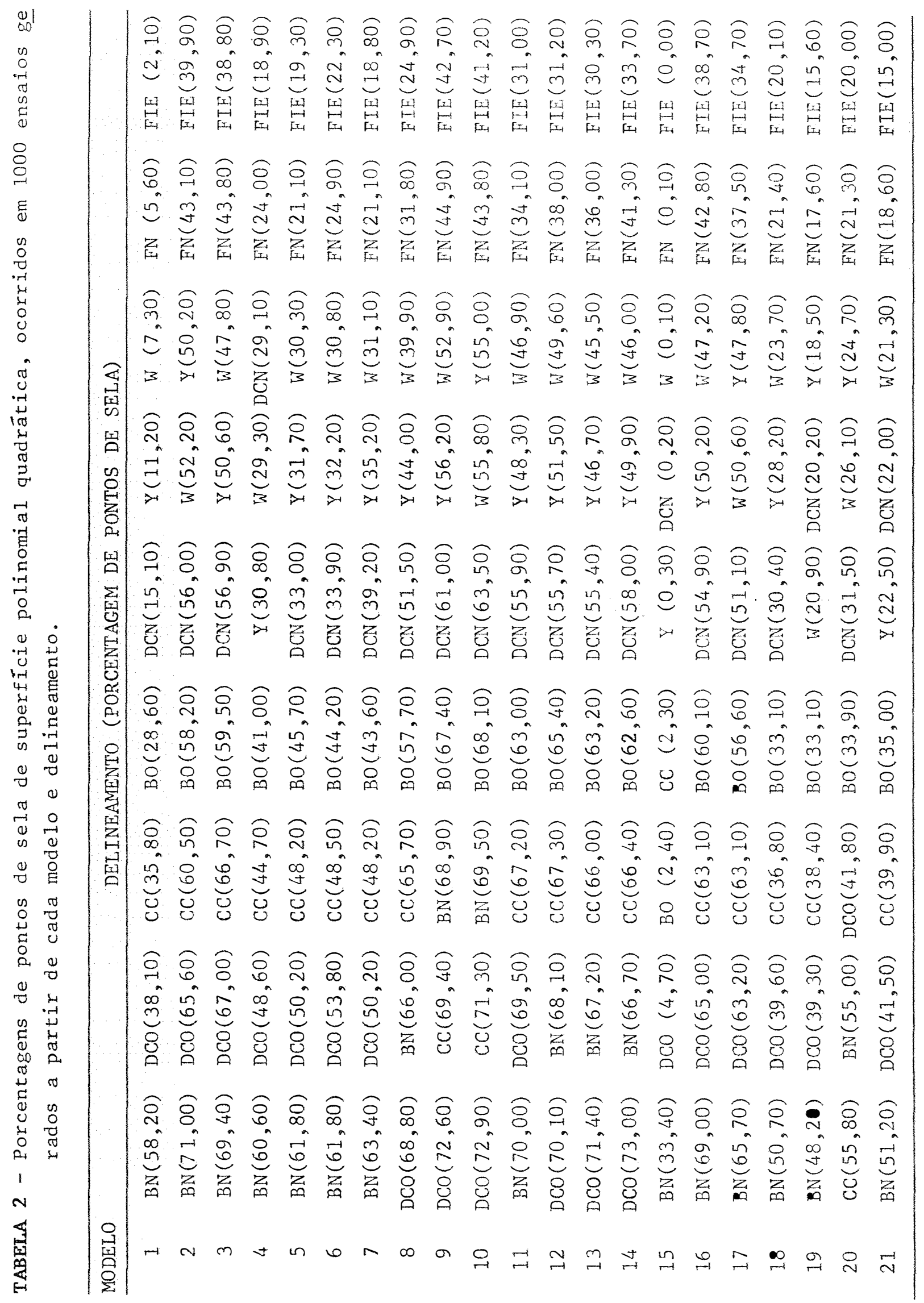




\section{3. o ponto de máximo estimado}

A Tabela 3 contém as porcentagens relativas de pontos de mä ximo ( $X_{1}^{*}, X_{2}^{*}, X_{3}^{*}, \widehat{Y}_{M}$ ) da superfície de resposta $\hat{n}$ em algumas condições de interesse, onde $X_{i}^{*}, i=1,2,3$, são as coordenadas do ponto de mäximo e $\widehat{Y}_{M} \bar{e}$ o valor numérico de $\hat{n}$ em $X_{1}=X_{1}^{*}, X_{2}=X_{2}^{*}$ e $X_{3}=X_{3}^{*}$. As condições de interesse que Foram consideradas são que $\left|x_{i}^{*}-4\right| \leq 0,5, i=1,2,3$ e $\left|\widehat{Y}_{M}-4100\right| \leq 0,5 \sigma$, onde $\sigma=300$. As porcentagens que constam dessa tabe la são relativas aos totais de pontos de máximo, isto é, foram calculadas para cada modelo e delineamento, como o quociente entre o total de pontos de máximo obtidos nas condições de interesse e o total de pontos de máxí mo obtidos nos 1000 ensaios gerados.

Os resultados contidos nesta tabela refletem a proximidade entre o ponto de máximo estimado e o ponto de máximo real (4, 4, 4, 4100) da função de resposta $\eta$, para cada modelo e delineamento. Conforme se no ta, as porcentagens relativas são bem pequenas, indicando que, no geral, o ponto de máximo estimado não é muito próximo do ponto de máximo real. As maiores porcentagens, ainda que pequenas, ocorreram para os modelos de números 15, 18, 19, 20 e 21. Estes modelos são aqueles que representam situações reais de maiores curvaturas.

\subsection{O ponto de sela}

Na Tabela 4 estão as porcentagens relativas de pontos de se la $\left(X_{1}^{*}, X_{2}^{*}, X_{3}^{*}, \widehat{Y}_{S}\right)$ da superficie de resposta $\hat{n}$ tais que $\left|X_{i}^{*}-4\right| \leq 0,5$, $i=1,2,3$ e $\left|\hat{Y}_{S}-4100\right| \leq 0,50$, com $\sigma=300$, onde $X_{i}^{*}, i=1,2,3$ são as coordenadas do ponto de sela e $\widehat{\mathrm{Y}}_{\mathrm{S}}$ é o valor numérico de $\hat{n}$ em $\mathrm{X}_{\sim}^{*}=\left(\mathrm{X}_{1}^{*}\right.$, $\left.\mathrm{X}_{2}^{*}, \mathrm{X}_{3}^{*}\right)^{\prime}$. Estas porcentagens foram calculadas para cada modelo e delinea mento, como o quociente entre o total de pontos de sela nas condições es pecificadas e o total de pontos de sela obtidos nos 1000 ensaios gerados.

Como se pode observar na Tabela 4 , as porcentagens relati vas são excessivamente pequenas, havendo uma grande quantidade de porcen tagens nulas. Isso mostra que o ponto de sela obtido na superfície de responsta $\hat{n}$ não é muito próximo do ponto de máximo real não encontrado.

Numa comparação com as porcentagens relativas corresponden tes da Tabela 3, as porcentagens da Tabela 4 são, no geral, ainda muito 


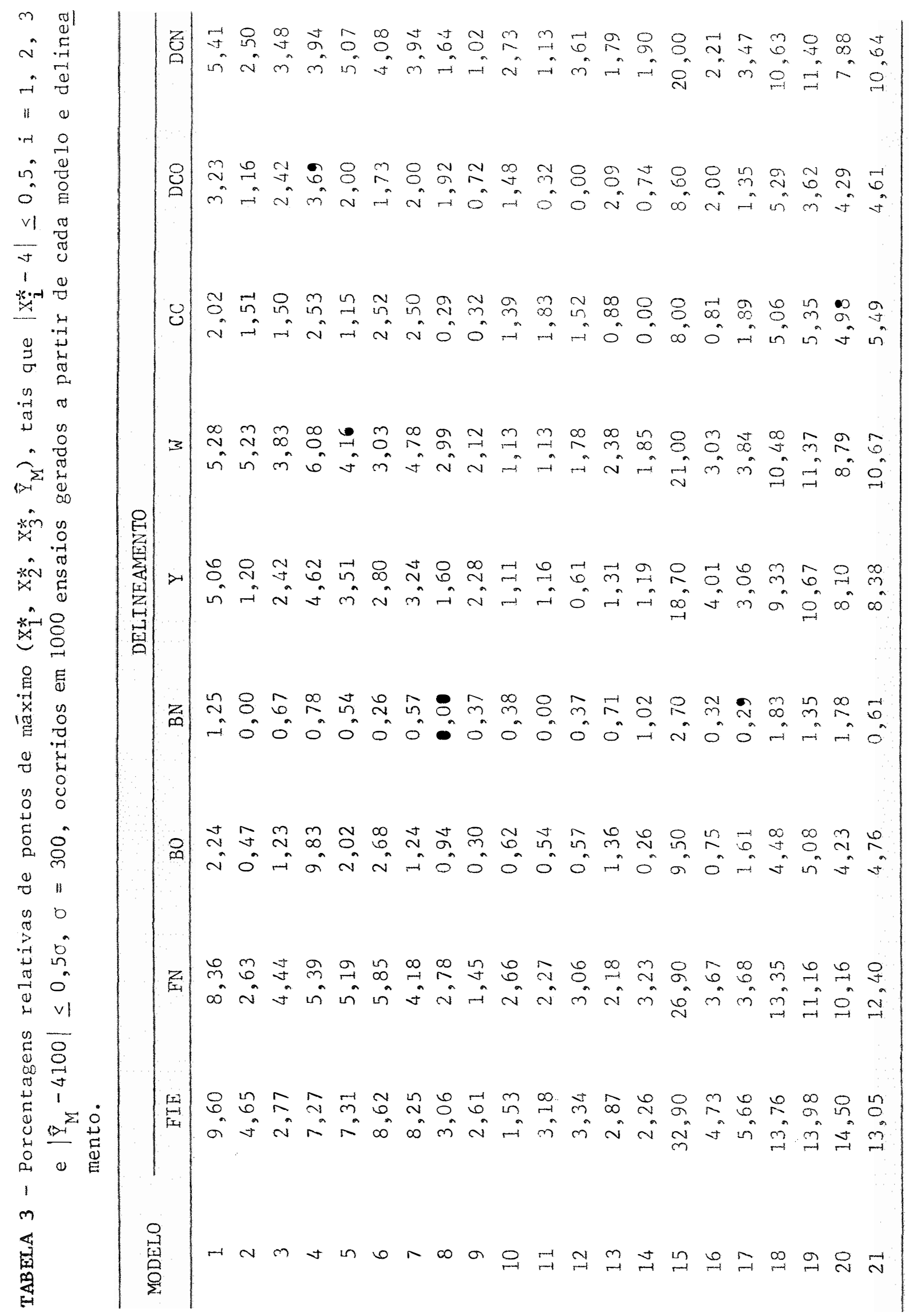




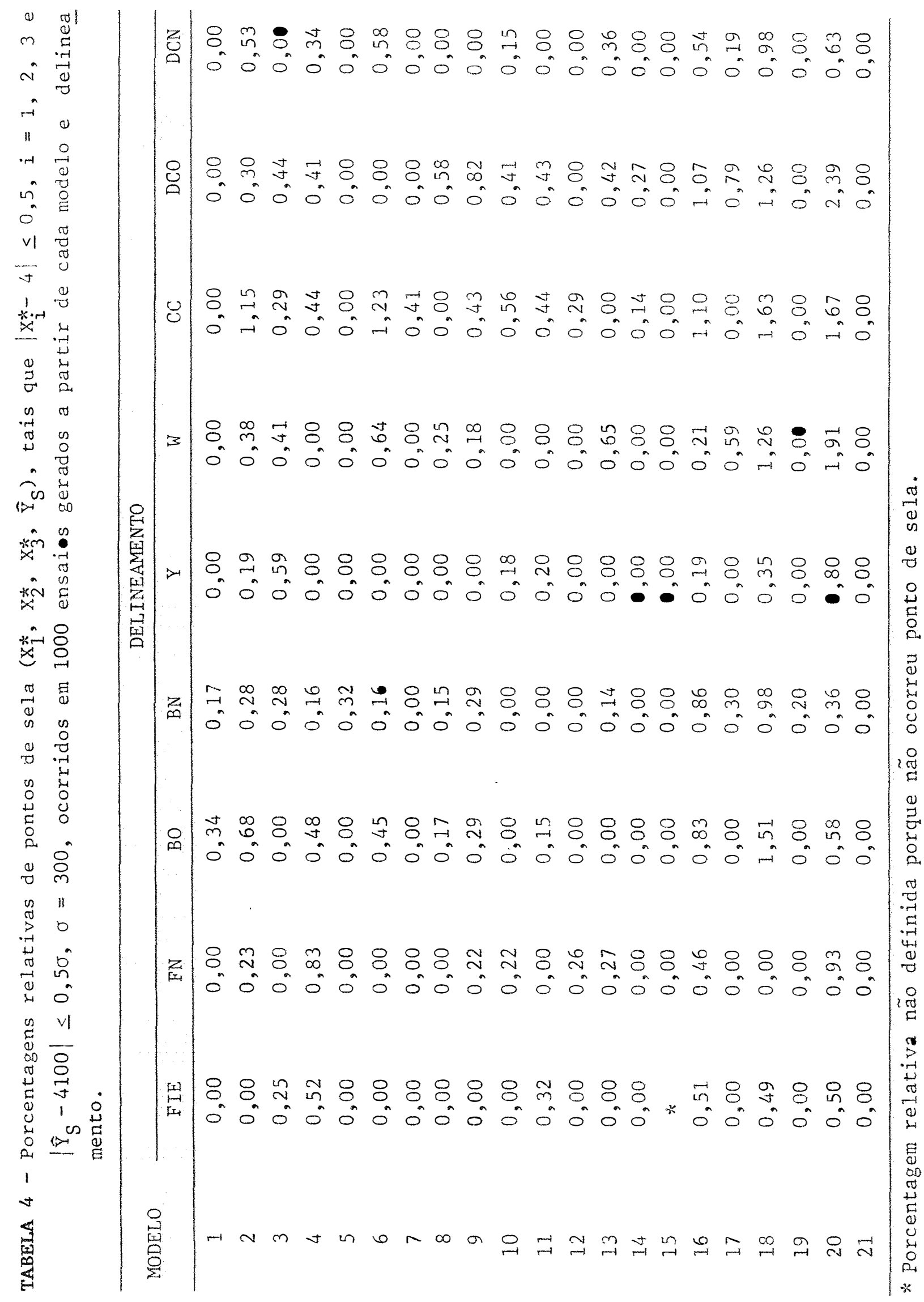


menores. Este fato, sugere que näo $\bar{e}$ aconselhävel se utilizar o ponto de sela como substituto do ponto de máximo não encontrado. Os resultados ob tidos na segunda etapa roforçan essa conclusão.

\subsection{O ponto de máximo fronteira}

A Tabela 5 contém as porcentagens relativas de pontos de mä ximo fronteira $\left(X_{1}, x_{2}, x_{3}, \widehat{Y}_{M F}\right)$, tais que $\left|x_{i}-4\right| \leq 1,0$ e $\left|\widehat{Y}_{M F}-4100\right| \leq 0,50$ $\operatorname{com} \sigma=300$. Como foi dito na seção 4.4, o ponto de máximo fronteira foi calculado somente nos casos onde a superfície de resposta $\hat{\eta}$ apresentou ponto de sela. Sendo assim, as porcentagens relativas foram calculadas para cada modelo e delineamento, como o quociente entre o total de pontos de máximo fronteira nas condições dadas e o total de pontos de sela obti dos nos 1000 ensaios gerados.

Nos 189000 ensaios gerados, em todos aqueles onde ocorreu ponto de sela da superfície de resposta $\hat{n}$, o cálculo do ponto de máximo fronteira levou a somente $1(\mathrm{um})$ caso de indeterminação numa face da re gião experimental. Isto ocorreu no delineamento de Box com 15 pontos e $\alpha=2$, em um ensaio gerado a partir do modelo de resposta nümero 13 .

Conforme se pode observar, as porcentagens relativas da Ta bela 5 não são grandes, no geral, mas são bem maiores que as porcentagens relativas correspondentes da Tabela 3. Este ültimo fato, por si só, pode ria justificar a utilização do ponto de máximo fronteira como substituto do ponto de máximo não encontrado nos casos onde $\hat{\eta}$ tem ponto de sela, se não fosse levado em consideração que a condição $\left|x_{i}-4\right| \leq 1,0, i=1,2,3$, $\vec{e}$ muito menos restritiva que $\left|x_{i}^{*}-4\right| \leq 0,5, i=1,2,3$, da Tabela 3. As sim, as condições menos restritivas para o ponto de máximo fronteira e as porcentagens relativas muito baixas da Tabela 3 , não permitem uma conclu são definitiva sobre o ponto de mäximo fronteira como substituto do ponto de mäximo não encontrado. Como serả visto, os resultados obtidos na se gunda etapa, em condições idênticas e menos restritivas, permitirão as conclusões desejadas.

Ainda, referente à Tabela 5, è importante observar que foi

tomada a quantidade 1,0 como limitante superior de $\left|x_{i}-4\right|$ porque se es sa quantidade fosse 0,5 , todas as porcentagens seriam nulas, visto que se o ponto está na fronteira, tem-se que $\left|x_{i}-4\right|=1$ para algum $i$. 


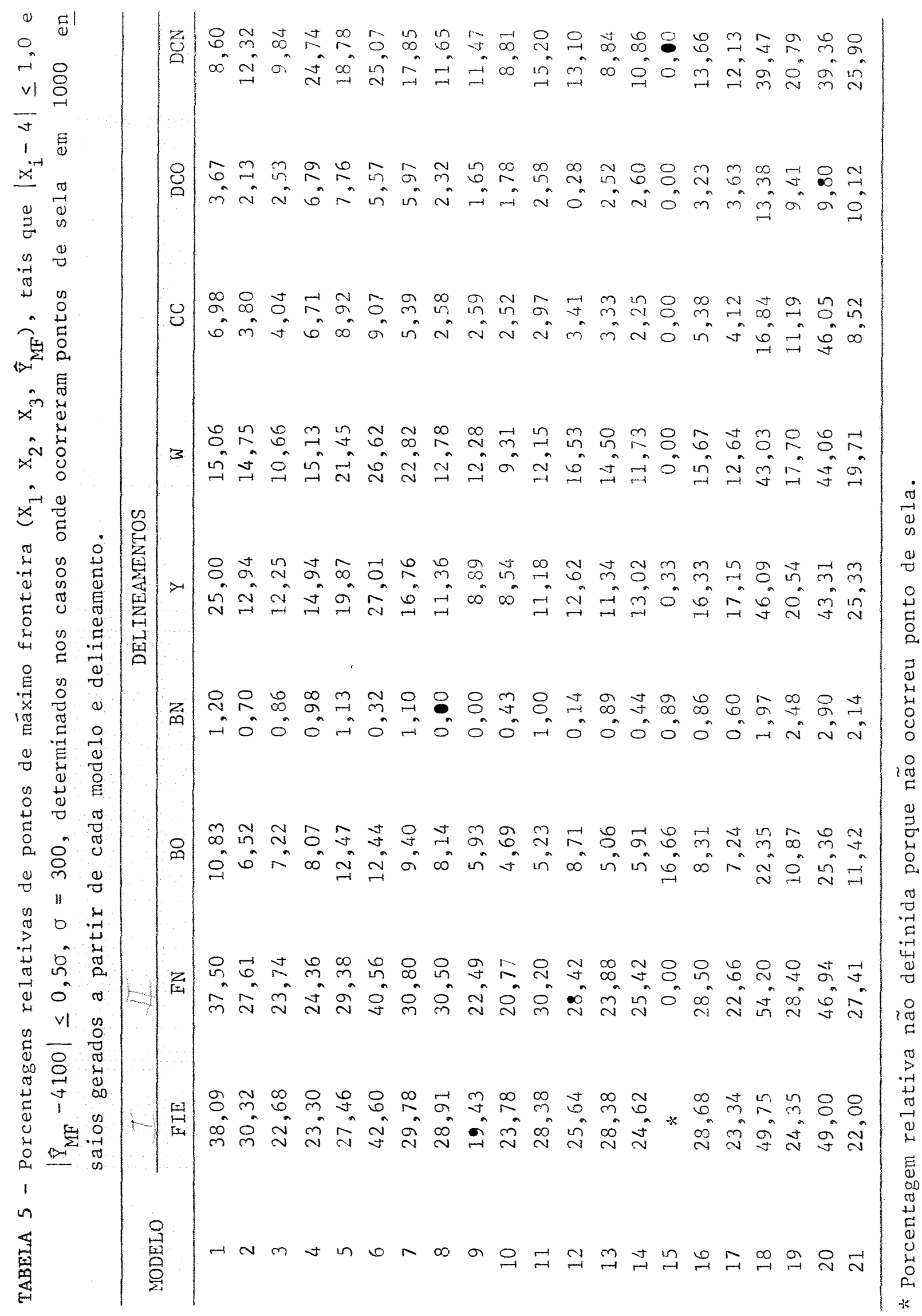




\section{6. o ponto de máximo experimental}

Na Tabela 6 estão as porcentagens relativas de pontos de má ximo experimentais $\left(X_{1}, X_{2}, X_{3}, \widehat{Y}_{M E}\right)$ nas condições $\left|X_{i}-4\right| \leq 1,0, i=1$, 2,3 e $\left|\widehat{Y}_{M E}-4100\right| \leq 0,5 \sigma, \operatorname{com} \sigma=300$. Como foi dito na seção 4.4, o ponto de máximo experimental foi calculado somente nos ensaios onde $\widehat{\eta}$ apresentou ponto de sela. Portanto, as porcentagens relativas foram cal culadas para cada modelo e delineamento, como o quociente entre o total de pontos de máximo experimentais nas condiçöes especificadas e o total de pontos de sela obtidos nos 1000 ensaios gerados.

Como se pode ver na Tabela 6 , as porcentagens relativas são também pequenas e, no geral, pode-se dizer que são ligeiramente maiores que as porcentagens relativas correspondentes da Tabela 3. Deve-se notar, contudo, que aqui, tal como na Tabela 5, a condição sobre $x_{i}, i=1,2,3$, é também muito menos restritiva do que a condição correspondente da Tabe 1a 3. Os resultados obtidos na segunda etapa permitirão uma melhor ava liação do ponto de máximo experimental como substituto do ponto de máximo não encontrado.

Tal como na Tabela 5, aqui na Tabela 6, o limitante superior de $\left|x_{i}-4\right|$ foi tomado como 1,0 ao invés de 0,5. Isso foi feito porque se fosse 0,5 , todas as porcentagens nas duas primeiras colunas serian nu las, visto que para os dois delineamentos $3^{3}$ tem-se, necessariamente, $\left|x_{i}-4\right|>0,5, \forall i$

\subsection{Discussões finais}

Com o objetivo de se obter uma melhor avaliação das proprie dades do ponto de sela, do ponto de máximo fronteira e do ponto de máximo experimental, como substitutos do ponto de máximo de $\hat{\eta}$ não encontrado, fo ram tomados três modelos de resposta e simulados mais 27000 ensaios, sen do 1000 para cada modelo e delineamento. Os modelos de resposta utiliza dos foram os modelos 6, 14 e 18, sendo um para cada condição, isto é,

$$
\begin{aligned}
& \sum_{i=1}^{3} \lambda_{i}=-150 \text { (média curvatura), } \\
& \sum_{i=1}^{3} \lambda_{i}=-90 \text { (pequena curvatura), e }
\end{aligned}
$$




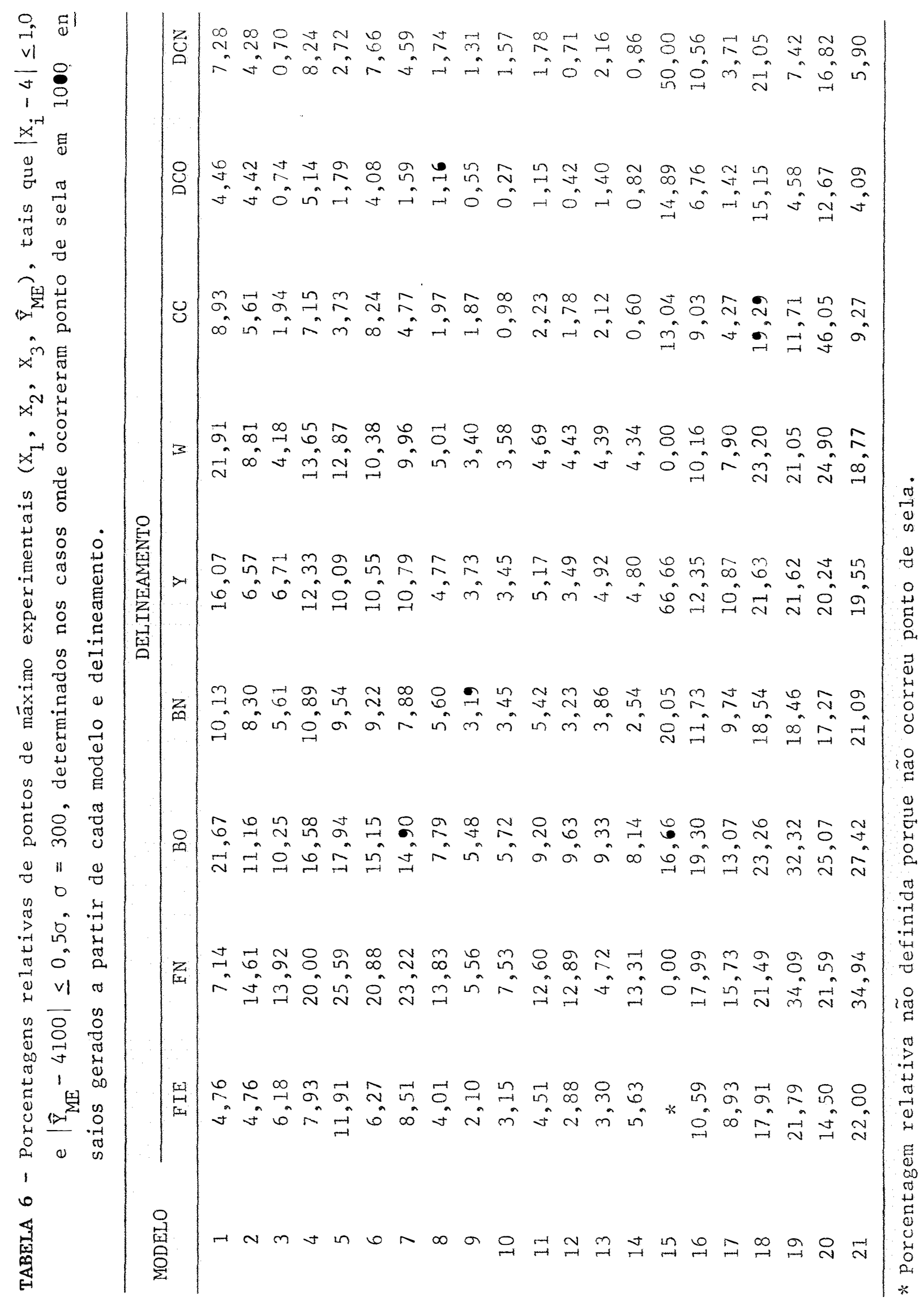



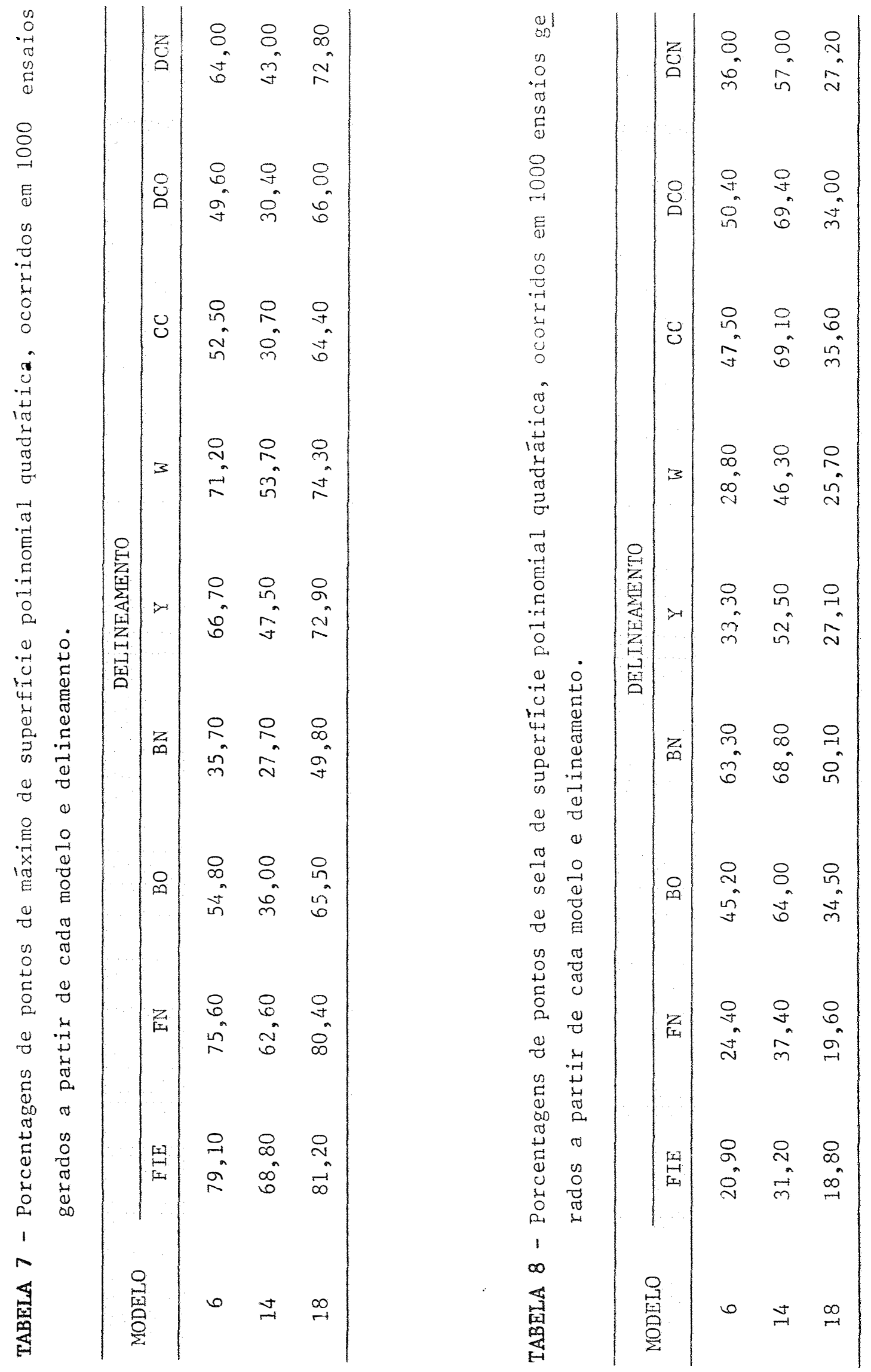

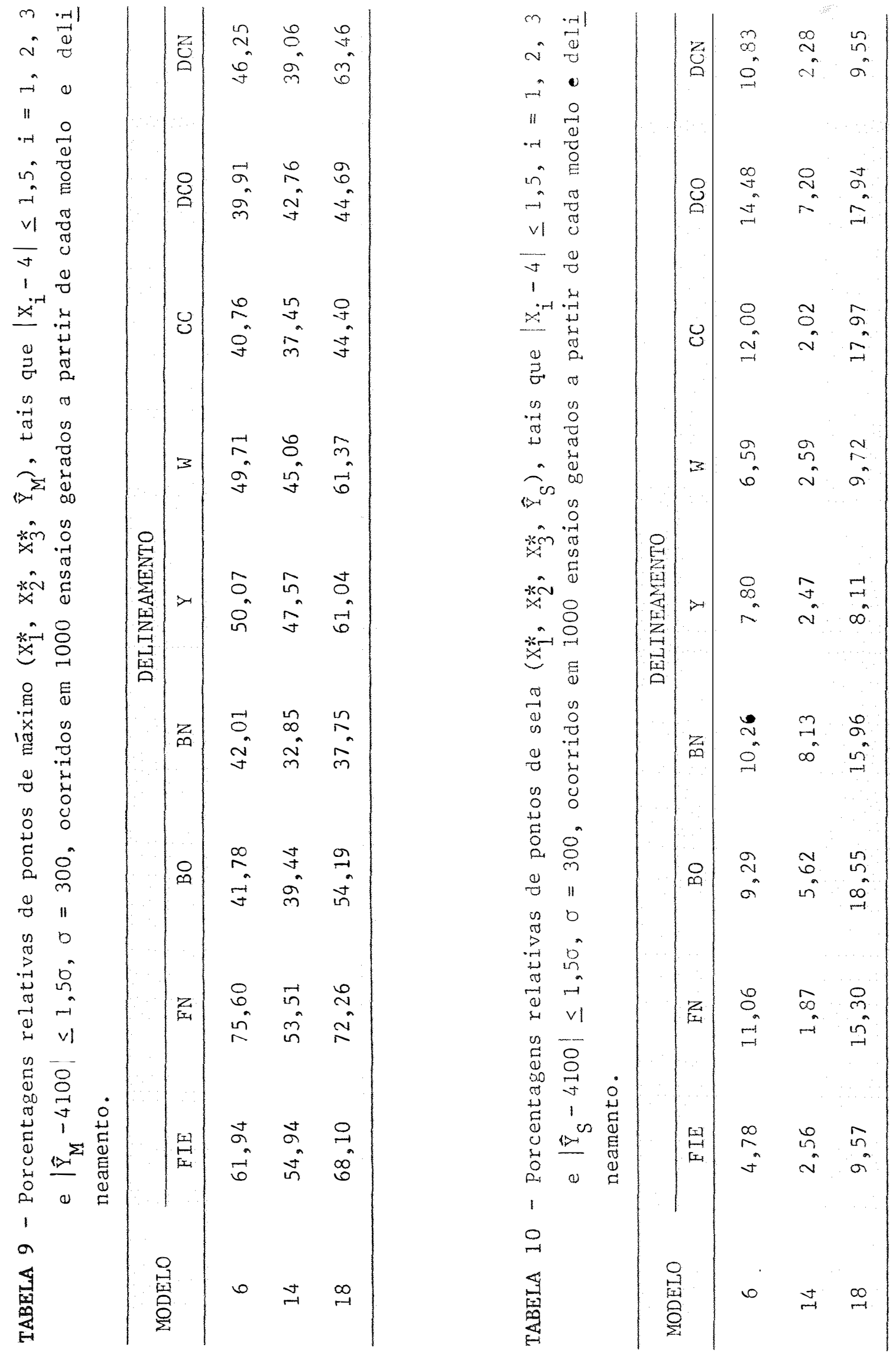

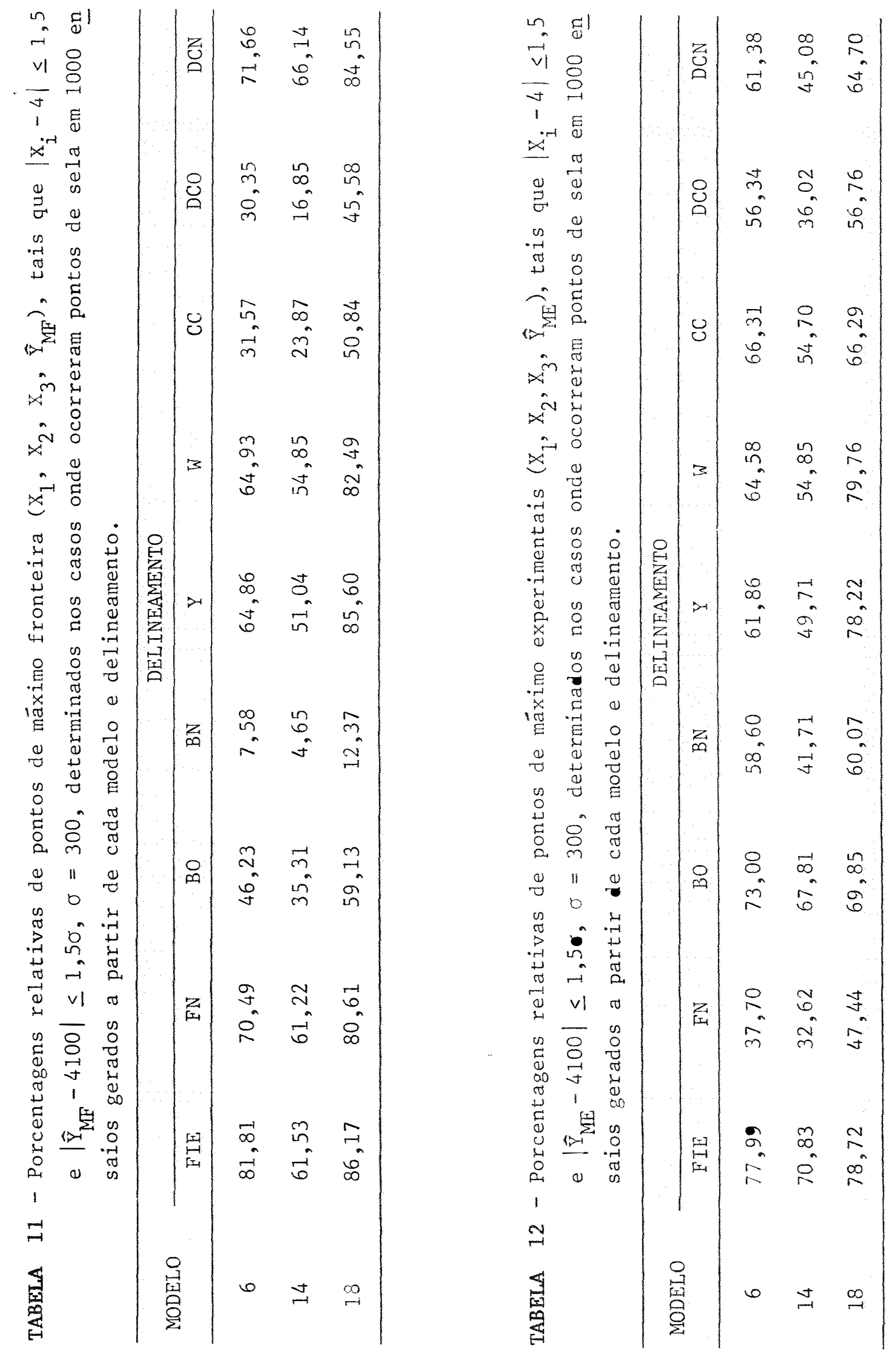


$$
\sum_{i=1}^{3} \lambda_{i}=-255 \text { (grande curvatura), }
$$

respectivamente. Como se pode ver pela Tabela 1 , esses três modelos apre sentam porcentagens de máximo nem muito altas e nem muito baixas, entre os 21 modelos de resposta considerados.

As Tabelas 7 e 8 contêm, respectivamente, as porcentagens de pontos de máximo e de pontos de sela em 1000 ensaios simulados, para cada modelo e delineamento. Como não ocorreram indeterminações, a porcen tagem de pontos de mínimo para cada modelo e delineamento pode ser obtida como a diferença entre 100 e a soma dos totais correspondentes das Tabe las 7 e 8. Os delineamentos que apresentaram pontos de mínimo foram os seguintes: $B N(1,00)$ para o modelo $6, \operatorname{BN}(3,50)$, CC $(0,20)$ e DCO $(0,20)$ para o modelo 14 e $B N(0,10)$ para o modelo 18 . Como se vê pelas porcenta gens indicadas entre parênteses, foram poucas as ocorrências de pontos de mínimo.

Conforme se pode notar, as maiores porcentagens de mínimo, ainda que pequenas, ocorreram para o modelo 14 que representa a situação onde $\Sigma \lambda_{i}$ é menor. Esse resultado não é surpreendente, pois, em termos comparativos, a situação onde

$$
\sum_{i=1}^{3} \lambda_{i}=-90
$$

tem muito maior probabilidade de produzir inversões de concavidade do que as outras duas situações.

As condições de interesse, sob as quais foram obtidas as porcentagens relativas de pontos de máximo, pontos de sela, pontos de mâa ximo fronteira e pontos de máximo experimentais da superfície de resposta $\hat{n}$, nas Tabelas 9, 10, 11 e 12, respectivamente, foram alteradas em rela ção às condições das Tabelas 3, 4, 5 e 6, tornando-se menos restritivas. Isso foi feito para proporcionar porcentagens relativas maiores e com 1s so fazer-se as comparações desejadas. O cálculo das porcentagens relati vas das Tabelas 9, 10, 11 e 12, foi feito do mesmo modo que nas Tabelas 3, 4, 5 e 6, respectivamente, considerando-se, é claro, as novas condições de interesse.

A Tabela 9 contém as porcentagens relativas de pontos de mä ximo ( $\mathrm{X}_{1}^{*}, \mathrm{X}_{2}^{*}, \mathrm{X}_{3}^{*}, \widehat{\mathrm{Y}}_{\mathrm{M}}$ ), tais que $\left|\mathrm{X}_{i}^{*}-4\right| \leq 1,5, i=1,2,3$ e $\left|\hat{\mathrm{Y}}_{M}-4100\right| \leq$ $1,5 \sigma, \sigma=300$. Nota-se pelos resultados que, realmente, a estimativa do 
ponto de máximo não é muito próxima do ponto de máximo real. Essa falta de proximidade é mais acentuada numa situação real de pequena curvatura, como se pode observar pelas porcentagens menores do modelo 14, em relação aos outros dois, em praticamente todos os delineamentos.

Numa comparação dos delineamentos quanto às porcentagens re lativas da Tabela 9 para os três modelos considerados, a preferência fica para os dois delineamentos fatoriais $3^{3}$, com uma ligeira preferência para o delineamento fatorial $3^{3}$ com níveis do tipo 0 , q e $3 q$. Em seguida, nu ma ordem decrescente de preferência, podem ser colocados os delineamentos Y e W em condições praticamente iguais, vindo depois nessa ordem, os de lineamentos DCN, BO, depois CC e DCO em condições praticamente iguais e finalmente o delineamento BN.

A avaliação das propriedades do ponto de sela, ponto de mä ximo fronteira e do ponto de máximo experimental como substitutos do pon to de mäximo não encontrado para $\hat{n}$, será feita pela comparação das porcen tagens relativas das Tabelas 10,11 e 12 com as porcentagens relativas cor respondentes da Tabela 9. Assim, qualquer uma das três soluções alterna tivas que venha a ser recomendada, deverá ter porcentagens no mínimo bem próximas das porcentagens relativas correspondentes da Tabela 9.

A Tabela 10 contém as porcentagens relativas de pontos de sela (X $X_{1}^{*}, X_{2}^{*}, X_{3}^{*}, \widehat{Y}_{S}$ ), tais que $\left|X_{i}^{*}-4\right| \leq 1,5, i=1,2,3$ e $\left|\widehat{Y}_{S}-4100\right| \leq$ $1,5 \sigma, \sigma=300$. Conforme se observa nessa tabela, as porcentagens relati vas de pontos de sela são ainda muito pequenas, mostrando que o ponto de sela é, no geral, muito afastado do ponto de máximo real. Em termos com parativos, estas porcentagens relativas são bem menores que as porcenta gens relativas da Tabela 9, o que reforça a conclusão jả obtida de que o ponto de sela não é um bom substituto para o ponto de máximo de $\hat{n}$ não en contrado.

Na Tabela 11 estão as porcentagens relativas de pontos de máximo fronteira $\left(X_{1}, x_{2}, x_{3}, \widehat{Y}_{M F}\right)$, tais que $\left|x_{i}-4\right| \leq 1,5$ e $\left|\widehat{Y}_{M F}-4100\right| \leq$ $1,5 \sigma, \sigma=300$. Para o modelo 14 , as porcentagens desta tabela são maio res que as porcentagens correspondentes na Tabela 9, para os delineamen. tos FIE, FN, Y, W e DCN, e são bem menores para os delineamentos CC, DCO, principalmente para o BN. Para o delineamento BO também é menor, mas di fere pouco. Para o modelo 6 , as porcentagens desta tabela são maiores que as porcentagens correspondentes da Tabela 9 para os delineamentos FIE, 
BO, Y, W e DCN, não muito menores para os delineamentos FN, CC e DCO e bem menor para o delineamento $B N$. Numa situação real de grande curvatu ra, como é o caso do modelo 18, todas as porcentagens desta tabela são maiores que as correspondentes da Tabela 9 para todos os delineamentos, com exceção apenas do delineamento BN onde a porcentagem é bem menor.

Esta análise simples mostrou que para us delineamentos FIE, $\mathrm{Y}, \mathrm{W}$ e DCN, o ponto de máximo fronteira pode ser utilizado como substitu to do ponto de máximo não encontrado, em situações de pequenas, médias ou grandes curvaturas. Para esses delineamentos, devido às maiores porcenta gens obtidas na Tabela 11, o ponto de máximo fronteira tem maior probabi lidade de estar mais pröximo do ponto de máximo real do que o pröpric pon to de máximo estimado (nos casos onde $\vec{e}$ encontrado). Para os delineamen tos FN, BO, CC e DCO, a utilização do ponto de máximo fronteira, de modo satisfatório, dependerá do fato de se estar numa situação de grande curvatuva. Este resultado é uma indicação cie que em presença de situa ções reais de grande curvatura, o ponto de mäximo fronteira pode ser uti lizado como solução alternativa para o máximo não encontrado para um núme ro bem maior de delineamentos. Para o delineamento BN, os resultados ob tidos não permitem a recomendação do ponto de máximo fronteira como solu ção alternativa para o ponto de máximo não encontrado, em vista das peque nas porcentagens obtidas na Tabela 11.

A Tabela 12 contëm as porcentagens relativas de pontos de máximo experimentais $\left(X_{1}, X_{2}, X_{3}, \widehat{Y}_{M E}\right)$, tais que $\left|x_{i}-4\right| \leq 1,5$ e $\left|\widehat{\mathrm{Y}}_{\mathrm{ME}}-4100\right| \leq 1,5 \sigma, \sigma=300$. Para os modelos 6 e 18 , as porcentagens desta tabela são maiores que as porcentagens correspondentes da Tabela 9 , para os delineamentos FIE, BO, BN, Y, $W$, CC, DCO e DCN, e bem menores pa ra o delineamento FN. Para o modelo 14, as porcentagens desta tabela são maiores para os delineamentos FIE, BO, BN, Y, W, CC e DCN, pouco menor pa ra o DCO e bem menor para o FN. Um pouco surpreendente foi o delineamen to FN apresentar porcentagens relativas tão baixas em comparação com o de lineamento FIE. Quanto aos delineamentos com 7 e 9 niveis, espera-se por centagens bem maiores do que aquelas obtidas, exatamente pelo grande nüme ro de niveis que apresentam. Este fato pode estar mais uma vez sugerindo a afirmativa de que um grande número de níveis pouco resolve se isso não resultar em uma distribuição adequada de pontos na região experimental.

Esta análise pelos modelos utilizados mostrou que o ponto 
de máximo experimental pode ser utilizado como substituto do ponto de mä ximo de $\hat{\eta}$ não encontrado, para os delineamentes FIE, BO, BN, Y, W, CC e DCN. Para o DCO, a utilização dessa solução alternativa, dependerá de se estar numa situação real de média ou grande curvatura. Esse fato, permi te a conclusão que o ponto de máximo experimental pode ser utilizado como uma solução alternativa para o ponto de máximo não encontrado, para um nú mero maior de delineamentos, sempre que se estiver em situaçōes reais de grandes curvaturas. Para o delineamento FN, os resultados obtidos não re comendam a substituição do ponto de máximo não encontrado pelo ponto de mäximo experimental.

Ao final destas discussões, vale ressaltar dois resultados interessantes, sendo o primeiro deles referente às propriedades do deli neamento fatorial $3^{3} \mathrm{com}$ níveis igualmente espaçados. Nas condições em que foram estudados todos os delineamentos, o FIE foi o melhor quanto à capacidade de reproduzir máximos, foi um dos dois melhores quanto a proxi midade do ponto de máximo estimado do ponto de máximo real e ainda apre sentou, na maioria das situações, as maiores porcentagens nas Tabelas 11 e 12. Esses resultados colocam o delineamento fatorial $3^{3}$ com níveis igualmente espaçados numa posição de destaque no confronto com os outros delineamentos estudados.

o segundo resultado interessante é que as análises des re sultados obtidos indicaram duas soluções alternativas para o pont• de mä ximo de $\hat{\eta}$ não encontrado que, juntas, resolvem o problema para todos os delineamentos estudados. O Quadro 5.7.1 é um resumo das comparações das Tabelas 11 e 12 com a Tabela 9 e dá uma visão geral dos delineamentos es tudados quanto às duas soluções alternativas que podem ser utilizadas.

QUADRO 5.7.1 - Delineamentos e as soluções alternativas.

\begin{tabular}{lcccccccccc}
\hline SOLUÇÄO & \multicolumn{10}{c}{ DELINEAMENTO } \\
\cline { 2 - 9 } ALTERNATIVA & FIE & FN & BO & BN & Y & W & CC & DCO & DCN \\
\hline Máx. fronteira & $*$ & + & + & 0 & $*$ & $*$ & - & - & $*$ \\
Máx. experimental & $*$ & $\circ$ & $*$ & $*$ & $*$ & $*$ & $*$ & + & $*$ \\
\hline
\end{tabular}

Para cada delineamento, a indicação com (*) significa que a solução alternativa correspondente pode ser utilizada satisfatoriamente 
nas três situações (modelos de resposta) estudadas. A indicação com (t) significa que a solução alternativa correspondente pode ser utilizada sa tisfatoriamente em duas das situações estudadas e a indicação com (-) sig nifica que pode ser utilizada somente em uma situação, no caso, aquela de grande curvatura. A indicação com (o) significa que não pode ser utiliza da. 


\section{CONCLUSÕES}

Os nove delineamentos utilizados nesta pesquisa, foram os seguintes: fatorial $3^{3}$ com níveis igualmente espaçados, fatorial $3^{3} \mathrm{com}$ níveis do tipo $0, q$ e $3 q, q>0$, Box com 15 pontos e $\alpha=1,215$, Box com 15 pontos e $\alpha=2,(1 / 5) 5^{3}$ tipo Y (ou tipo I, III, IV), (1/5) $5^{3}$ tipo $W$, composto central com duas estrelas, duplo central composto com 29 pontos e $\alpha=1,51$ e duplo central composto com 29 pontos $\mathrm{e} \alpha=1$. Para todos esses delineamentos, os resultados obtidos indicaram uma elevada porcenta gem de falsos pontos de sela na maioria das situações reais criadas para a simulação de dados.

Nas situações reais em que os modelos de resposta utiliza dos para simulação exibiam pequenas curvaturas, foram observadas porcenta gens de pontos de sela superiores a $50 \%$ em mais da metade dos delineamen tos utilizados. Para modelos de resposta com maiores curvaturas foram ob tidas, como era esperado, menores porcentagens de pontos de sela. No en tanto, apesar dessa diminuição, tem-se ainda essas porcentagens variando desde zero atê quase $70 \%$, dependendo do elineamento e da situação real que se tem para o modelo de resposta. Estes fatos aumentam a importância de se buscar uma solução alternativa satisfatória diante da ocorrência de ponto de sela, num problema prático onde se espera ponto de mäximo.

No que se refere aos objetivos propostos e considerando-se as hipóteses sob as quais o trabalho foi desenvolvido, os resultados obti dos levaram às seguintes conclusões:

1a) O ponto de sela não é um bom substituto do ponto de mäxí mo não encontrado, pois, em todas as situações estudadas e para todos os 
nove delineamentos, esse ponto se mostrou sempre bem afastado do ponto de mäximo real. Em termos comparativos, mostrou-se, no geral, muito mais afastado do ponto de máximo real do que o ponto de máximo estimado (nos casos onde é encontrado). Em vista disso, não se recomenda a sua utiliza ção como uma estimativa do ponto de máximo real.

2a) O ponto de máximo fronteira mostrou-se um bom substitu to do ponto de máximo não encontrado, para quatro cos delineamentos utili zados, quais sejam: fatorial $3^{3}$ com níveis igualmente espaçados, (1/5) $5^{3}$ tipo Y, (1/5) $5^{3}$ tipo W e duplo central composto com 29 pontos e $\alpha=1$. Pa ra esses delineamentos, mostrou-se, no geral, com maior proximidade do pon to de máximo real do que o próprio ponto de máximo estimado (nos casos on de é encontrado). Assim, nesses delineamentos recomenda-se a sua utiliza ção como uma solução alternativa para o ponto de máximo não encontrado. Para situações reais de máximo e de grande sensibilidade da resposta (fun ção de resposta verdadeira com grande curvatura) o ponto de máximo fron teira pode também ser utilizado como solução alternativa satisfatória pa ra o ponto de máximo não encontrado, para os delineamentos de Box com 15 pontos e $\alpha=1,215$, composto central com duas estrelas e duplo central com posto $\operatorname{com} \alpha=1,51$.

3a) O ponto de mäximo experimental mostrou-se um bom substi tuto para o ponto de máximo não encontrado para seis dos delineamentos utilizados, quais sejam: fatorial $3^{3}$ com níveis igualmente espaçados, Box com 15 pontos e $\alpha=1,215$, Box com 15 pontos e $\alpha=2$, (1/5) $5^{3}$ tipo Y, $(1 / 5) 5^{3}$ tipo W e composto central com duas estrelas. Para esses delinea mentos os resultados indicaram que o ponto de máximo experimental exibe, no geral, uma proximidade do máximo real, ligeiramente maior do que o prö prio ponto de máximo estimado (nos casos onde é encontrado). Quando se tem situações reais de grande sensibilidade da resposta, esta solução a1 ternativa também pode ser utilizada, de modo satisfatório, para o delinea mento duplo central composto com 29 pontos e $\alpha=1,51$.

4a) Para cada um dos nove delineamentos estudados, tem-se pelo menos uma das duas soluções alternativas para o problema do ponto de sela que são o ponto de máximo fronteira e o ponto de máximo experimental. Nos delineamentos onde se tem as duas soluções alternativas, há uma ten dência de superioridade (maior proximidade do ponto de máximo real) do ponto de máximo fronteira sobre o ponto de máximo experimental, à medida 
que se tem situações reais de maior sensibilidade da resposta.

5a) Na comparação de todos os nove delineamentos entre si, o fatorial $3^{3}$ com níveis igualmente espaçados foi o que apresentou maior eficiência na obtenção de pontos de mäximo, isto $\vec{e}$, maiores porcentagens de pontos de mäximo para situações reais de mäximo. A classificação cọn junta na ordem decrescente de preferência, quanto à eficiência na obten ção de pontos de máximo, foi a seguinte: fatorial $3^{3}$ com níveis igualmen te espaçados, fatorial $3^{3}$ com níveis do tipo 0 , q e $3 q, q>0,(1 / 5) 5^{3}$ ti pow, (1/5) $5^{3}$ tipo $Y$, duplo central composto com 29 pontos e $\alpha=1$, Box com 15 pontos e $\alpha=1,215$, composto central com duas estrelas, duplo cen tral composto com 29 pontos e $\alpha=1,51$ e Box com 15 pontos e $\alpha=2$.

6ạ) O aumento do nümero de níveis não é causa que, por si só, pode determinar uma maior eficiência na obtenção de pontos de máximo. Isso pode ser visto pela classificação conjunta dos nove delineamentos es tudados, onde o delineamento $3^{3}$ com níveis igualmente espaçados é melhor que vários delineamentos de maior nümero de nïveis, especialmente aqueles com 7 e 9 níveis que são o composto central com duas estrelas e o duplo central composto com 29 pontos e $\alpha=1,51$.

7 ạ) A presença de interação entre os fatores não apresentou alteração na ordem de preferência dos delineamentos quanto à eficiência na obtenção de pontos de máximo.

8a) Num ensaio de adubação com 3 fatores, onde (a) a prodụ ção vai ser estudada através da função polinomial quadrática, (b) os in tervalos das doses que vão ser utilizadas estão fixados nas doses mínima e máxima, (c) sabe-se que o ponto de máximo real deve estar próximo das doses maiores e (d) quer-se obter a combinação de doses de produção mäxi ma, então, entre os nove delineamentos estudados, o pesquisador deve esco ther o delineamento fatorial $3^{3}$ pelas seguintes razões: (i) e o delinea mento para o qual se tem maior probabilidade de se obter um ponto de máxi mo para a função de resposta estimada $\hat{\eta}$, (ii) $\vec{e}$ um dos dois melhores quan to a proximidade do ponto de máximo estimado do ponto de máximo real e (iii) se ocorrer ponto de sela para $\hat{n}$, este delineamento tem, na maioria das situações estudadas, as duas soluções alternativas em melhores condi ções do que os outros oito delineamentos, em termos de maior proximidade com o ponto de máximo real. 


\section{LITERATURA CITADA}

ANDERSON, R.L. e L.A. NELSON, 1975. A family of models involving inter secting straight 1 ines and concomitant experimental designs usefel in evaluating response to fertilizer nutrients. Biometrics, 31:303-318.

ARRUDA, H.V., 1959. Contribuição para o estudo da adubaçäo mineral do mi Tho nas terras roxas do municipio de Ribeirão Ereto. Piracicaba, ESALQ/ USP, $39 \mathrm{p} . \quad$ (Tese)

BOX, G.E.P., 1958. A note on generating normal deviates. Ann. Math. Stat., vol. 20 .

BOX, G.E.P. e K.B. WILSON, 1951. On the experimental attainment of opti mum conditions. Jour. Roy. Stat. Soc., B, 13:1-45.

CAMPOS, H., 1967. Aspectos da aplicação das superficies de resposta a en saios fatoriais $3^{3}$ de adubação. Piracicaba, ESALQ/USP, 82 p. (Tese de Livre-Docência).

ConAGIN, A., 1978. Delineamentos de ensaios de adubação. Campinas, Ins tituto Agronômico. 39 p. (Circular no 101).

CONAGIN, A., 1982. Delineamento composto central com duas estrelas. Pesq. Agrop. Bras., $17(9): 1261-1269$.

CONAGIN, A. e J.P.N. JORGE, 1977. Delineamentos (1/5) $5^{3}$. Bragantia, 36: $23-58$.

CONAGIN, A. e J.P.N. JORGE, 1979. Delineamento duplo cental composto com 29 pontos. Bragantia, 38:217-235. 
CONAGIN, A., J.P.N. JORGE e W.R. VENTURINI, 1969. Delineamentos experi mentais utilizāveis na experimentação de campo. In: Reynaert, E.E. La investigación de fertilidade de suelos para la produción agricola en la zona templada. Montevideo, IICA, Zona Sur. p. 183-201.

DĀVILA, L.E.R., 1979. Algunos diseños para estudios la superficie de res posta a la aplicacion de fertilizantes. In: Reunião Internacional de Biometria, Piracicaba, SP, 1975. Anais, p. 131-156.

DEPIZzolatTI, A.L.V., 1983. Pontos criticos de superificie de resposta com raiz quadrada em função das doses de nutrientes usadas nos experi mentos de adubação. Piracicaba, ESALQ/USP, 110 p. (Tese de Doutoramen to).

FUZATTO, M.G., W.R. VENTURINI e P.A. CAVALERI, 1970. Estudo técnico eco nômico da adubação do algodoeiro no Estado de São Pauzo. Campinas, Ins tituto Agronômico. $15 \mathrm{p}$. (Projeto BNDE/ANDA/CIA no 1).

HILL, W.J. e W.G. HUNTER, 1966. A review of response methodology: A 1ite rature survey. Technometrics, $\underline{8}: 571-590$.

IGUE, T.; H.A.A. MASCARENHAS e S. MIYASAKA, 1971. Estudo comparativo dos métodos de Mitscheriich e do trinömio do segundo grau, na determinação das doses mais economicas de fertilizantes, na adubaça do feijoeiro. Campinas, Instituto Agronômico. 15 p. (Projeto BNDE/ANDA/CIA no 4).

JOHN, P.W.M., 1971 Statistical design and analysis of experiments. New York, The Macmillan Company. 355 p.

JOHN, P.W.N. e N.R. DRAPER, 1975. D-optimality for regression designs: A review. Technometrics, 17:15-23.

JORDAN, L., 1979. Some new developments on potimal designs for polinomial fitting. In: Reunião Internacional de Biometria, Piracicaba, SP, 1975. Anais. p. 59-77.

JORGE, J.P.N. e A. CONAGIN, 1977. Estudos em um grupo especial de deli neamentos $(1 / 5) 5^{3}$. Bragantia, 36:59-88.

MALHEIROS, E.B. e D. PERECIN, 1983. Posição das doses de nutrientes na anālise de uma superfície de resposta à adubação. Rev. Mat. Est., 1:6978 . 
MEAD, R. e D.J. PIKE, 1975. A review of response surface methodology from a biometric viewpoint. Biometrics, 31:803-851.

MIRANDA, L.T., 1966. Resultados de experimentos de adubação e sugestões para a interpretação baseada na anälise química do solo. In: Cultura e adubą̧ão do mitho. São Paulo, Instituto Brasileiro de Potassa. p.451472 .

MIRANDA, L.T., 1971. Adubação do mitho. I-Retação entre dados de en saios de campo e de análise química do solo. Campinas, Instituto Agro nômico. $11 \mathrm{p}$. (Projeto BNDE/ANDA/CIA no 11).

MYERS, R.H., 1971. Response surface methodology. Boston, Allyn and Ba con, Inc. $246 \mathrm{p}$.

NELDER, J.A., 1966. Inverse polynomials, a useful group of multipactor response functions. Biometries, 22:128-141.

NOGUEIRA, I.R., 1960. Pesquisa sobre o planejamento expemimental em en saíos de adubag̨ão. Piracicaba, ESALQ/USP. 44 p. (Tese de Livre-Docên cia).

PAEZ, G. e T. SILVA, 1975. Delineamento dos experimentos de adubação. De partamento de Processamento de Dados, EMBRAPA. 50 p. (Mimeografado).

PERECIN, D.; E. B. MALHEIROS e D.A. BANZATTO, 1982. Tipos de delineamen to $(1 / 5) 5^{3}$ e superficies de respostas. Cientifica, 10:193-201.

ROJAS, B.A., 1982. Designs of fertilizer experiments. In: Conferência Internacional de Biometria, 10, Guarujā, SP, 1979. Anais, p. 49-60.

TRAMEL, T.E., 1957. A suggested procedure for agronomic-economic fertili zer experiments. In: Baum, E.L. e outros. Economie and technical ana lysis of fertilizer innorations and resource use. Ames, Iowa, State College Press. p. 168-175.

VIEIRA, S., 1970. Aspectos das funções de produção ajustadas aos ensaios fatoriais $3^{3}$ de adubação. Piracicaba, ESALQ/USP. 160 p. (Tese de Dou toramento) .

VOSS, R. e J.T. PESEK, 1967. Yeld of corn as affected by fertilizer ra tes and environmental factors. Agronomy, 59:567-572. 


\section{APENDICE}

Se $v_{1}$ e $V_{2}$ são variäveis aleatórias com distribuição unifor me no intervalo $(0,1)$, então

$$
z_{1}=\left(-2 \log V_{2}\right)^{1 / 2} \cos \left(2 \pi V_{1}\right)
$$

tem distribuição normal com média 0 (zero) e variância 1 (BOX, 1958). Com isso, tem-se que

$$
\mathrm{Y}=\mathrm{m}+\sigma \mathrm{Z}_{1}
$$

tem distribuição normal com média m e variância $\sigma^{2}$.

A sub-rotina (em BASIC), que foi utilizada para gerar NT ob servações correspondentes a todos os NT tratamentos de um delineamento $\vec{e}$ a seguinte:

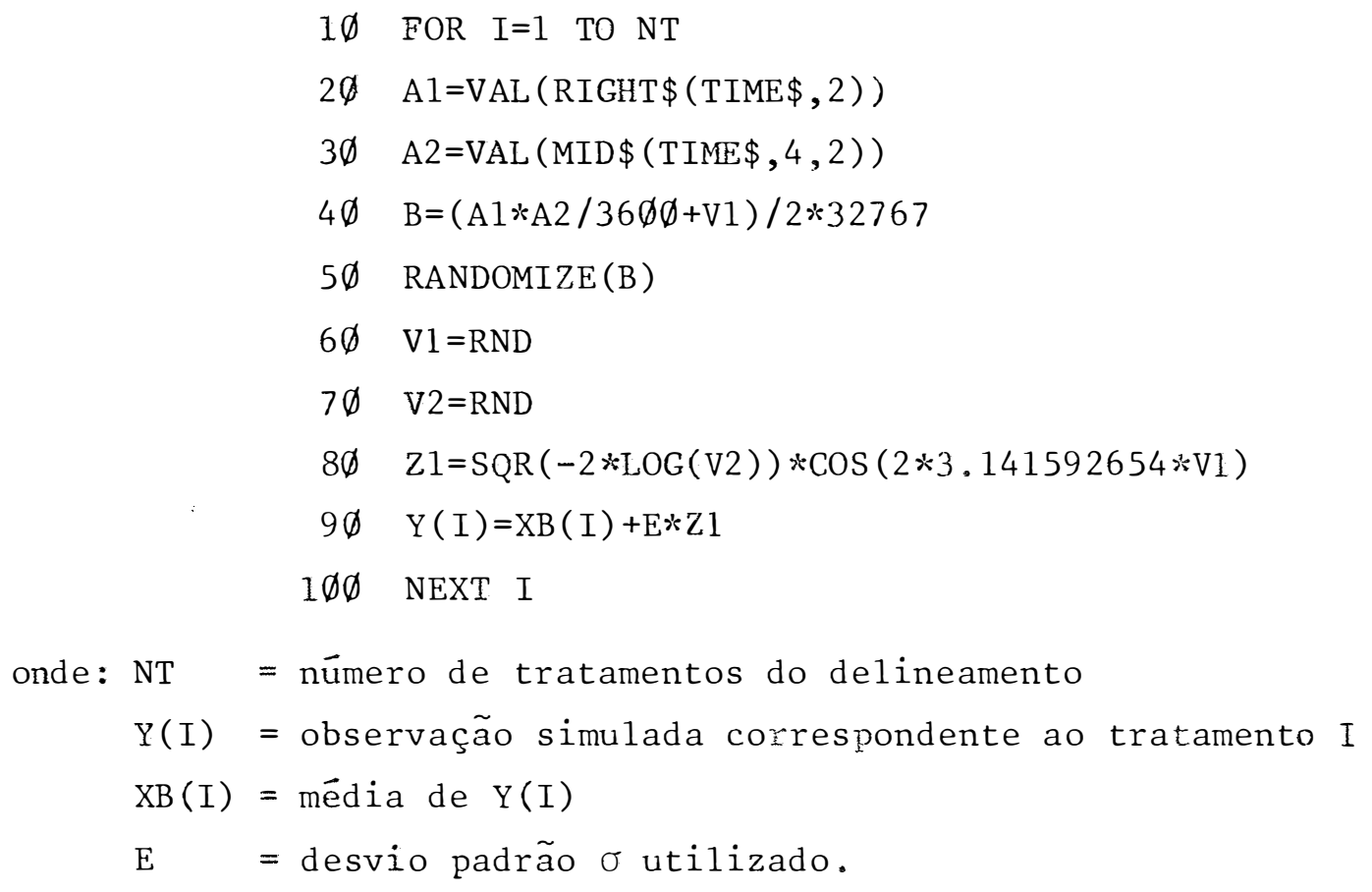

